\title{
Redoxmodulation Hippokampaler Neurone
}

\author{
Dissertation \\ zur Erlangung des Doktorgrades \\ der Mathematisch-Naturwissenschaftlichen Fakultät \\ der Georg-August-Universität zu Göttingen
}

vorgelegt von

Florian Gerich

aus Köln

Göttingen 2007 
D 7

Referent: Prof. Dr. Rüdiger Hardeland

Koreferent: Prof. Dr. Ralf Heinrich

Tag der mündlichen Prüfung: 31.10.2007 
Meinen Eltern 
Half my life's in books' written pages live and learn from fools and from sages 


\section{Inhaltsverzeichnis}

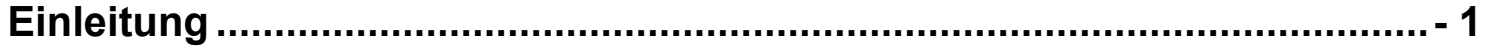

Die Atmungskette....................................................................... 1 -

Die Bildung von Sauerstoffradikalen in der Atmungskette.................... 4 -

Blocker der Atmungskette ........................................................... 5 -

Der Hippokampus und seine synaptische Verschaltung ........................ 6 -

Der Mechanismus der spreading depression .................................... 8 -

Material und Methoden ........................................................................ - 11 -

Versuchstiere und Gewebe.......................................................... 11 -

Präparation der Hirnschnitte...................................................... 11 -

Anlegen einer gemischten Primärkultur aus Gliazellen und Neuronen - 14 -

Elektrophysiologie .................................................................... 16 -

Elektrophysiologische Messungen ............................................ 16 -

Hypoxie induzierte spreading depression...................................... 17 -

Optische Messungen ............................................................... 19 -

Fluoreszenzmikroskopie....................................................... 19 -

Zwei-Photonen-Mikroskopie ....................................................... 20 -

Autofluoreszenz von NADH und FAD ...................................... 22 -

Farbstoffe ........................................................................... 23 -

Intrinsische optische Signale .................................................. 25 -

Transfektion von Zellkulturen ...................................................... 25 -

Durchführung der Transfektion.................................................... 27 -

Bestimmung des ATP-Gehaltes hippokampaler Hirnschnitte ................ 29 -

Verwendete Pharmaka und Chemikalien ............................................ 31 -

Blocker und Modulatoren ............................................................ 32 -

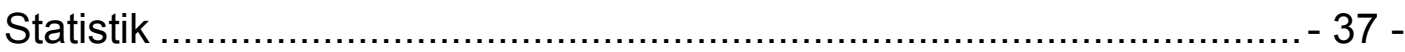

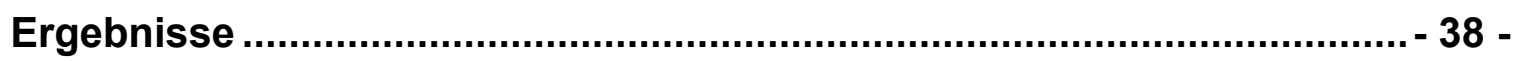

Redoxmodulation der Hypoxie-Antwort........................................... 38 -

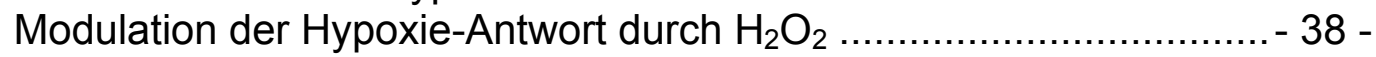

Einfluss der mitochondrialen Funktion auf die Hypoxie-Antwort......... - 40 -

Intrinsische optische Signale ................................................... 45 -

Optische Quantifizierung mitochondrialer Parameter und des Redox-Status - 48 -

Messung des mitochondrialen Membranpotentials $(\Delta \psi \mathrm{m})$ mit Rh123 - 48 -

Autofluoreszenz von NADH und FAD ........................................... 52 -

Messungen des Redox-Potentials mit redoxsensitiven Farbstoffen ... - 54 -

Dynamische Messungen der ROS Bildung mit roGFP transfizierten Zellen - 55 -

ATP Messungen ............................................................... 61 -

Identifizierung redoxsensitiver molekularer Angriffspunkte .................... 63 -

Modulation der synaptischen Plastizität und Funktion durch $\mathrm{H}_{2} \mathrm{O}_{2} \ldots . . .63$ -

Mitochondriale Ziele von extrazellulär appliziertem $\mathrm{H}_{2} \mathrm{O}_{2} \ldots \ldots \ldots \ldots \ldots \ldots . .64$ -

Messung des intrazellulären Calciums mit Fluo-3 ............................. 66 -

Intrazelluläre Ableitungen aus Gliazellen ........................................ 70 -

Diskussion .......................................................................................

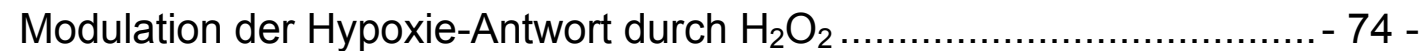

Einfluss der mitochondrialen Inhibition auf den zellulären ATP-Gehalt.. - 75 -

Modulation des cytosolischen Redox-Status ..................................... - 78 -

Auswirkung mitochondrialer Inhibition ........................................... 78 -

Wechselseitige Auswirkung von schwerer Hypoxie und Redox-Status- 80 -

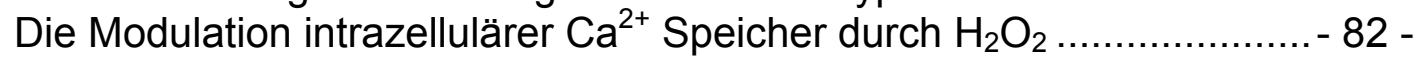

Fazit ................................................................................................... 84

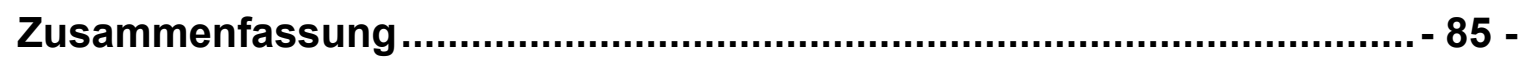


Benutzte Abkürzungen: ........................................................................ - 86 -

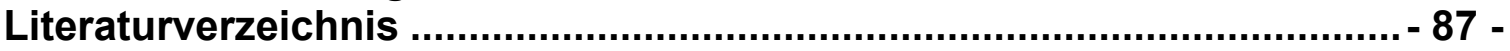

Eigene Veröffentlichungen ....................................................................... 96 -

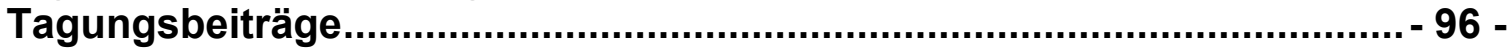

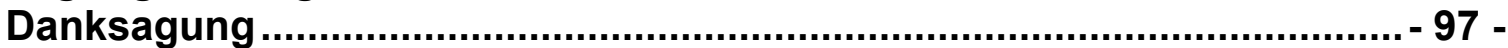

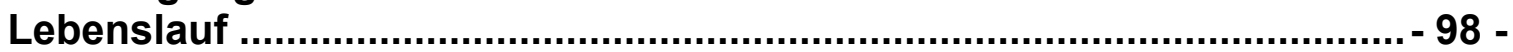




\section{Abbildungsverzeichnis}

Abb. 1: Skizze Mitochondrium und Atmungskette ................................. 3 -

Abb. 2: Skizze Blocker der Atmungskette........................................... 5 -

Abb. 3: Lage des Hippokampus im Rattenhirn ....................................... 6 -

Abb. 4: Die synaptische Verschaltung im Hippokampus ........................... 7 -

Abb. 5: Hippokampale Formation in einem Hirnschnitt........................... 12 -

Abb. 6: Aufbau und Prinzip der Interfacekammer ................................... 13 -

Abb. 7: Entwicklung der Zellkultur ................................................. 15 -

Abb. 8: Platzierung der Reiz- und Ableitelektroden .............................. 17 -

Abb. 9: Skizze des Versuchsaufbaus ............................................... 20 -

Abb. 10: Vereinfachtes Jablonski Diagramm ...................................... 21 -

Abb. 11: Restriktionskarte des pEGFP-N1 Vektors und strukturelle

Besonderheiten des redoxsensitiven roGFP .............................. 26 -

Abb. 12: Cytosolische und mitochondriale Exprimierung von roGFP ....... 27 -

Abb. 13: Redoxmodulation der Hypoxie-Antworten .................................. 40 -

Abb. 14: Modulation von HSD durch mitochondriale Entkopplung und

Blockade der ATP-Synthase ................................................... 42 -

Abb. 15: Modulation von HSD durch gezielte Atmungskettenblockade..... 44 -

Abb. 16: Vergleich der elektrophysiologischen und optischen Charakteristika von Hypoxie- und Pharmaka-induzierten SD.............................. 47 -

Abb. 17: Wirkung der Mitochondrien-Inhibitoren auf das mitochondriale Membranpotential..................................................................... 50 -

Abb. 18: Detektion von $\Delta \psi m$ in Zellkultur ......................................... 51 -

Abb. 19: Auswirkung der Atmungsketten-Modulatoren auf den mitochondrialen Metabolismus ............................................. 53 -

Abb. 20: $\mathrm{H}_{2} \mathrm{O}_{2}$ oxidiert ROS sensitive Farbstoffe irreversibel ................... 55 -

Abb. 21: Ratiometrische Messungen von ROS mit roGFP ..................... 56 -

Abb. 22: roGFP reagiert auf unterschiedliche ROS ............................ 57 -

Abb. 23: Wirkung der mitochondrialen Blocker auf roGFP ..................... 59 -

Abb. 24: Ratiometrische Messungen von roGFP auf Sauerstoffentzug und chemische Anoxie. ................................................................. 60 -

Abb. 25: Aufzeichnung der Bestimmung des ATP-Gehaltes ................... 61 -

Abb. 26: Zusammenfassung der Auswirkungen der verschiedenen Mitochondrienblocker auf den ATP-Gehalt.

Abb. 27: Die synaptische Funktion und Plastizität werden durch $\mathrm{H}_{2} \mathrm{O}_{2}$ nicht beeinflusst

Abb. 28: Wirkung von $\mathrm{H}_{2} \mathrm{O}_{2}$ auf das mitochondriale Membranpotential..... 64 -

Abb. 29: Auswirkung von $\mathrm{H}_{2} \mathrm{O}_{2}$ auf den mitochondrialen Metabolismus.... 65 -

Abb. 30: Wirkung von $\mathrm{H}_{2} \mathrm{O}_{2}$ auf den ATP-Gehalt................................. 65 -

Abb. 31: $\mathrm{H}_{2} \mathrm{O}_{2}$ führt zu einem Dosis-abhängigen Anstieg von $\left[\mathrm{Ca}^{2+}\right]_{\mathrm{i}} \ldots \ldots \ldots . . . . .67$ -

Abb. 32: $\mathrm{H}_{2} \mathrm{O}_{2}$ aktiviert Ryanodin Rezeptoren .................................... 68 -

Abb. 33: Gliazellen depolarisieren unter DTT Einfluss und ziehen ihre

Ausläufer zurück................................................................

Abb. 34: Intrazelluläre Redox-Targets ............................................. 73 - 


\section{Tabellenverzeichnis}

Tabelle 1: Die Bildung der verschiedenen ROS $-4-$

Tabelle 2: Eigenschaften der benutzten Farbstoffe ................................. 24 -

Tabelle 3: Blocker und Modulatoren I: Mitochondriale Blocker .................. 32 -

Tabelle 4: Blocker und Modulatoren II: Calciumspeicher und SH-Gruppen - 33 -

Tabelle 5: Reagenzien der Zellkultur Medien und ATP Messungen ........... 34 -

Tabelle 6: Wertetabelle Autofluoreszenz von NADH und FAD ................... 54 - 


\section{Einleitung}

Mitochondrien sind verantwortlich für die Generierung eines Großteils intrazellulärer Sauerstoffradikale. Superoxid $\left(\cdot \mathrm{O}_{2}^{-}\right)$entweicht aktivitätsabhängig aus der Atmungskette und reagiert im Cytosol weiter zu reaktiven $\mathrm{O}_{2}$-Spezies (ROS). Veränderungen der Atmungskettenaktivität aufgrund des wechselnden metabolischen Bedarfs oder verminderter $\mathrm{O}_{2}$-Versorgung (Anoxie/Hypoxie) beeinflussen somit unmittelbar den cytosolischen ROS-Spiegel und damit den zellulären Redox-Status. Da ROS intrazelluläre Signalfunktionen auszuüben scheinen (Prabhakar et al., 2007; Zhang und Gutterman, 2007), ist damit zu rechnen, dass Änderungen der Mitochondrienaktivität so die neuronale Erregbarkeit beeinflussen. Beteiligt daran sind offenbar die reaktiven Sulfhydryl (SH-) Gruppen des Cysteins. Je nach intrazellulärem Redox-Status werden die reaktiven SH-Gruppen verschiedenster zellulärer Proteine oxidiert oder reduziert, was die Proteinkonformation und damit auch ihre Aktivität beeinflusst.

Im Rahmen dieser Arbeit wurde untersucht, wie hippokampale Netzwerke durch gezielte Redoxmodulation oder durch Redox-Änderungen aufgrund von Inhibition mitochondrialer Funktion beeinflusst werden. Dabei wurden verschiedene Techniken zur optischen und elektrophysiologischen Detektion cytosolischer Redox-Änderungen genutzt bzw. etabliert und mit deren Hilfe redoxsensitive Targets in CA1 Neuronen identifiziert. Die Untersuchungen wurden in akuten hippokampalen Hirnschnitten auf der Ebene des intakten Netzwerks, auf Zellebene in kultivierten Neuronen und auf molekularer Ebene (z.B. ATP-Gehalt in Zellen) durchgeführt.

\section{Die Atmungskette}

Fast alle zellulären Prozesse benötigen Energie, zumeist in der Form von ATP. Neuronales Gewebe weist einen besonders hohen Energiebedarf auf. Um die Funktion zu gewährleisten, muss die lonenverteilung $\left(\mathrm{Na}^{+} / \mathrm{K}^{+}\right)$und das Membranpotential durch die kontinuierliche Arbeit der ATP-abhängigen Natrium-Kalium-Pumpe stabil gehalten werden. Selbst in Ruhephasen weisen Neurone eine Spontanaktivität auf, welche kompensiert werden muss.

In der Atmungskette wird die durch die Glykolyse und den Citratzyklus bereitgestellte Energie genutzt, um ATP zu bilden. Dabei werden Elektronen 
und Protonen der Elektronentransporter NADH und $\mathrm{FADH}_{2}$ auf Sauerstoff übertragen, wobei Wasser entsteht (Knallgasreaktion). Würde diese sehr exotherme Reaktion in einem Schritt durchgeführt, wäre sie wenig effizient und es käme zu Zellschäden. Indem der Wasserstoff- und Elektronentransfer in vier Teilschritten erfolgt, wird die freiwerdende Energie optimal und gefahrlos ausgenutzt.

Die vier Enzymkomplexe, die den Energietransfer leisten, sind in der inneren Mitochondrienmembran lokalisiert (Abb. 1). Dabei handelt es sich um:

- Komplex I: NADH-Q-Reduktase

- Komplex II: Succinat-Q-Reduktase

- Komplex III: Cytochrom-Reduktase

- Komplex IV: Cytochrom-Oxidase

Die vier Komplexe sind fest in der inneren Mitochondrienmembran verankert. Der Transfer der Elektronen zwischen den einzelnen Komplexen wird durch die frei beweglichen Transportmolekülen Ubichinon (Coenzym $Q, Q$ ) und Cytochrom $\mathrm{C}$ gesteuert.

Im Gegensatz zur äußeren Membran der Mitochondrien ist die innere, stark gefaltete Membran für praktisch alle geladenen Moleküle undurchlässig. Die Komplexe I, III und IV dienen als Protonenpumpen und transportieren während des Elektronentransfers $\mathrm{H}^{+}$-lonen durch die Membran aus der Matrix hinaus wodurch über die innere Membran ein Protonengradient gebildet und aufrechterhalten wird, welcher die Grundlage für das mitochondriale Membranpotential $(\Delta \psi \mathrm{m})$ darstellt. In Komplex IV werden die Elektronen auf Sauerstoff übertragen, wodurch Wasser entsteht. Dabei bleibt der Sauerstoff fest an den Enzymkomplex gebunden, bis er durch die Aufnahme von 4 Elektronen vollständig zu $\mathrm{H}_{2} \mathrm{O}$ reduziert ist (Berg et al., 2003).

Die oxidative Phosphorylierung, also die Bildung von ATP aus ADP und anorganischem Phosphat $\left(P_{i}\right)$, findet mit Hilfe der ATP Synthase $\left(\mathrm{F}_{0} \mathrm{~F}_{1}\right.$-ATPase $)$ statt. Dieser Komplex besteht aus zwei Untereinheiten. $\mathrm{F}_{0}$ ist ein in der inneren Mitochondrienmembran fest verankerter Protonenkanal auf dem die frei rotierbare $F_{1}$ Untereinheit aufsitzt. Die Treibkraft für die ATP Synthese ist der durch die Atmungskette aufgebaute Protonengradient. Dabei strömen $\mathrm{H}^{+}$-lonen entlang ihres Gradienten durch den Protonenkanal, der 
$\mathrm{F}_{0}$-Untereinheit und treiben so die $\mathrm{F}_{0} \mathrm{~F}_{1}$-ATPase an. Durch die enge Kopplung von Atmungskette und oxidativer Phosphorylierung wird die ATP Synthase oft auch als Komplex V der Atmungskette bezeichnet.

A

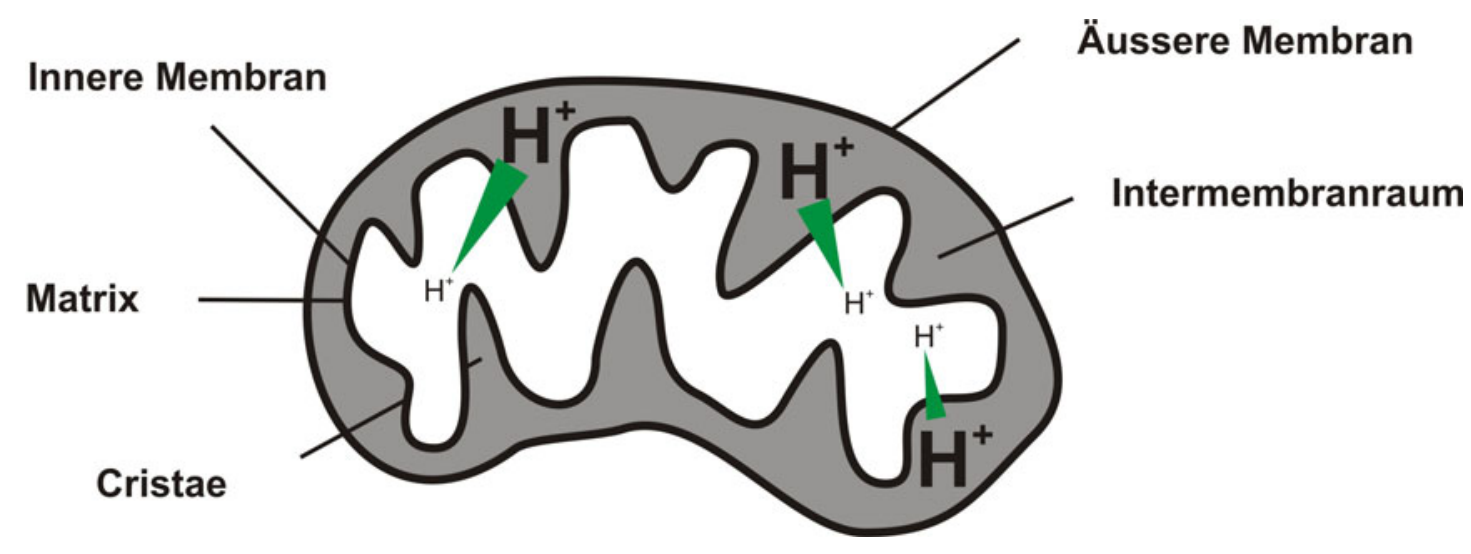

B

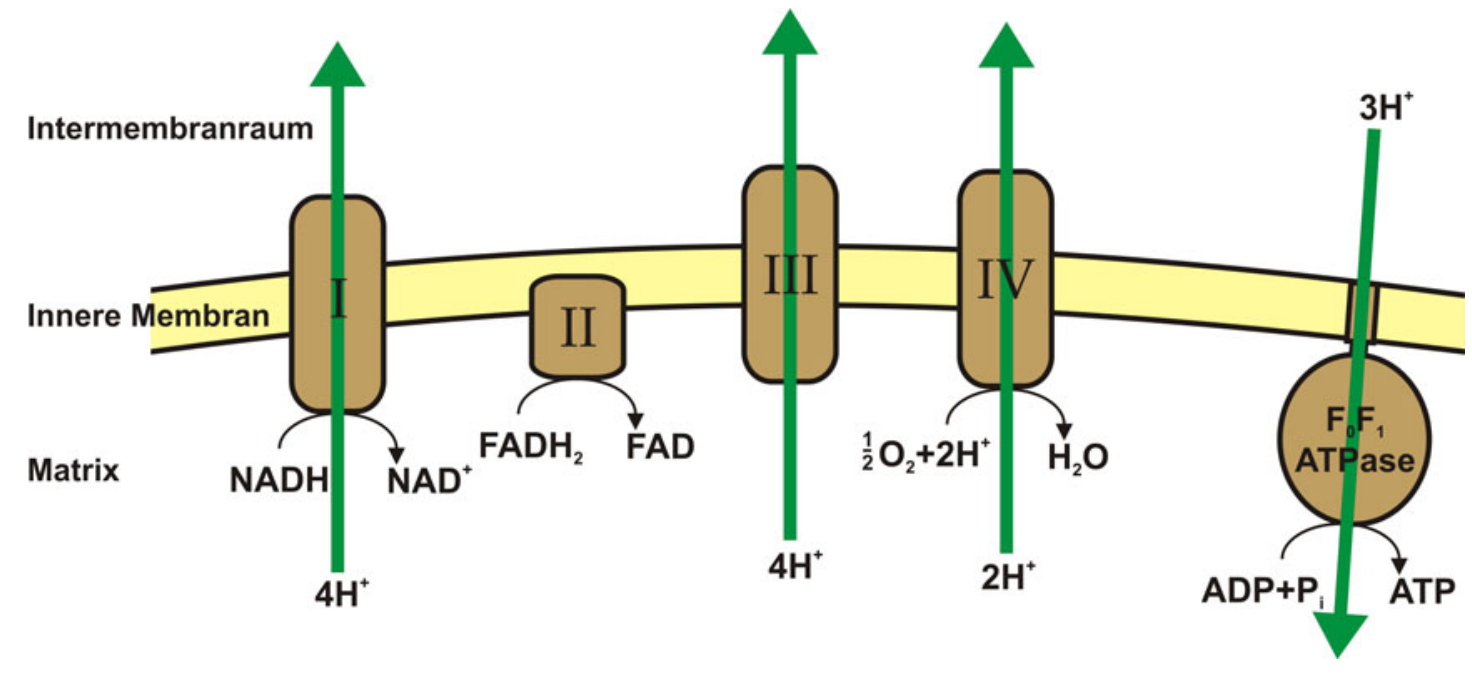

\section{Abb. 1: Skizze Mitochondrium und Atmungskette}

Die Coenzyme NADH und $\mathrm{FADH}_{2}$ übertragen Elektronen in mehreren Teilschritten auf Sauerstoff, wobei Wasser entsteht. Dieser Mechanismus ist in der inneren Mitochondrienmembran verankert (A). Die Komplexe I, III und IV pumpen dabei Elektronen in den Intermembranraum der Mitochondrien. Der so entstehende Protonengradient hält das mitochondriale Membranpotential $(\Delta \psi \mathrm{m})$ aufrecht und wird von der ATPase zur Synthese von ATP genutzt (B). 


\section{Die Bildung von Sauerstoffradikalen in der Atmungskette}

Nicht alle Elektronen, die die Atmungskette durchlaufen, werden in Komplex IV auf Sauerstoff übertragen. Bis zu 5\% der Elektronen entweichen in Komplex I und III aus dem System und reduzieren Sauerstoff zu Superoxid $\left(\cdot \mathrm{O}_{2}{ }^{-}\right)$(Turrens, 2003; Karihtala und Soini, 2007). Superoxid wird durch das Enzym Superoxid Dismutase (SOD) in Wasserstoffperoxid, $\mathrm{H}_{2} \mathrm{O}_{2}$ umgewandelt. Dieses kann entweder durch Katalase oder Glutathion Peroxidase in Wasser und molekularen Sauerstoff umgewandelt werden oder in der Fenton-Reaktion in Anwesenheit von reduzierten Metallionen $\left(\mathrm{Fe}^{2+}\right.$ $\mathrm{Cu}^{2+}$ oder $\mathrm{Ni}^{2+}$ ) zu Hydroxyl Radikalen, $(\bullet \mathrm{OH})$ reagieren (Lloyd und Phillips, 1999). Daher wird Wasserstoffperoxid, obwohl es keine ungepaarten Elektronen besitzt, zu den Sauerstoffradikalen gezählt. Im Gegensatz zu den anderen ROS ist $\mathrm{H}_{2} \mathrm{O}_{2}$ Membrangängig und kann so entfernt vom Entstehungsort oder sogar in anderen Zellen wirken (Gerich und Müller, 2006). Neuste Studien zeigen die Möglichkeit auf, dass auch Superoxid durch Anionenkanäle Zellmembranen passieren kann (Hawkins et al., 2007).

Hydroxyl Radikale haben aufgrund ihrer hohen Reaktivität eine sehr kurze Halbwertszeit im Bereich von Nanosekunden (Karihtala und Soini, 2007) und reagieren daher nur mit Molekülen in der direkten Umgebung ihrer Entstehung, können aber zu DNA Schäden und Zerstörung von Membranen durch Lipidperoxidation führen (Kontos, 2001). Die Konzentration von ROS wird durch ein komplexes System von Antioxidantien und Enzymen so niedrig wie möglich gehalten (Valko et al., 2007).

\section{Tabelle 1: Die Bildung der verschiedenen ROS}

\begin{tabular}{lll}
\hline Reaktion & & Bezeichnung \\
\hline $\mathrm{O}_{2}+\mathrm{e}^{-}$ & $\longrightarrow \mathrm{O}_{2}^{-}$ & $\begin{array}{l}\text { Bildung von Superoxid in der } \\
\text { Atmungskette }\end{array}$ \\
$2 \cdot \mathrm{O}_{2}^{-}+2 \mathrm{H}^{+} \longrightarrow \mathrm{H}_{2} \mathrm{O}_{2}+\mathrm{O}_{2}$ & $\begin{array}{l}\text { SOD katalysierte } \mathrm{H}_{2} \mathrm{O}_{2} \text { Bildung } \\
\mathrm{H}_{2} \mathrm{O}_{2}+\mathrm{Fe}^{2+} \longrightarrow \cdot \mathrm{OH}+\mathrm{OH}^{-}+\mathrm{Fe}^{3+}\end{array}$ \\
\end{tabular}




\section{Blocker der Atmungskette}

Auf die einzelnen Komplexe der Atmungskette kann mit verschiedenen Pharmaka Einfluss genommen (Abb. 2) und so der Elektronenfluss an den gewünschten Stellen gezielt unterbrochen werden. Alle Komponenten vor dem Block werden daher durch die auflaufenden Elektronen vollständig reduziert, während die Komponenten hinter dem Block vollständig oxidiert vorliegen. In den Komplexen I und III kann es dadurch verstärkt zum Entweichen von Elektronen aus der Atmungskette kommen. Viele Insektizide und Pestizide wirken z.B. auf Komplex I, während einige Antibiotika auf Komplex III wirken. Wirkstoffe, welche die Verwendbarkeit von Sauerstoff beeinflussen, blockieren Komplex IV (Foster et al., 2006). Die am häufigsten verwendeten Blocker sind Rotenon für Komplex I, Antimycin für Komplex III und Cyanid für Komplex IV. Zur Inhibition von Komplex II und der ATPase werden oft 3-NPA beziehungsweise Oligomycin genutzt. Eine weitere Möglichkeit, die Atmungskette zu beeinflussen, sind Protonophoren, wie z.B. FCCP, die ungesteuerte Wasserstoffkanäle in die innere Mitochondrienmembran einbauen, wodurch der Protonengradient über die Membran zusammenbricht und so die Atmungskette von der ATP-Produktion entkoppelt wird.

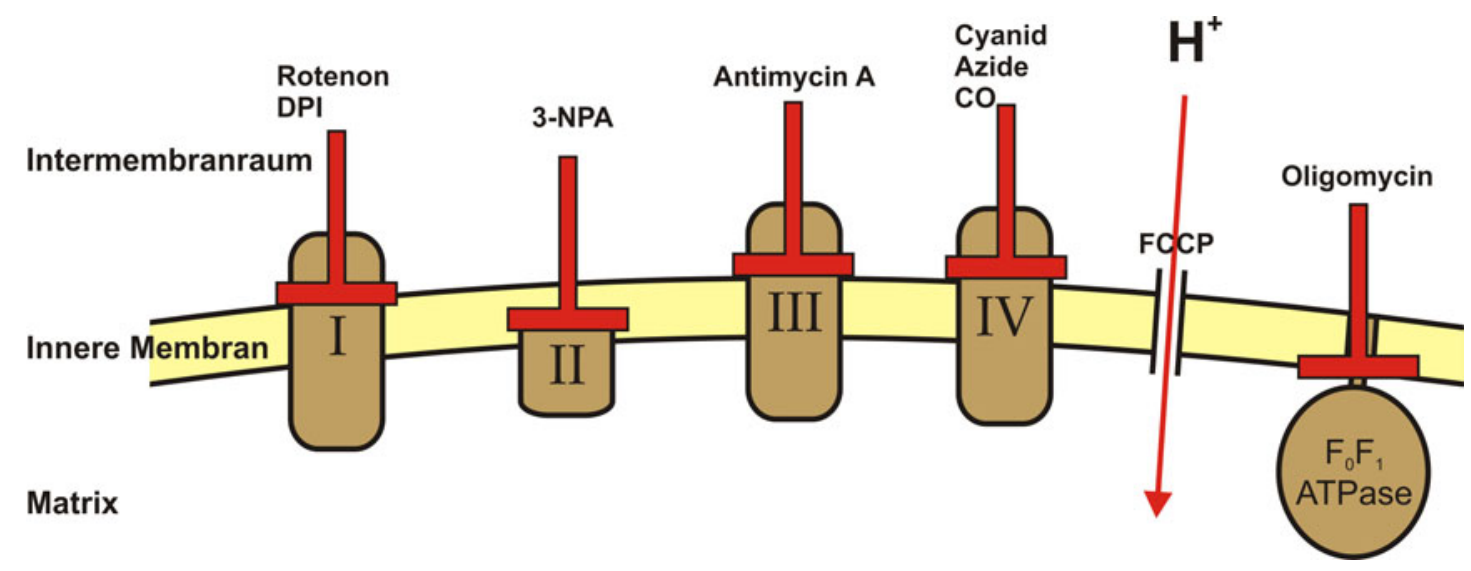

\section{Abb. 2: Skizze Blocker der Atmungskette}

Die verschiedenen Komplexe der Atmungskette können durch diverse Blocker gezielt reversibel oder irreversibel inhibiert werden. 


\section{Der Hippokampus und seine synaptische Verschaltung}

Die starke Anfälligkeit hippokampalen Gewebes gegenüber Sauerstoffmangel und die Variation dieser Anfälligkeit in den verschiedenen Regionen machen den Hippokampus zum idealen Forschungsobjekt bezüglich Hypoxie und Anoxie.

Die hippokampale Formation (kurz: Hippokampus, Abb. 3 und 5) besteht aus dem Ammonshorn (cornu ammonis) mit den Regionen CA1-3, dem hilus (auch CA4), dem gyrus dentatus und dem subiculum. Der hilus wird aufgrund seiner Lage meist als Teil des gyrus dentatus angesehen (Abb. 4). Der Hippokampus ist phylogenetisch eine der ältesten Strukturen im Säugergehirn. Bereits bei Amphibien, Reptilien, Vögeln (El-Falougy und Benuska, 2006) und Fischen (Braford, 1995) gibt es dem Hippokampus homologe Strukturen, die sich in ihrem zellulären Aufbau aber stark vom Säuger Hippokampus unterscheiden.

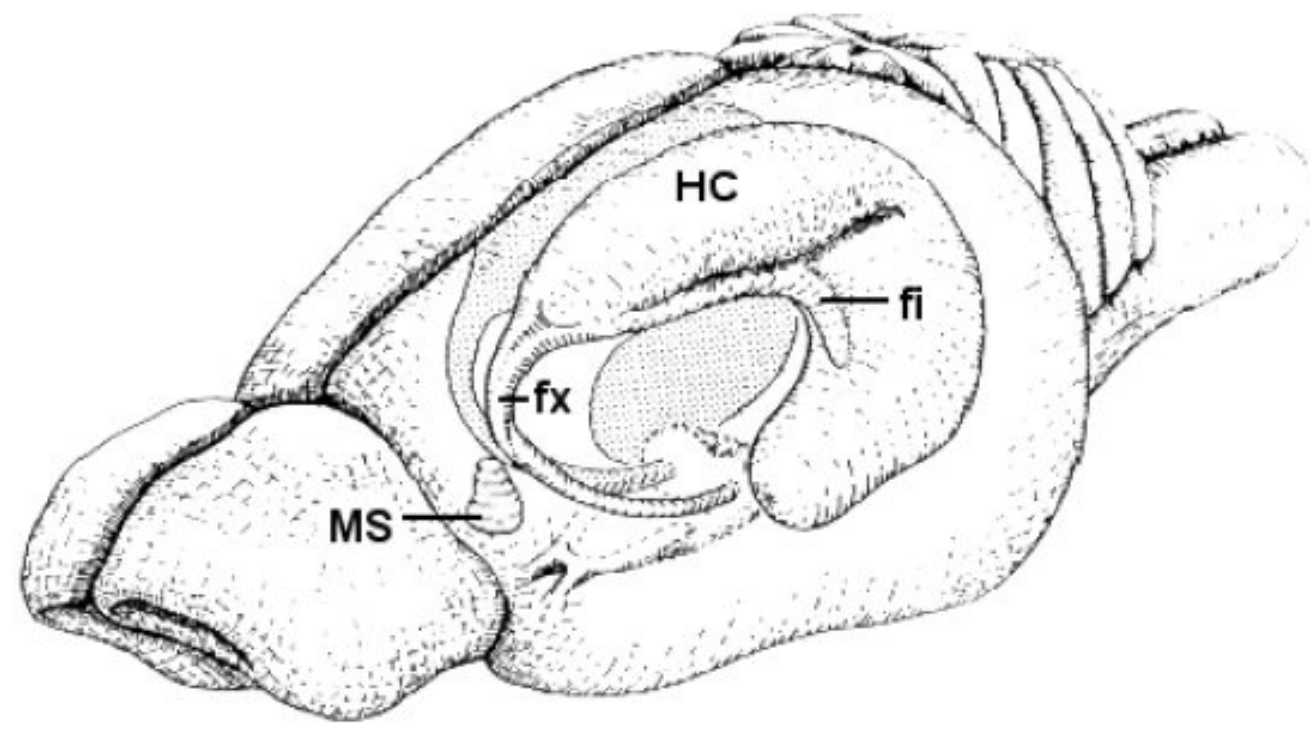

\section{Abb. 3: Lage des Hippokampus im Rattenhirn}

fx: fornix; fi: fimbria; HC: Hippokampus; MS: mediales septum Quelle: Ikonen, 2001

Der Hippokampus spielt eine zentrale Rolle in der Speicherung von Informationen in das explizite (auch: deklarative) Langzeitgedächtnis, nicht jedoch beim Abrufen der gespeicherten Informationen (Kandel et al., 1996). 
Er hat keinen Einfluss auf das Kurzzeitgedächtnis sowie das implizite (auch: nichtdeklarative) Gedächtnis, welches weder bei der Speicherung noch beim Abruf bewusste kognitive Vorgänge beinhaltet und eher reflexartige, motorisch sowie sensorisch gesteuerte Verhaltensweisen steuert.

Neben dieser Funktion bei der Gedächtnissteuerung ist der Hippokampus als Teil des limbischen Systems auch in der Verarbeitung von Emotionen (Kandel et al., 1996; Richardson et al., 2004) und Motivation (Tracy et al., 2001) beteiligt.

Die synaptische Verschaltung im Hippokampus nennt man auch die trisynaptische hippokampale Schleife (trisynaptic circuit) (Witter et al., 2000). Der Hippokampus erhält einen Großteil seiner synaptischen Eingänge vom entorhinalen Cortex über den tractus perforans auf die Körnerzellen des gyrus dentatus. Die Axone der Körnerzellen bilden die Moosfasern, welche zu den Pyramidenzellen der CA3 Region ziehen. Deren Axone verlaufen als Schaffer-Kollaterale zu den Pyramidenzellen der CA1 Region, welche über das Subiculum zurück zum entorhinalen Cortex und anderen cortikalen und subcorticalen Bereichen wie z.B. den Mammilarkörpern des Hypothalamus (Kandel et al., 1996) projizieren. Diese klare Struktur der Verschaltung prädestiniert den Hippokampus zur Untersuchung der Wirkungen von synaptischen Modulatoren.

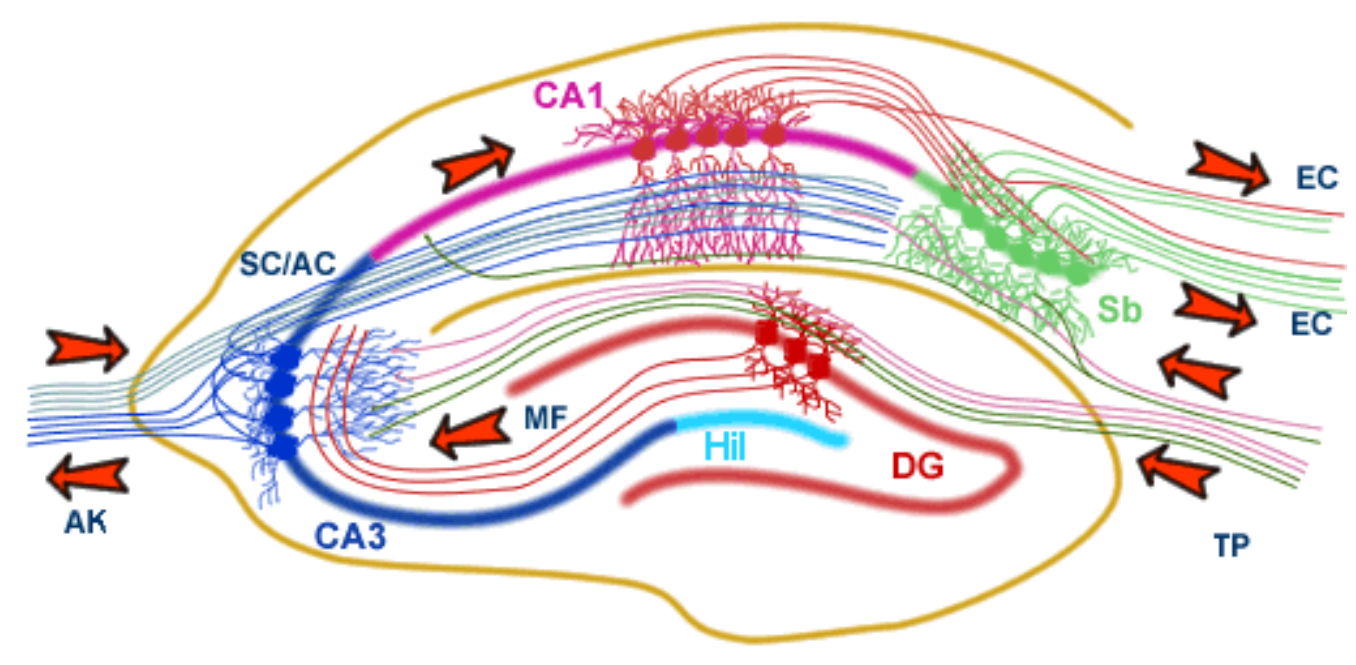

\section{Abb. 4: Die synaptische Verschaltung im Hippokampus}

AK: assoziative und kommissurale Kollaterale, Die Verbindung zum kontralateralen Hippokampus; CA1-3: cornu ammonis Regionen; DG: gyrus dentatus; EC: Entorhinaler Cortex; Hil: hilus; 
MF: Moosfasern; Sb: subiculum; SC: Schaffer-Kollaterale; TP: tractus perforans

Quelle:

http://www.bris.ac.uk/Depts/Synaptic/info/pathway/figs/hippocampus.gif (verändert)

\section{Der Mechanismus der spreading depression}

Bei einer spreading depression (SD) handelt es sich um eine synchronisierte Depolarisation von Neuronen und Glia, die sich von einem Fokus aus wellenartig durch neuronales Gewebe fortpflanzt. Dabei kommt es zu einer massiven Verschiebung des lonengleichgewichts zwischen den betroffenen Zellen und des sie umgebenden Extrazellularraumes. Sie wurde bereits 1944 von Aristides Leão als wiederauftretendes und reversibles physiologisches Phänomen auf der Cortex Oberfläche von Kaninchengehirnen beschrieben (Leão, 1944).

Eine SD kann z.B. durch tetanische elektrische Stimulierung (Leão, 1944), mechanische Belastung oder Beschädigung des Gewebes (Roitbak und Bobrov, 1975; Somjen et al., 1992) sowie eine Vielzahl von chemischen Einflüssen (Gerich et al., 2006) oder auch Hypoxie (siehe unten) ausgelöst werden. Als Beispiele sein hier nur Kalium (Reid et al., 1988) und Glutamat (Hossmann, 2003) erwähnt.

Diese Auflistung deckt natürlich nur einen kleinen Teil der erforschten Bedingungen ab. Einen ausführlichen Überblick findet man in der Review von George Somjen (2001).

Eine SD kann in praktisch allen Regionen des Zentralnervensystems ausgelöst werden wobei einige Areale besonders anfällig sind. Am empfindlichsten ist die CA1-Region des Hippokampus und in etwas geringerem Ausmaß der Neocortex. Im Cerebellum und im Rückenmark lässt sich eine SD schwer und nur unter bestimmten nicht physiologischen Bedingungen auslösen (Frosch Rückenmark: Streit et al., 1995). In fötalem und neonatalem Gewebe lässt sich eine SD in der Regel nicht oder nur sehr 
schwer auslösen, was durch den großen Extrazellulärraum in diesen frühen Stadien der Entwicklung erklärt werden kann (Lehmenkühler et al., 1993).

Während einer SD kommt es zu einem massiven Anstieg der extrazellulären Kalium-Konzentration $\left(\left[\mathrm{K}^{+}\right]_{\mathrm{a}}\right)$. Gleichzeitig verringern sich $\left[\mathrm{Na}^{+}\right]_{\mathrm{a}},\left[\mathrm{Ca}^{2+}\right]_{\mathrm{a}}$ und $\left[\mathrm{Cl}^{-}\right]_{\mathrm{a}}$. Dies lässt die Vermutung zu, das $\mathrm{K}^{+}$gegen $\mathrm{Na}^{+}$und $\mathrm{Ca}^{2+}$ ausgetauscht wird, wobei $\mathrm{Cl}^{-}$passiv dem Natrium-lonenfluss folgt (Müller, 2005). Durch die gestörte lonenverteilung kommt es zu einer Schwellung der Neuronen und Glia, was den Intrazellularraum weiter verkleinert und somit das Ungleichgewicht der lonenverteilung noch verstärkt (Hansen und Olsen, 1980).

An der Oberfläche von Hirnschnitten, die eine SD durchlaufen, kann man eine charakteristische Veränderung der Lichtstreuung im betroffenen Gebiet erkennen. Der genaue Mechanismus, der hinter diesen von extrazellulärem Chlorid abhängigen (Martins-Ferreira et al., 1971; Müller und Somjen, 1999) intrinsischen optischen Signalen steckt, ist noch nicht völlig erforscht. Zellschwellung kann aber als Hauptgrund ausgeschlossen werden (Müller und Somjen, 1999). Mögliche Ursachen sind eine Veränderung der Oberflächenwölbung der Hirnschnitte (Kreisman et al., 1995), Veränderungen in der Cytoarchitektur, wie z.B. Schwellung der Mitochondrien (Aitken et al., 1999) oder auch eine Schädigung der Dendriten (Beading), was aber dem reversiblen Charakter der SD widerspricht. Ein Film, der die intrinsischen optischen Signale einer SD in einem Hirnschnitt zeigt, kann unter folgender Internet Adresse eingesehen werden:

http://wwwuser.gwdg.de/ mmuelle7/SD.html

Für den Fall, das die SD durch schwere Hypoxie bzw. Anoxie ausgelöst wird gibt es unterschiedliche, zum Teil irreführende Bezeichnungen (Überblick in: Somjen, 2001). In dieser Arbeit wird die Bezeichnung „(durch) Hypoxie induzierte spreading depression“ (Englisch: hypoxia induced spreading depression; HSD) genutzt.

Zwischen SD und HSD gibt es einige wenige aber bedeutende Unterschiede. Zur Regeneration und zum Wiederherstellen des lonengleichgewichts ist Energie erforderlich, die durch zelluläre Respiration bereitgestellt werden muss. Die Dauer einer HSD ist daher direkt von der Wiederherstellung der Sauerstoffversorgung abhängig. SD und HSD unterscheiden sich auch im 
Zeitverlauf der Störung der synaptischen Funktion. Bei einer SD funktionieren die Synapsen bis zu dem Moment, in dem die massive Depolarisation der Zellmembran eintritt. Dieser Verlust der synaptischen Funktion tritt bei einer HSD schon einige Minuten vor der Depolarisation ein (Somjen et al., 1993). Im Gegensatz zu einer SD lässt sich eine HSD durch NMDA-Antagonisten nicht blockieren (Somjen, 2001).

Soweit die Sauerstoffversorgung rechtzeitig wiederhergestellt ist, zeigen HSD und SD deutliche Übereinstimmungen in Bezug auf den Verlauf der Änderung des Membranpotentials, der intrinsischen optischen Signale und deren Ausbreitungsgeschwindigkeit sowie der Verkleinerung des Extrazellulärraumes.

Das Auftreten von SD und HSD ist mit Krankheitsbildern der Migräne, Epilepsie Hirn-Ödemen und -verletzungen sowie der apoplexia cerebri (Schlaganfall) gekoppelt (Somjen 2001). 


\section{Material und Methoden}

\section{Versuchstiere und Gewebe}

Alle Versuche wurden an akuten Hirnschnitten bzw. primären Zellkulturen durchgeführt. Das dazu notwendige Hirngewebe wurde Ratten (rattus norvegicus) der Zuchtlinie Sprague-Dawley entnommen. Die Tiere wurden in der zentralen tierexperimentellen Einrichtung der Universität gehalten und gezüchtet. Da Östrogene in vielen neurodegenerativen Krankheiten und Verletzungen eine neuroprotektive Rolle erfüllen (Suzuki et al., 2006) und besonders cortikale und hippokampale Neurone vor Schäden durch Ischämie schützen (Merchenthaler et. al, 2003), wurden für die Anoxie-Versuche größtenteils männliche Tiere ausgewählt. Kontrollversuche zeigten jedoch bezüglich der hier gezeigten Ergebnisse keine signifikanten Unterschiede zwischen Männchen und Weibchen.

Neuronales Gewebe weist einen sehr hohen Energie- und damit auch einen hohen Sauerstoffbedarf auf. Es ist daher gegenüber Störungen in der Sauerstoffversorgung extrem anfällig. Da hippokampale Neurone besonders sensibel auf hypoxische Verhältnisse reagieren (Pulsinelli et al. 1982; Schmidt-Kastner und Freund, 1991), ist der Hippokampus in der Hypoxie- und Ischämie-Forschung schon von jeher eines der häufigsten verwendeten Gewebe.

\section{Präparation der Hirnschnitte}

Männliche Sprague-Dawley Ratten im Alter von 6-8 Wochen und einem Gewicht von 200-280 g wurden mit Ether betäubt und dekapitiert. Der Schädel wurde geöffnet und das Gehirn mit eiskalter ACSF gespült, zügig entnommen und für 1-2 min in eiskalter, begaster ACSF abgekühlt, um Ischämie-Schäden zu minimieren.

Die Hemisphären wurden getrennt und das Cerebellum auf Höhe der Pons abgetrennt. Ebenso wurden der Olfaktorische Bulbus sowie das vordere Drittel des frontalen Cortex entfernt. Der verbliebene Rest der Hemisphäre wurde mit dem Frontalende nach oben auf einen Vorgekühlten Schneideblock 
geklebt und mit einem tissue slicer (752M Vibroslice, Campden Instruments, Loughborough, UK) in $400 \mu \mathrm{m}$ dicke transversale Schnitte des Hippokampus und des umliegenden Gewebes geschnitten.
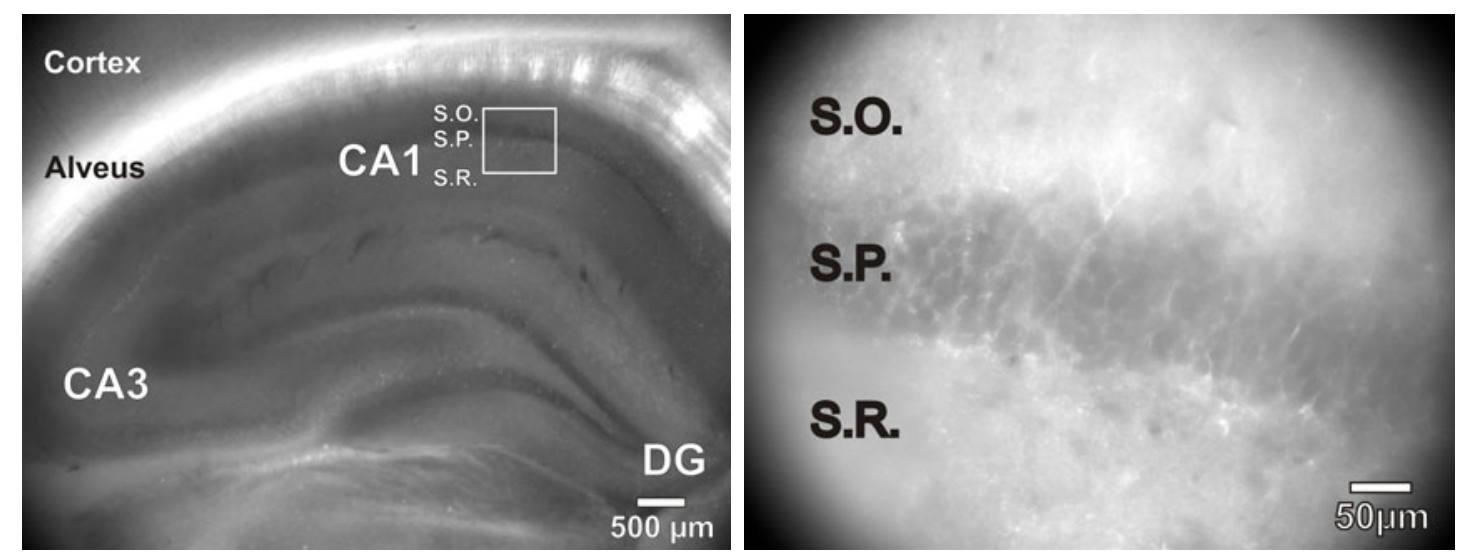

\section{Abb. 5: Hippokampale Formation in einem Hirnschnitt}

Vergrößerung: Links 2,5x, Rechts (Vergrößerter Ausschnitt) 63x CA1-3: CA (cornu ammonis) Regionen des Hippokampus; DG: gyrus dentatus; S.O.: stratum oriens; S.P.: stratum pyramidale; S.R.: stratum radiatum

Die Hirnschnitte (Abb. 5) wurden in eine Interfacekammer vom Oslo-Typ (Croning \& Haddad, 1998) überführt und für 90 Minuten ungestört gelassen, um eine Erholung vom Präparationstrauma zu gewährleisten. In dieser Art Versuchskammer liegen die Hirnschnitte auf einem Netz an der Grenzfläche zwischen artifizieller cerebrospinaler Flüssigkeit (ACSF) und der Luft (Abb. 6). Da die Hirnschnitte praktisch ihre gesamte Sauerstoffversorgung aus der Luft und nicht aus der begasten Lösung beziehen, kann man so ohne nennenswerte Zeitverzögerung zwischen normoxischen und hypoxischen Verhältnissen wechseln. Die Wirkung von Pharmaka hingegen tritt im Gegensatz zu einer Submersionskammer aufgrund des verlängerten Diffusionsweges deutlich verzögert ein. 


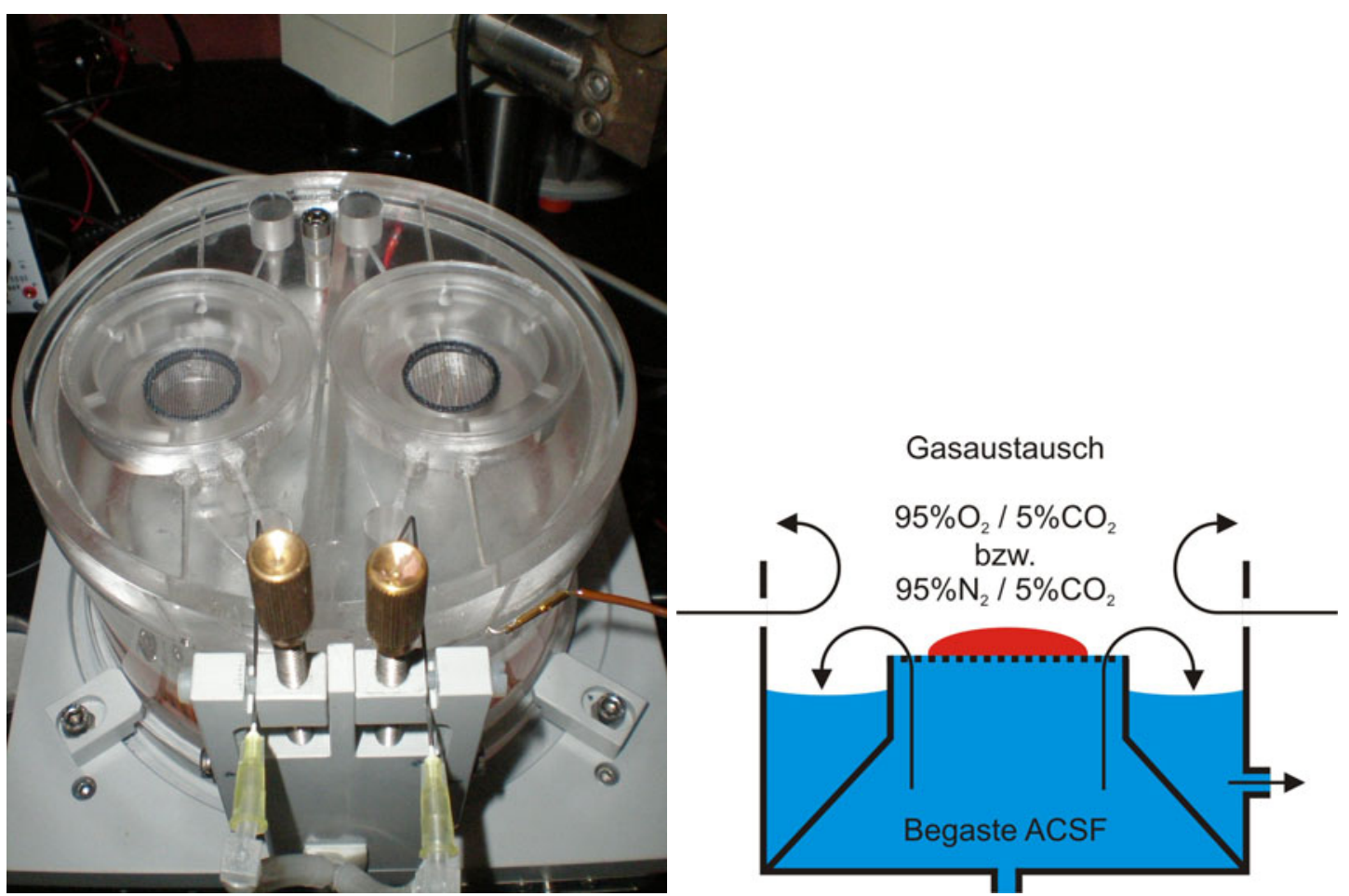

Abb. 6: Aufbau und Prinzip der Interfacekammer

Die Hirnschnitte liegen auf einem Netz auf der Grenzfläche zwischen Flüssigkeit und Luft. Die Sauerstoffversorgung geschieht fast vollständig durch die Gasphase, wobei die Gasgemische Carbogen bzw. $\mathrm{N}_{2} / \mathrm{CO}_{2}$ durch ein erwärmtes Wasserbad geleitet (hier nicht gezeigt) und so befeuchtet werden.

Die Kammer wurde kontinuierlich mit Carbogen $\left(95 \% \mathrm{O}_{2} / 5 \% \mathrm{CO}_{2}\right)$ mit einer Flussrate von ca. $\sim 400 \mathrm{ml} / \mathrm{min}$ begast und die Hirnschnitte mit begaster ACSF perfundiert (3-4 ml/min). Die Temperatur in der Kammer betrug $35-36^{\circ} \mathrm{C}$. Die verwendete Interfacekammer verfügte über zwei vollständig voneinander getrennte Kammern mit eigener Gasversorgung und ACSF-Zufluss. So konnten die Hirnschnitte in einer Versuchskammer untersucht bzw. mit den jeweils benötigten Pharmaka behandelt werden, während die Hirnschnitte in der zweiten Kammer in Carbogen begaster Kontrolllösung aufbewahrt wurden.

Für einige optische Messungen sowie für die Messungen des ATP-Gehaltes wurde die hippokampale Formation isoliert. In diesen Fällen fanden die Messungen in einer Submersionskammer statt. 


\section{Anlegen einer gemischten Primärkultur aus Gliazellen und Neuronen}

Um Untersuchungen auf Einzelzellebene sowie die Transfektion von Zellen mit dem neuartigen redoxsensitiven roGFP zu ermöglichen wurde eine Methode zum Anlegen von Primärkulturen hippokampaler Neurone neu etabliert.

Zur Herstellung dieser Primärkulturen (verändert nach Malgaroli \& Tsien, 1992) wurden 2-5 Tage alte Ratten beiderlei Geschlechts verwendet. Die Tiere wurden dekapitiert, das Gehirn entnommen und in eiskalten Puffer (Hank's balanced salts solution, HBSS) $+20 \%$ fötales Rinderserum überführt. Sofern nicht anders erwähnt, wurden in allen weiteren Schritten eisgekühlte Lösungen eingesetzt. Die Hemisphären wurden getrennt, die Hippokampi isoliert und transversal in kleinere Stücke geschnitten. Nach Waschen mit HBSS (+20\% FBS) (3x) und HBSS (3x) wurden die Stücke 10 min bei $37^{\circ} \mathrm{C}$ trypsiniert. Trypsin spaltet die extrazellulären Proteine, die zur Zelladhäsion beitragen. Dadurch wird eine Dissoziierung des Gewebes ermöglicht. Die Trypsinierung wurde durch Zugabe von HBSS (+20\% FBS) gestoppt und die Stücke erneut gewaschen (s.o.). Die Hippokampus Scheibchen wurden in Dissoziationspuffer überführt und mit einer feuerpolierten Pasteurpipette durch vorsichtiges Trituieren dissoziiert, bis keine Gewebereste mehr zu erkennen waren. Die Zell-Suspension wurde zentrifugiert (10 min, 1500 rpm, $4^{\circ} \mathrm{C}$ ) und das Pellet in Platierungsmedium oder Kulturmedium I resuspendiert.

Die ersten Versuche wurden mit Platierungs- und Wachstumsmedium durchgeführt. Da diese Medien für eine Transfektion ungeeignet sind, wurden später alle weiteren Zellkulturen mit Kulturmedium I und II angesetzt.

Die Zellen wurden mit Hilfe einer Neubauer-Zählkammer ausgezählt, in einer Dichte von 20.000-30.000 Zellen auf mit Matrigel benetzten Deckgläschen ( $1,3 \mathrm{~cm}^{2}$ ) ausplatiert und in 4-Kammern-Kulturplatten (4-well culture plates) (Nunc, Wiesbaden, Deutschland) bei $37^{\circ} \mathrm{C}$ in befeuchteter $95 \% \mathrm{O}_{2} / 5 \% \mathrm{CO}_{2}$ Atmosphäre inkubiert. Nach einer Stunde, in der Neurone und Gliazellen am Glas Festhaften konnten, wurden die Kammern der Kulturplatten mit $800 \mu \mathrm{l}$ Platierungsmedium bzw. Kulturmedium I aufgefüllt. Am zweiten Tag wurde das Medium gegen Wachstumsmedium bzw. Kulturmedium II ausgetauscht. Danach wurde das Medium alle 2 Tage zur Hälfte ausgewechselt. 


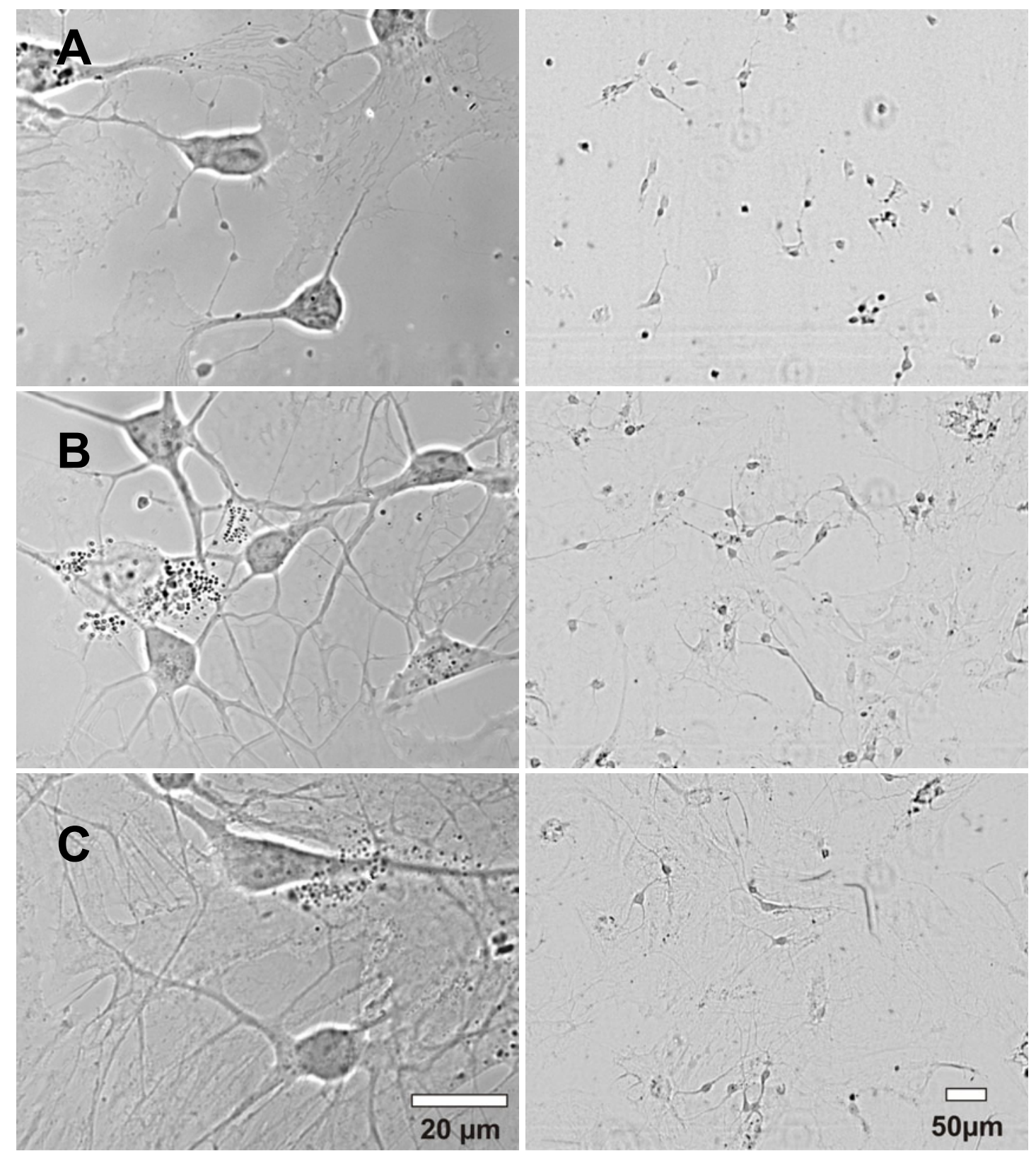

\section{Abb. 7: Entwicklung der Zellkultur}

Neurone und Gliazellen beginnen direkt nach dem Ausplatieren mit der Bildung von Ausläufern. Dabei wachsen die Neurone fast immer auf Gliazellen, was dazu führen kann, dass sich die Zellen bei Färbungen nur unklar voneinander abgrenzen lassen.

A: Zellkultur, Alter 1 Tag (days in vitro, DIV); B: DIV 3; C: DIV 11 Vergrößerung: links 60x, rechts 10x

Die Neurone begannen direkt nach dem Ausplatieren mit der Bildung von Ausläufern (Abb. 7) und nach 2 Tagen waren die Zellen voll ausdifferenziert. Die meisten Versuche fanden mit Zellen im Alter von 3-7 Tagen (DIV) statt. 


\section{Elektrophysiologie}

\section{Elektrophysiologische Messungen}

Im Rahmen dieser Arbeit wurden folgende Elektrophysiologische Messungen durchgeführt:

1. Evozierte Feldpotentiale

2. DC Potentiale während Hypoxie

3. Intrazelluläre Ableitungen aus Gliazellen

Die Messelektroden zur Messung extrazellulärer DC Potentiale wurden aus dünnwandigem Borosilikat-Glas (GC150TF-10, Harvard Apparatus, Edenbridge, UK) mit einem Horizontal-Puller (P-97, Flaming/Brown Micropipette Puller, Sutter Instrument Co., Novato, USA) hergestellt. Sie wurden mit ACSF befüllt und wiesen einen Widerstand von ca. $5 \mathrm{M} \Omega$ auf. Zur Stimulation wurden mit einem Stimulator (Grass S88 Stimulator, West Warwick, USA) rechteckförmige unipolare Stimuli mit einer Länge von 0,1 ms über eine aus Stahldraht ( $\varnothing 50 \mu \mathrm{m}$, AM-Systems, Hildesheim, Deutschland) gefertigte Mikroelektrode gegeben. Orthodrom evozierte Antworten wurden durch Stimulation der Schaffer-Kollaterale ausgelöst, die mit einer Ableitelektrode im stratum radiatum, dem Bereich der Dendriten, in der CA1 Region aufgezeichnet wurden (Abb. 8). In diesem Bereich tritt die HSD in der Regel zuerst auf.

Die Messungen wurden mit einem DC-Potential Verstärker (Eigenbau, Elektronikwerkstatt, Zentrum Physiologie, Universität Göttingen) durchgeführt. Zur visuellen Kontrolle wurden die Signale auf einem Oszilloskop (TDS2014, Tektronix, Beaverton, USA) wiedergegeben und mit dem Software Paket pCLAMP 9 (Molecular Devices, Sunnyvale, USA) aufgezeichnet und ausgewertet. 


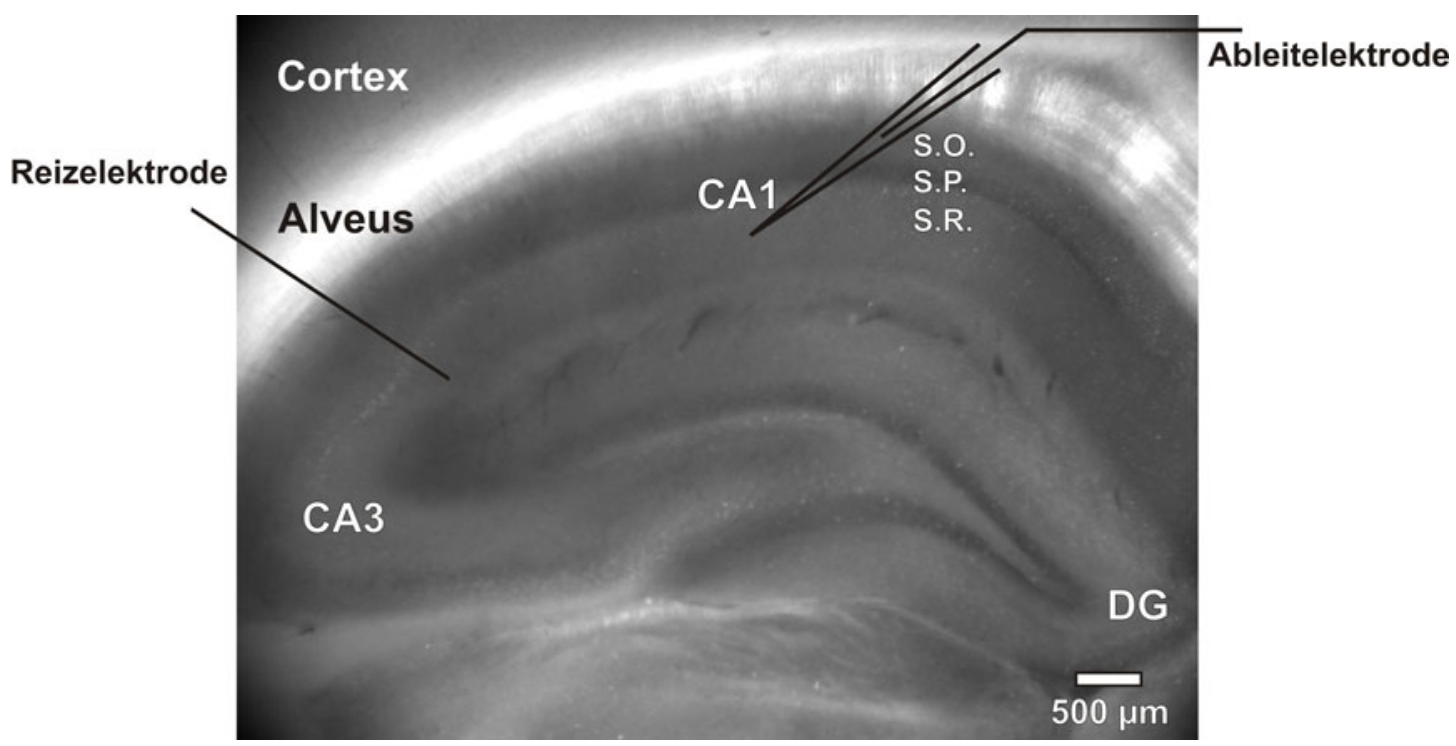

\section{Abb. 8: Platzierung der Reiz- und Ableitelektroden}

Über die Reizelektrode wurden die Schaffer-Kollaterale, d.h. die Axone der CA3 Pyramidenzellen, die von CA3 nach CA1 ziehen und dort auf die apikalen Dendriten der Pyramidenzellen projizieren, stimuliert. Die Ableitelektrode wurde in der CA1 Region im stratum radiatum (S.R.) platziert.

Gliazellen (Astrozyten) aus der Grenzregion zwischen S.R. und S.P. wurden anhand ihres negativen Membranpotentials von -80 bis $-90 \mathrm{mV}$, ihres geringen Eingangswiderstandes und der fehlenden Fähigkeit, Aktionspotentiale zu generieren, identifiziert (D'Ambrosio et al., 1998). Es wurden nur Zellen akzeptiert, deren Membranpotential mindestens $-80 \mathrm{mV}$ betrug.

\section{Hypoxie induzierte spreading depression}

Die Hirnschnitte wurden wie oben beschrieben präpariert und in der InterfaceKammer aufbewahrt. Die Ableit- und Reizelektroden wurden wie oben beschrieben platziert. Um eine schwere Hypoxie auszulösen, wurde die Begasung der Versuchskammer von Carbogen auf 95\% $\mathrm{N}_{2}-5 \% \quad \mathrm{CO}_{2}$ umgestellt. Die Versuchslösungen wurden weiterhin mit Carbogen begast. Daher wird hier durchgehend der Begriff Hypoxie verwendet, obwohl im Gewebe tatsächlich anoxische Bedingungen vorherrschen. Durch den Sauerstoffmangel wurde in der Regel nach 2 - 4 Minuten eine HSD ausgelöst. 
Das Auftreten einer HSD wurde durch eine plötzliche massive Negativierung des extrazellulären DC-Potentials angezeigt. Um eine Vergleichbarkeit der Untersuchungen zu gewährleisten, wurden nur die Hirnschnitte verwendet, bei denen die HSD im Zeitrahmen von $90 \mathrm{~s}$ bis $480 \mathrm{~s}$ nach $\mathrm{O}_{2}$ Entzug auftrat und dabei mindestens eine Amplitude von -10 mV aufwies. 15 - $20 \mathrm{~s}$ nach dem Beginn der HSD hatte die Potentialänderung ihre maximale Amplitude erreicht, und die Begasung wurde wieder auf Carbogen umgestellt, um eine Schadensfreie Erholung zu gewährleisten. Unter diesen Versuchsbedingungen können mehrere HSD-Episoden nacheinander in einem Schnitt ausgelöst werden. Dabei kommt es bei den ersten drei HSD zu keinen signifikanten Abweichungen in den gemessenen Parametern, wenn zwischen den HSD-Episoden eine ausreichende Erholzeit von ca. $30 \mathrm{~min}$. eingehalten wird (Müller und Somjen, 1998).

Zur Modulation der HSD wurden die zu untersuchenden Pharmaka über die Perfusionslösung zugegeben. Um eine ausreichende Diffusion in das Gewebe zu gewährleisten, wurde die Hirnschnitte 20 - 25 Minuten behandelt, bevor eine HSD ausgelöst wurde. Die gemessenen Parameter einer HSD unter Inhibitor Einfluss wurden jeweils mit den Werten einer zuvor induzierten Kontroll-HSD am selben Schnitt verglichen. 


\section{Optische Messungen}

\section{Fluoreszenzmikroskopie}

Die Fluoreszenzmikroskopie beruht auf der Anregung von geeigneten Fluorophoren durch energiereiches Licht bestimmter Wellenlängen. Dabei absorbiert ein Elektron des Fluorophors ein Photon und wird dadurch in einen angeregten Zustand versetzt. Beim Zurückfallen auf sein normales Energieniveau emittiert das Elektron einen Teil der Photonenenergie als Licht einer längeren, d.h. energieärmeren Wellenlänge.

Sofern nicht anders angegeben, wurden alle in dieser Arbeit vorgestellten optischen Messungen an einem aufrechten Fluoreszenzmikroskop (Axiotech vario, Zeiss, Oberkochen, Deutschland) durchgeführt (Abb. 9). Als Lichtquelle diente eine polychromatische Lichtquelle mit Xenon Hochdrucklampe (Polychrom II, Till Photonics, Gräfelfing, Deutschland) der mithilfe eines galvanometrisch gesteuerten optischen Gitters Licht in der eingestellten Wellenlänge durch einen dünnen Schlitz projiziert. Das emittierte Licht wies aufgrund dieses Prinzips eine gaußsche Wellenlängenverteilung von $\pm 15 \mathrm{~nm}$ um die eingestellte Wellenlänge herum auf. Im Weiteren wird immer nur der Mittelpunkt des emittierten Wellenlängenspektrums angegeben (Abb. 9).

Das durch die Anregung der Farbstoffe emittierte Licht konnte noch durch einen Bandpass-Filter sauber vom kurzwelligeren Licht der Lichtquelle getrennt werden und wurde von einer CCD Kamera (Imago QE, PCO Imaging, Kelheim, Deutschland) aufgenommen und die Bilder mit der Software TILLvisION (Till Photonics) bearbeitet. Einige Auswertungen wurden mit der Software Metamorph Offline (Molecular Devices) durchgeführt. 


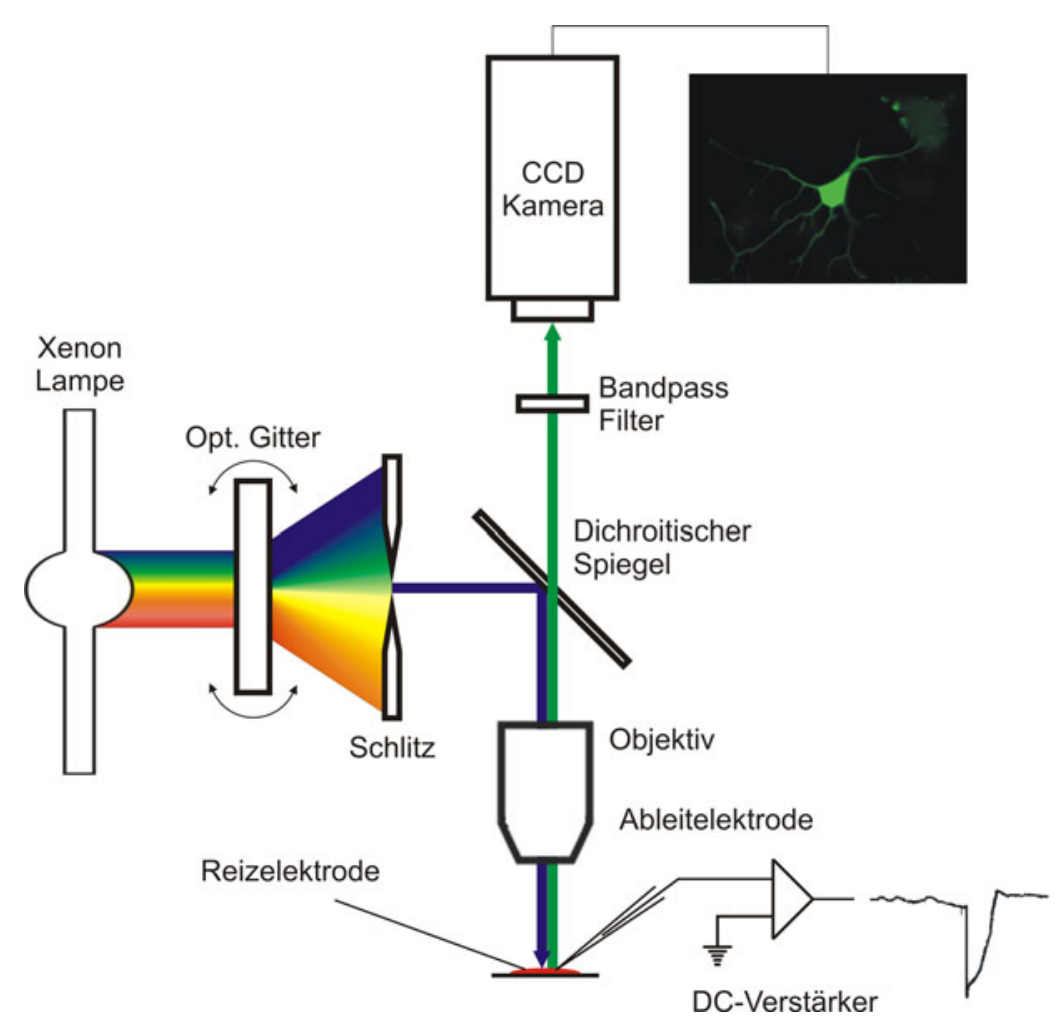

\section{Abb. 9: Skizze des Versuchsaufbaus}

Das Licht der Lichtquelle wird durch ein optisches Gitter gebeugt und auf einen schmalen Spalt projiziert, so dass nur der gewünschte Wellenlängenbereich passieren kann. Der Dichroitische Spiegel lenkt den Lichtstrahl um, der nun durch das Mikroskop auf das Präparat fokussiert wird. Die angeregten Farbstoffe emittieren daraufhin ein Licht längerer Wellenlänge, welches nun den Dichroiten passiert und von der Kamera aufgefangen werden kann. Gleichzeitig zu den optischen Messungen können elektrophysiologische Versuche durchgeführt werden.

\section{Zwei-Photonen-Mikroskopie}

Bereits 1931 stellte Maria Göppert-Mayer (Göppert-Mayer, 1931) die Theorie auf, dass ein Elektron, wenn es von zwei energiearmen Photonen, deren summierte Energie ausreicht, um es in einen angeregten Zustand zu versetzen, gleichzeitig getroffen wird, tatsächlich diesen angeregten Zustand erreicht. Da die zwei Photonen das Elektron innerhalb eines Zeitfensters im Femtosekundenbereich treffen müssen, benötigt man eine Photonenquelle sehr hoher Intensität. 


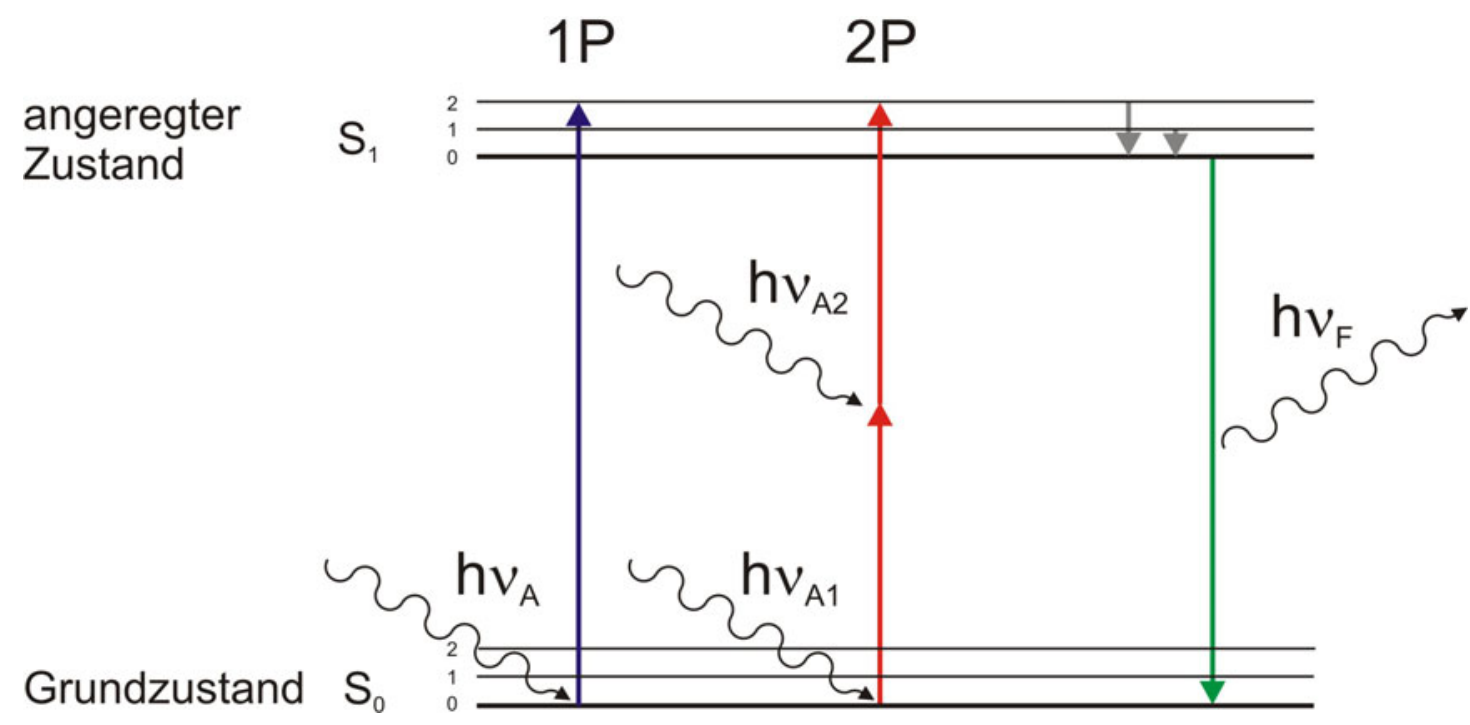

Abb. 10: Vereinfachtes Jablonski Diagramm

Die freien Elektronen des Fluorophors werden durch die Absorption eines Photons $\left(h v_{A}\right)$ kurzwelliger Wellenlänge in einen angeregten Zustand $\left(S_{1}\right)$ versetzt. Kurze Zeit später fallen sie dann über Zwischenstufen auf ihren Grundzustand $\left(\mathrm{S}_{0}\right)$ zurück. Dabei emittieren sie einen Teil der absorbierten Energie in Form von längerwelligen Photonen $\left(h v_{F}\right)$. Nah-infrarotes Licht $(>700 \mathrm{~nm})$ hat nicht genügend Energie, um Elektronen in den angeregten Zustand zu heben. Treffen aber 2 dieser Photonen $\left(h v_{A 1}+h v_{A 2}\right)$ gleichzeitig, d.h. in einem Zeitfenster im Femtosekundenbereich $\left(10^{-15} \mathrm{~s}\right)$ auf das Elektron, addieren sie ihre Energie und erregen das Elektron.

Einige optische Messungen mit dem Farbstoff Rhodamin 123 sowie die Calcium Messungen mit Fluo-3 in DTNB wurden an einem selbstgebautem Zwei-Photonen Mikroskop (Müller et al. 2003) durchgeführt. Dieses System bestand aus einem modifiziertem aufrechten Mikroskop (Axioskop II, Zeiss) mit einem Ti:Saphir Laser (Tsunami, Modell 3941-M3BB, Spectra-Physics, Irvine, USA) der von einem $5 \mathrm{~W}$ Festkörperlaser (Millenia Vs, SpectraPhysics) gepumpt wird. Die laterale und axiale Auflösung lag bei $0,5 \mu \mathrm{m} \times 1,4 \mu \mathrm{m}$. Durch den Einsatz von Neutralgraufiltern konnte die Laserintensität am Präparat auf 1-2 mW eingestellt werden.

Die Zwei-Photonen-Mikroskopie hat gegenüber der normalen Fluoreszenzmikroskopie unter anderem den Vorteil, dass die Energie nur im 
Fokus des Lasers ausreicht, um die Elektronen der Fluorophoren anzuregen. So ergibt sich eine hervorragende axiale Auflösung. Es können viel tiefere Schichten im Gewebe untersucht werden, ohne das es zu einer Störung durch Streulicht aus höher oder tiefer liegenden Schichten des Gewebes kommen kann. Dadurch kommt es auch nur zu minimalem störenden Hintergrundsrauschen.

Das langwellige Laserlicht ist bei kurzer Exposition schonender für Gewebe und Farbstoffe als das UV-Licht der regulären Fluoreszenzmikroskopie (Dunn und Young, 2006). So werden Gewebeschäden vermieden und es tritt eine Bleichung der Farbstoffe, wenn überhaupt, dann nur im Fokus der Beleuchtung auf.

Der Einsatz des Zwei-Photonen Mikroskops ermöglichte Messungen von intrazellulärem Calcium mit dem Farbstoff Fluo-3 in Anwesenheit von DTNB. DTNB absorbiert Licht im Wellenlängenbereich von 300-450 nm. Das führt dazu, dass die Anregung und die Emission durch eine DTNB Zugabe scheinbar auf ein Minimum fällt. Eine 1-Photon Anregung war unter diesen Umständen praktisch nicht möglich.

\section{Autofluoreszenz von NADH und FAD}

Die Wasserstoff-Carrier NAD/NADH und FAD/FADH ${ }_{2}$ dienen in ihrer reduzierten Form der oxidativen Phosphorylierung der mitochondrialen Atmungskette als Elektronendonor, wobei sie oxidiert werden. Da sowohl $\mathrm{NADH}$ als auch FAD autofluoreszierende Eigenschaften aufweisen, eignen sie sich sehr gut, um metabolische Vorgänge in Mitochondrien und die neuronale Aktivität optisch zu untersuchen. Durch eine Optimierung des Versuchsaufbaus und den Einsatz von geeigneten Filtern gelang es, NADH und FAD gleichzeitig zu messen (Foster et al., 2006). Die Messungen wurden an Hirnschnitten durchgeführt. Dabei wurden NADH mit 360 nm und FAD mit $460 \mathrm{~nm}$ abwechselnd angeregt. Eine Messung an einzelnen Neuronen in Zellkultur war nicht möglich, da die Intensität der Autofluoreszenz von NADH sehr schwach ist und selbst durch die hochempfindliche Kamera QE mit einer Quanteneffizienz von 70\% nicht detektierbar war. 


\section{Farbstoffe}

Die Färbungen der Zellkulturen fanden in Kulturmedium im Inkubator bei $37^{\circ} \mathrm{C}$ und $5 \%$ iger $\mathrm{CO}_{2}$ Atmosphäre statt. Die akuten hippokampalen Hirnschnitte wurden in einer selbstgebauten Färbekammer in Carbogen-begaster ACSF bei Raumtemperatur oder im Wasserbad bei $37^{\circ} \mathrm{C}$ gefärbt. Zellen und Hirnschnitte wurden je nach Farbstoff für 25 bis 45 Minuten gefärbt. Fluo-3 wurde in der AM-Ester-Form verwendet. Bei diesen membrangängigen ungeladenen Farbstoffen werden im Cytosol die Estergruppen von Esterasen abgespalten wodurch der Farbstoff erst seine fluoreszenten Eigenschaften erhält und die dann geladene Moleküle nicht so leicht aus den Zellen transportiert werden können. Nach dem gleichen Prinzip funktionieren auch die Fluorescein Di-Acetat Varianten 5(und 6) Chloromethyl-2',7'Dichlorodihydrofluorescein Di-Acetat (CM- $\mathrm{H}_{2}$ DCFDA $)$ und 2',7'Dichlorodihydrofluorescein Di-Acetat $\left(\mathrm{H}_{2} \mathrm{DCFDA}\right)$.

Da diese Farbstoffe wasserunlöslich sind und sich das Anfärben von Neuronen daher als schwierig erwies, wurden die Farbstoffe in $10 \%$ iger Pluronic F-127 in DMSO Lösung angesetzt. Die Eigenschaften der benutzten Farbstoffe sind in folgender Tabelle zusammengefasst. Die bei den Bandpass-Filtern (BP) angegebenen Wellenlängen geben die mittlere Wellenlänge, die den Filter passieren kann, und den Wellenlängenbereich um diesen Mittelpunkt herum an. Die Wellenlängenangabe der Dichroitischen Filter (DC) gibt die Wellenlänge an, ab der längerwelliges Licht den Filter passieren kann. 


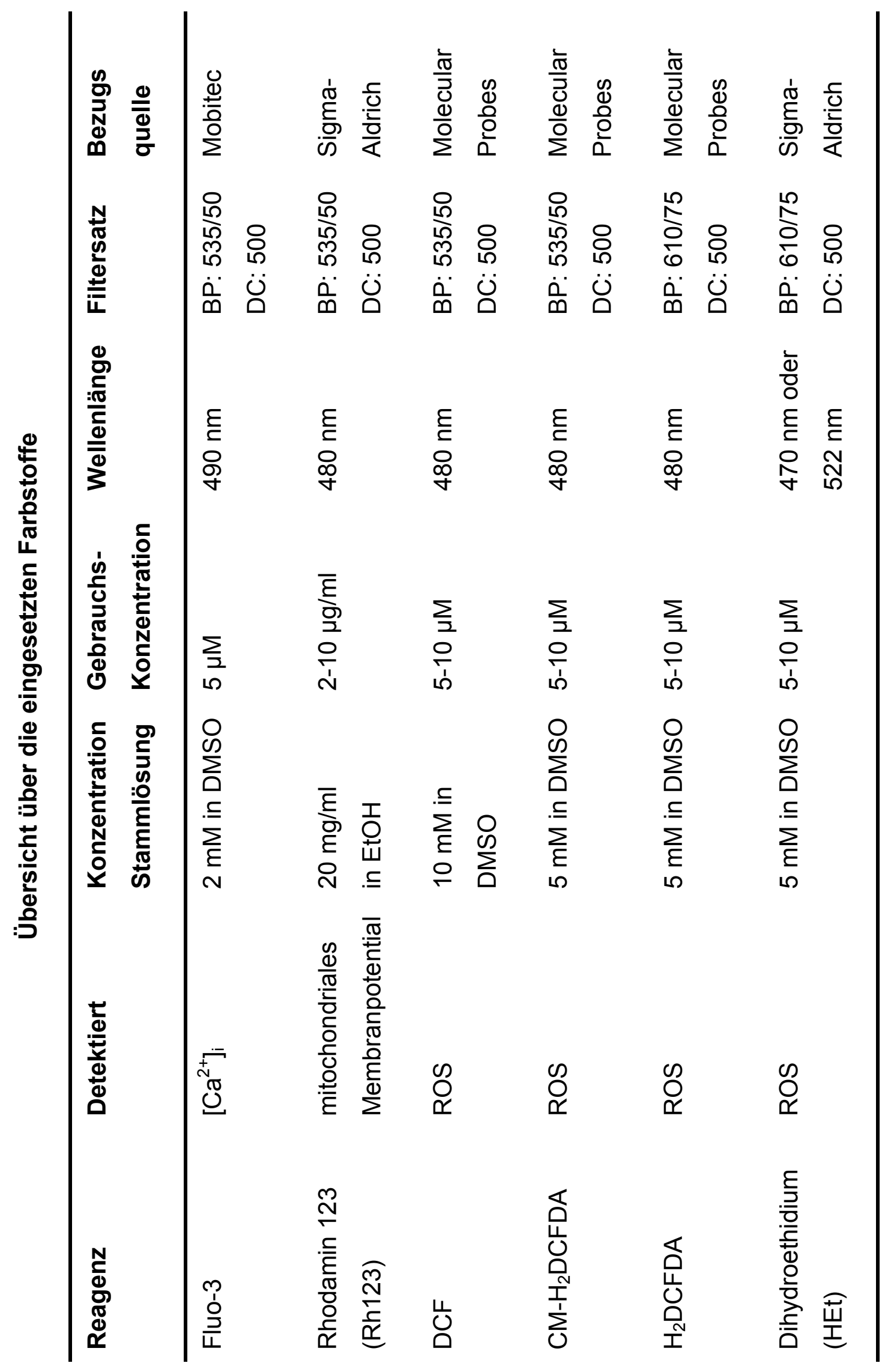




\section{Intrinsische optische Signale}

Wird in hippokampalen Hirnschnitten, die in einer Interfacekammer liegen, eine SD oder eine HSD ausgelöst, geht diese mit einem Anstieg der Lichtbrechung im betroffenen Gewebe einher. Diese charakteristischen intrinsischen optischen Signale (IOS) folgen dem Absinken des extrazellulären DC-Potentials. Das Aufzeichnen der IOS hat den Vorteil, dass es sich um eine nichtinvasive Methode handelt, die ohne den Einsatz von Farbstoffen genutzt werden kann. Dadurch, dass der gesamte Hippokampus betrachtet werden kann, können der Startpunkt der SD, ihre Ausbreitungsgeschwindigkeit und das betroffene Areal visualisiert werden.

Die Ausbreitungsgeschwindigkeit und das betroffene Areal der IOS wurden durch eine Quantifizierung der Änderung der Lichtreflexion in der CA1 Region von hippokampalen Hirnschnitten in der Interfacekammer gemessen. Dazu wurden die Hirnschnitte in einem Winkel von $40-45^{\circ}$ mit weißem Licht bestrahlt. Bilder wurden in 2-Sekunden-Intervallen mit einem 5-Fach 0.13-NA Objektiv (Epiplan, Zeiss) aufgenommen. Hypoxie- und Pharmaka-induzierte Effekte wurden durch Offline Bildsubtraktion sichtbar gemacht. Als Referenz diente ein Bild, das kurz vor dem Wechsel der Begasung von Carbogen auf Stickstoff aufgenommen wurde (Müller und Somjen, 1999).

Der Helligkeitswechsel wurde in einer quadratischen Region im stratum radiatum in der CA1 Region in der Nähe der Ableitelektrode gemessen. Die Ausbreitungsgeschwindigkeit der HSD wurde an der Wellenfront im stratum radiatum der CA1 Region gemessen. Das betroffene Areal wurde als der Bereich definiert, in dem die Helligkeitszunahme $\geq 5 \%$ betrug. Die Bilder wurden mit der Software TILLvisION (Till Photonics) aufgenommen und mit der Software MetaMorph Off-Line 6.1 (Universial Imaging) bearbeitet und analysiert.

\section{Transfektion von Zellkulturen}

Die Transfektion ist eine Methode zur Einschleusung von Fremd-DNA in eukaryotische Zellen. Man unterscheidet zwischen transienter Transfektion, bei der die Fremd-DNA von DNAsen nach einiger Zeit abgebaut wird, und 
stabiler Transfektion, bei der die DNA fest in das Genom der Zelle eingebaut wird. Das gewünschte DNA-Stück wird in einen Plasmid-Vektor eingebaut und über unterschiedliche physikalische oder chemische Wege in die Zielzelle transferiert.

Als Vektor für die in dieser Arbeit verwendeten redoxsensitiven roGFP wurde pEGFP-N1 (Clontech, Mountain view, USA) genutzt (Abb. 11, A).
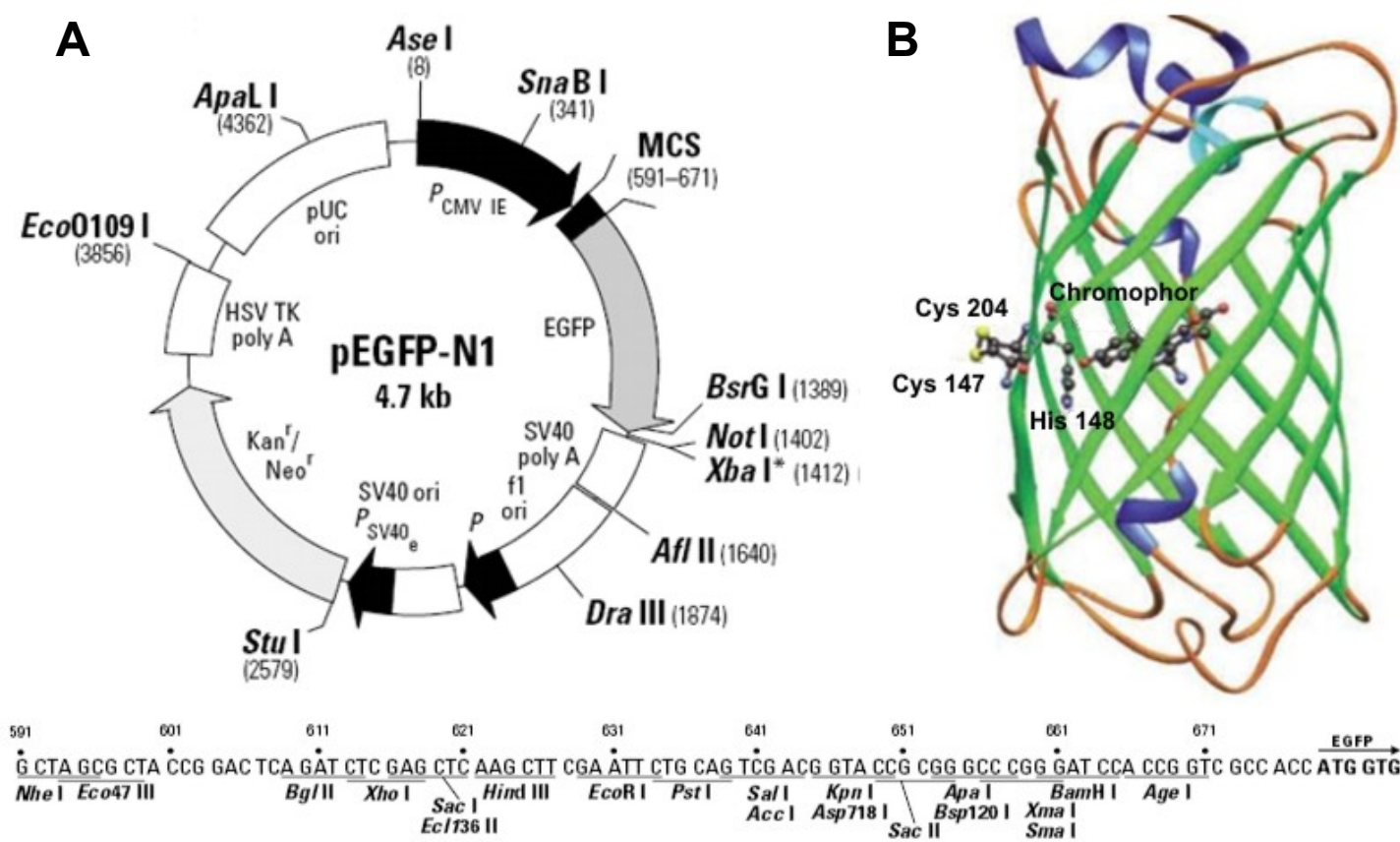

Abb. 11: Restriktionskarte des pEGFP-N1 Vektors und strukturelle Besonderheiten des redoxsensitiven roGFP

pEGFP-N1 ist ursprünglich eine Rot verschobene Variante des Wildtyp GFPs mit Anregungs- und Emissionsmaxima bei $488 \mathrm{~nm}$ und $507 \mathrm{~nm}$. Es enthält ein Resistenzgen gegen Neomycin und Kanamycin (A). Die hier verwendete Variante enthält die Mutationen C48S/T65S/S147C/Q204C. Durch diese Modifikation liegen die beiden Cystein-Reste 147 und 204 an der Oberfläche des Proteins (B). Quellen: http://www.clontech.com/images/pt/dis_vectors/PT3027-5.pdf und Hanson et al. (2004) (Verändert)

Dieses GFP hat bei $395 \mathrm{~nm}$ und 470nm zwei Anregungsmaxima. Im oxidierten Zustand bildet sich zwischen den beiden exponierten Cysteinresten (Abb 11, B) an der Oberfläche des Proteins eine Disulfid-Brücke, welche eine Konformationsänderung induziert, durch die die Protonierung des 
Chromophors unterstützt wird. Dadurch verstärkt sich das Maximum bei $395 \mathrm{~nm}$, während das Maximum bei $470 \mathrm{~nm}$ abgeschwächt wird. Diese Eigenschaft ermöglicht dynamische ratiometrische Messungen des RedoxZustandes der transfizierten Zellen. Das Verhältnis der Fluoreszenz bei $400 \mathrm{~nm}$ zu $470 \mathrm{~nm}$ zeigt das Ausmaß der Oxidation an, ohne dass mögliche Fehlerquellen wie ein Ausbleichen oder die Konzentration des Farbstoffs, eine Instabilität der Beleuchtung sowie die ungleichmäßige Verteilung des Indikators in den Zellen einen Einfluss auf die Messungen haben (Hanson et al., 2004; Dooley et al., 2004).
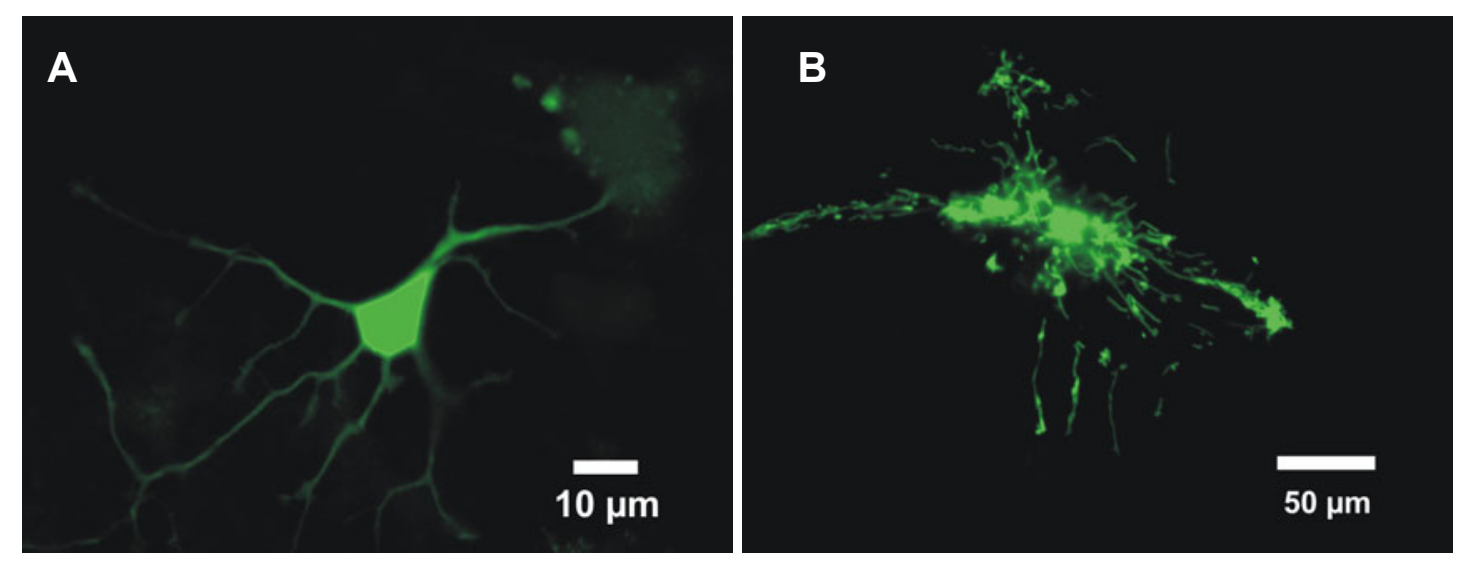

Abb. 12: Cytosolische und mitochondriale Exprimierung von roGFP

Das roGFP wurde in kultivierten hippokampalen Neuronen und Gliazellen im Cytosol (A) oder in den Mitochondrien (B) exprimiert.

Das redoxsensitive GFP wurde uns freundlicherweise von Professor S. James Remington, Institute of Molecular Biology, University of Oregon, überlassen.

\section{Durchführung der Transfektion}

Um die Plasmid-Vektoren in die Zielzellen einzubringen, wurden zwei Methoden, die Transfektion mit Lipofectamine 2000 (Invitrogen) oder durch Elektroporation, etabliert.

Bei der Transfektion mit Lipofectamine 2000 wird die Fremd-DNA in Liposomen eingeschlossen, die mit der Zellmembran verschmelzen können. Die Präparation von Zellkulturen zur Transfektion glich bis auf die letzten Schritte dem regulären Ansatz. Zur Transfektion wurden, um den cytotoxischen Nebenwirkungen des Lipofectamine 2000 entgegenzuwirken 
und um eine akzeptable Ausbeute trotz der geringen Transfektionseffizienz zu erhalten, 80.000-150.000 Zellen pro Deckgläschen aufgetragen. Die Kammern der Kulturschalen wurden an Tag 0 mit $500 \mu l$ Kulturmedium I aufgefüllt. Die Transfektionen wurden jeweils an Tag 1 (DIV1) durchgeführt. Pro Kammer wurden $2 \mu \mathrm{l}$ Lipofectamine 2000 in $48 \mu$ Optimem und 1-2 $\mu \mathrm{g}$ DNA in 48-49 $\mu$ l Optimem verdünnt. Nach $5 \mathrm{~min}$ Inkubation bei Raumtemperatur wurden die beiden Ansätze vermischt und weitere $20 \mathrm{~min}$ (RT) inkubiert, um die Bildung von Lipofectamine 2000-DNA Komplexen zu gewährleisten. In jede Kammer wurden $100 \mu$ l der Komplex-Lösung gegeben und bei $37^{\circ} \mathrm{C}$ für 1-3 Stunden inkubiert. Dann wurde das Medium komplett gegen Kulturmedium II ausgetauscht. Alle 2 Tage wurde das Medium zur Hälfte gewechselt. In späteren Versuchen hat sich gezeigt, dass es ausreicht, pro Kammer 0,5 $\mu$ l Lipofectamine $2000 \mathrm{zu}$ verwenden. So ergab sich eine geringere toxische Wirkung bei ausreichender Transfektionseffizienz.

Als alternative Methode wurden die Zellen mittels Elektroporation mit dem Rat Neuron Nucleofector ${ }^{\circledR}$ Kit (Amaxa, Köln, Deutschland) transfiziert. Dabei wird die Zellmembran durch einen kurzen elektrischen Impuls kurzfristig für die einzubringende DNA permeabel gemacht. Die benötigte Spannung, um eine zufrieden stellende Transfektionseffizienz zu erreichen, ist so hoch, dass ein großer Teil der Zellen dabei zerstört wird. Daher muss bei dieser Variante die Zelldichte viel höher sein als bei der Transfektion durch Lipofectamine.

Nach der Dissoziation der Gewebeschnitte wurden die Zellen gezählt und mindestens 1.000.000 Zellen zentrifugiert (1000 U/min, $5 \mathrm{~min}$ ), in $100 \mu \mathrm{l}$ Nucleofector-Lösung resuspendiert und in einer speziellen Transfektionsküvette mit 1-2 $\mu \mathrm{g}$ DNA vermischt. Die Küvette wurde im Nucleofector (Amaxa, Köln, Deutschland) einem elektrischen Feld ausgesetzt, um die Zellmembranen kurzzeitig durch Porenbildung für die zugegebene DNA permeabel zu machen. Dafür gibt es zwei mögliche Einstellungen, die entweder auf Transfektionseffizienz (G-13) oder schonende Behandlung der Zellen (O-03) ausgelegt sind (für Details siehe Nucleofector Anleitung).

Die transfizierten Zellen wurden auf die mit Matrigel beschichteten Deckgläschen zu je ca. 100.000 Zellen pro Glas ausplatiert. Dazu wurden die Zellen in jede Kammer der Kulturschalen zu je $300 \mu \mathrm{l}$ vorgewärmtem 
Kulturmedium I pipettiert und 4 Stunden bei $37^{\circ} \mathrm{C}$ inkubiert. In dieser Zeit sanken die Zellen ab und konnten sich am Deckglas festheften. Danach wurde das Medium komplett gegen frisches vorgewärmtes Kulturmedium I ausgetauscht. Nach 24 Stunden wurde das Medium komplett gegen Kulturmedium II ausgetauscht und alle 2 Tage zur Hälfte gewechselt.

In der Regel weist die Elektroporation eine höhere Transfektionseffizienz bei den überlebenden Zellen auf. Beide Methoden erlangten jedoch im Zusammenhang mit den hier verwendeten DNA-Konstrukten nur eine geringe Effizienz von bis zu $10 \%$.

\section{Bestimmung des ATP-Gehaltes hippokampaler Hirnschnitte}

Der ATP-Gehalt in hippokampalen Hirnschnitten, die mit den verschiedenen Atmungskettenblockern behandelt wurden, wurde photometrisch nach der Methode von Lamprecht und Trautschold (1985) bestimmt.

Die gekoppelten Reaktionen laufen nach folgendem Prinzip ab:

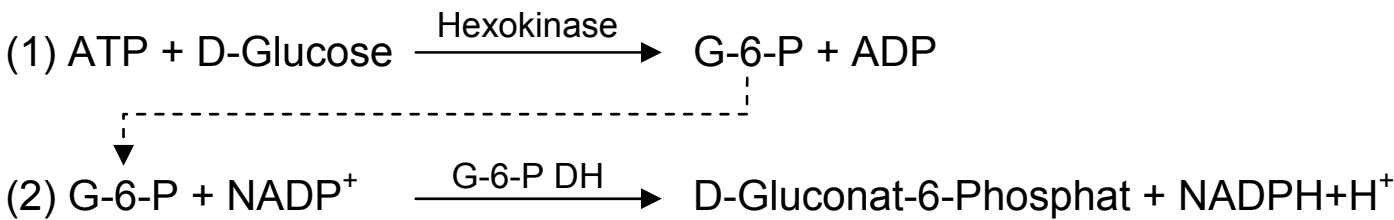

In Anwesenheit von $\mathrm{Mg}^{2+}$ entsteht pro Mol ATP ein Mol NADPH wodurch es zu einer Extinktionszunahme bei 366 nm kommt (Lamprecht und Trautschold, 1985). Da Glucose und $\mathrm{NADP}^{+}$in der Testlösung praktisch unbegrenzt vorhanden sind, wird die Reaktion durch den ATP-Gehalt der Probe begrenzt.

Hippokampale Hirnschnitte wurden wie oben beschrieben angefertigt. Die hippokampale Formation wurde isoliert und in einer Interfacekammer für 90 min bei $35,5-36^{\circ} \mathrm{C}$ gelagert. Je 2 isolierte Hippokampus Schnitte wurden dann über die Perfusion für 25 min mit den verschiedenen Blockern oder $\mathrm{H}_{2} \mathrm{O}_{2}$ behandelt. An jedem Versuchstag wurden als Kontrolle auch 2-4 Hirnschnitte für weitere $25 \mathrm{~min}$ in normaler ACSF belassen. Die 
Hirnschnitte wurden dann als Doppelprobe getrennt voneinander weiterbehandelt.

Die einzelnen Hirnschnitte wurden schnell in je ein Reaktionsgefäß mit $300 \mu \mathrm{l}$ eisgekühlter $8 \%$ iger Perchlorsäure überführt und sofort mit einer Ultraschallsonde (Cell Disruptor W-220F, Heat Systems - Ultrasonics [jetzt: Misonix], Farmingdale, USA) für 5-10 s homogenisiert, um alle zellulären Prozesse zu stoppen. Aufgrund der starken Hitzeentwicklung durch die Beschallung wurde die Homogenisierung auf Eis durchgeführt. Es war essentiell, dass dieser Schritt so schnell wie möglich durchgeführt wurde, da die Metabolitkonzentration bereits innerhalb von Sekundenbruchteilen absinken kann (Lamprecht und Trautschold, 1985). Das Homogenat wurde für $10 \mathrm{~min}$ bei $4^{\circ} \mathrm{C}$ mit $14.000 \mathrm{U} / \mathrm{min}$ zentrifugiert (Zentrifuge 5804R, Eppendorf, Hamburg, Deutschland) und das Pellet für eine spätere Proteinbestimmung (Bradford, 1976) eingefroren. Der Überstand wurde mit $\mathrm{KHCO}_{3}$ neutralisiert (pH 7-8), zentrifugiert und über Nacht eingefroren. Die aufgetauten Proben wurden dann erneut zentrifugiert, da weiteres unlösliches $\mathrm{KClO}_{4}$ über Nacht ausgefallen war. Jeweils $200 \mu \mathrm{l}$ einer Probe wurde mit $200 \mu \mathrm{l}$ Testlösung in einer 0,5 ml Quarzküvette vermischt. Die Messungen wurden mit einem Spektrometer (1101M, Eppendorf Gerätebau, Hamburg, Deutschland) bei $366 \mathrm{~nm}$ durchgeführt. In einem ersten Schritt wurde $1 \mu \mathrm{l}$ der verdünnten G-6-P-Dehydrogenase hinzugegeben, um in der Probe vorhandene Spuren von G-6-P zu metabolisieren. Sobald sich eine stabile Baseline eingestellt hatte, wurde die eigentliche Messung durch Zugabe von $1 \mu$ l Hexokinase gestartet.

Die Konzentration von NADPH wurde mit Hilfe des Lambert-Beer'schen Gesetzes bestimmt:

$$
\mathrm{E}=\varepsilon^{*} \mathrm{C}^{*} \mathrm{~d} \Rightarrow c=\frac{E}{\varepsilon^{*} d} \Rightarrow c=\frac{E}{3.4}
$$

$\mathrm{E}=$ Extinktionsänderung

$\varepsilon=$ Extinktionskoeffizient von $\mathrm{NADPH}+\mathrm{H}^{+}\left(\varepsilon_{366}=3,4 \mathrm{~cm}^{2} / \mu \mathrm{Mol}\right)$

$\mathrm{c}=$ Konzentration der Lösung in $\mathrm{mol} / \mathrm{L}$

$\mathrm{d}=$ Schichtdicke der Küvette in $\mathrm{cm}(=1 \mathrm{~cm})$ 
Die ATP Konzentration der Proben wurde dann auf ihren jeweiligen Proteingehalt ( $\mathrm{nmol}$ ATP/ug Protein), der durch eine Proteinbestimmung nach Bradford (1976) bestimmt wurde, normalisiert.

Dieses Analyseverfahren basiert auf der Farbänderung und damit einhergehenden Absorbtionsänderung von Coomassie-Blau durch die Reaktion mit bestimmten Aminosäureresten von Proteinen.

Dazu wurde das Pellet zur Proteinbestimmung in $100 \mu \mathrm{l} 1 \mathrm{~N} \mathrm{NaOH}$ aufgelöst. Um im linearen Bereich der Coomassie-Reaktion zu bleiben, wurden Verdünnungen im Faktor 1:10 angesetzt. In Reaktionsgefäßen wurden $10 \mu \mathrm{l}$ der Probe mit $190 \mu \mathrm{l}$ Wasser und $200 \mu \mathrm{l}$ Coomassie-Lösung vermischt und nach $10 \mathrm{~min}$ Reaktionszeit in eine $1 \mathrm{~cm}$ Plastikküvette überführt. Die Extinktion der Lösung wurde bei $578 \mathrm{~nm}$ abgelesen und der Proteingehalt der Probe mittels einer zuvor erstellten Eichgeraden bestimmt. Zur Erhöhung der Messgenauigkeit wurden Doppelproben gemessen und der Mittelwert bestimmt. Um Messfehler durch unterschiedliche Küvetten auszuschließen, wurden alle Proben sowie die Proteinstandard-Lösungen zur Bestimmung der Eichgerade in einer Küvette gemessen.

\section{Verwendete Pharmaka und Chemikalien}

Die einzelnen verwendeten Substanzen sind der Übersichtlichkeit halber nachfolgend tabellarisch aufgeführt. 


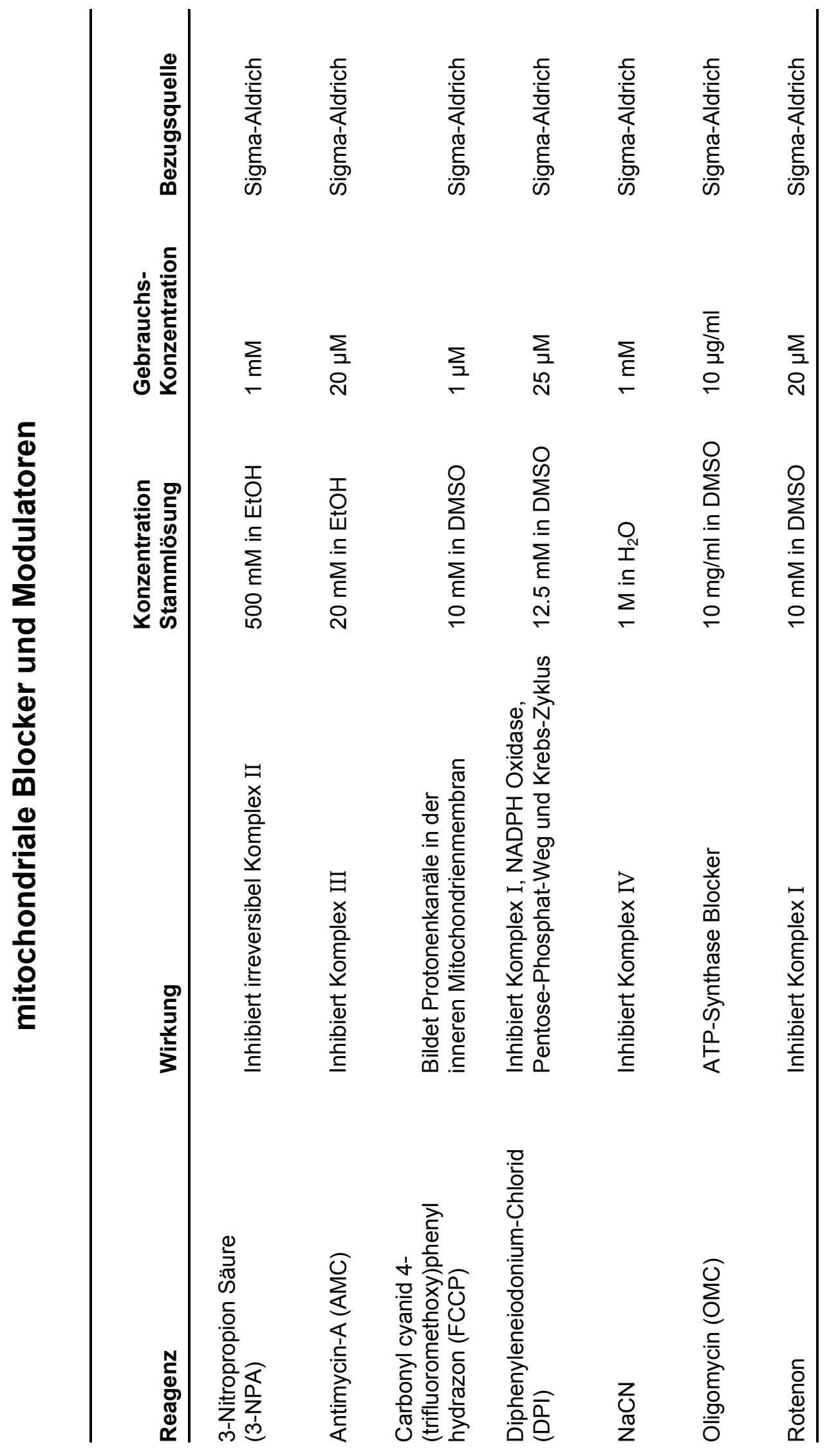




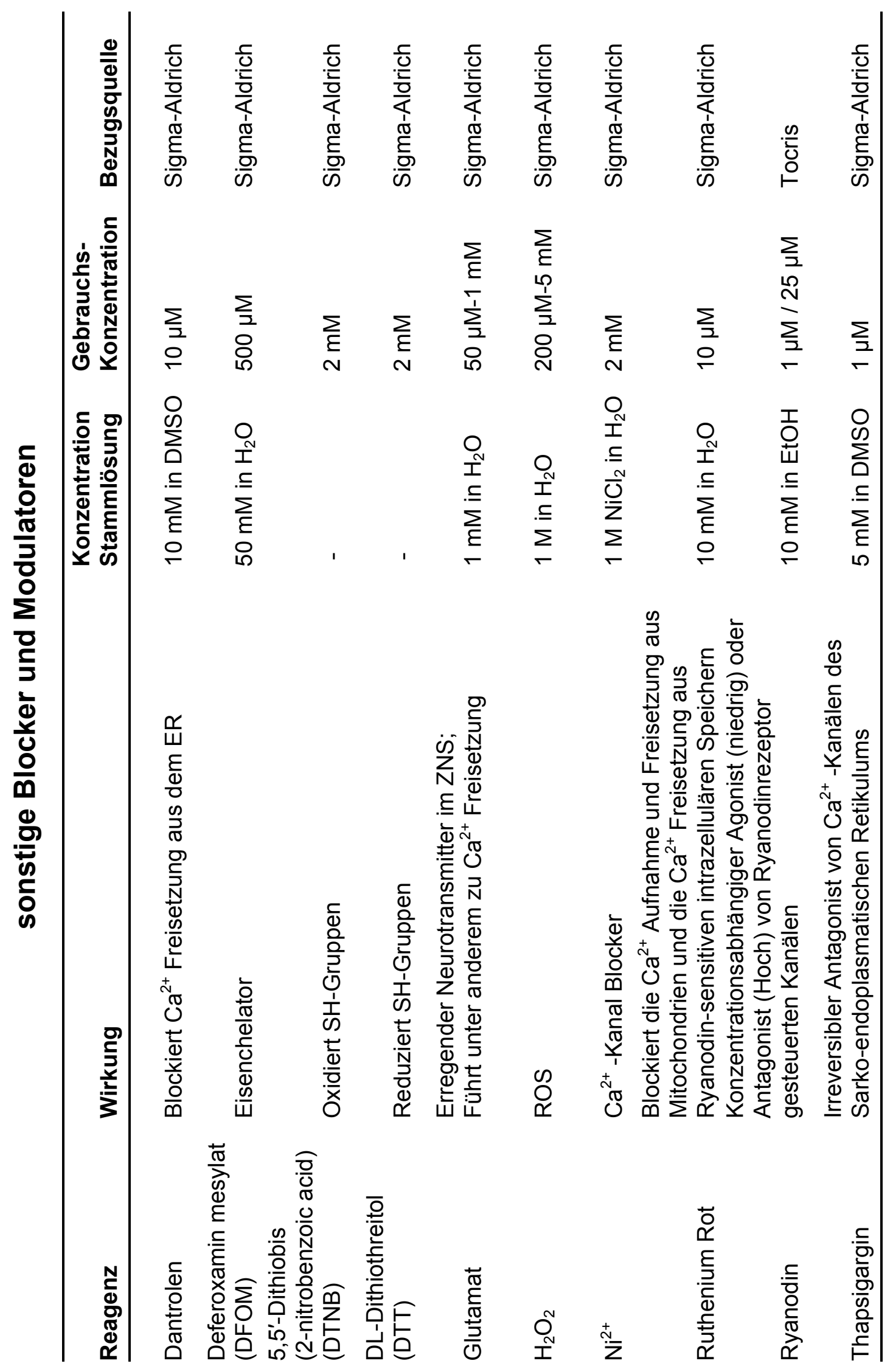


Tabelle 5: Reagenzien der Zellkultur Medien und ATP Messungen

\begin{tabular}{|l|l|}
\hline Substanz & Lieferant \\
\hline Ascorbinsäure & Sigma-Aldrich \\
\hline Azid & Sigma-Aldrich \\
\hline B-27 Supplement & Invitrogen \\
\hline Cytosine Arabinoide & Sigma-Aldrich \\
\hline Di-Ethyldithiocarbamat (DEDTC) & Sigma-Aldrich \\
\hline DMEM & Invitrogen \\
\hline DNase & Sigma-Aldrich \\
\hline Fötales bovines Serum (FBS) & Biochrom \\
\hline Glucose & Sigma-Aldrich \\
\hline G-6-P-Dehydrogenase & Roche \\
\hline Hanks & Sigma-Aldrich \\
\hline HEPES & Sigma-Aldrich \\
\hline Hexokinase (1000 U/1,4 ml) & Sigma-Aldrich \\
\hline Insulin & Sigma-Aldrich \\
\hline L-glutamine & Invitrogen \\
\hline Lipofectamine 2000 & Invitrogen \\
\hline Matrigel & BD Biosciences \\
\hline MEM & Invitrogen \\
\hline Mercaptobernsteinsäure (MCS) & Sigma-Aldrich \\
\hline NADP & Boehringer-Mannheim \\
\hline Optimem & Invitrogen \\
\hline Penicillin/Streptomycin & Biochrom \\
\hline Pluronic F-127 & Sigma-Aldrich \\
\hline Succhrose & Roth \\
\hline Transferrin & Calbiochem und Invitrogen \\
\hline Triethanolamin-hydrochlorid & Applichem \\
\hline Trolox & Sigma-Aldrich \\
\hline Trypsin & Sigma-Aldrich \\
\hline
\end{tabular}




\section{ACSF:}

Die, in der chemischen Beschaffenheit der Hirnflüssigkeit nachempfundene, artifizielle cerebrospinale Flüssigkeit (ACSF) hatte folgende Zusammensetzung:

$\mathrm{NaCl} 130$ mM; KCl 3,5 mM; NaH $\mathrm{PO}_{4}$ 1,25 mM; NaHCO 324 mM; $\mathrm{CaCl}_{2}$ 1,2 mM; $\mathrm{MgSO}_{4}$ 1,2 mM; Dextrose 10 mM Zur Einstellung des pH-Wertes auf 7,4 und zur Versorgung der Hirnschnitte und Zellen mit Sauerstoff wurde die ACSF kontinuierlich mit Carbogen $\left(95 \% \mathrm{O}_{2}-5 \% \mathrm{CO}_{2}\right)$ begast. Bei Versuchen mit Zellkultur wurde vor Versuchsbeginn die Osmolarität des Kulturmediums bestimmt, welche je nach Alter der Kultur zwischen 340-360 mosmol/l betrug, und die Osmolarität der ACSF mit Succhrose angeglichen.

\section{Kulturmedien:}

Hanks balanced salts solution (HBSS):

Hanks (ohne $\mathrm{Ca}^{2+}$ oder $\mathrm{Mg}^{2+}$ ) $9.5 \mathrm{~g}$ in $1 \mathrm{I} \mathrm{H}_{2} \mathrm{O}$ dest.

$\mathrm{NaHCO}_{3} 4 \mathrm{mM}$; HEPES $1 \mathrm{mM}$

$\mathrm{pH} 7.3-7.4$ mit $\mathrm{NaOH}$ einstellen

HBSS (+20\% FBS):

HBSS; FBS 20\%

\section{DNase Lösung:}

$\mathrm{H}_{2} \mathrm{O}$; DNase (150 kU) $25 \mathrm{mg} / \mathrm{ml}$

\section{Digestions-Lösung (Trypsinierung):}

$\mathrm{NaCl} 137$ mM; KCl 5 mM; Na $\mathrm{HPO}_{4} 7$ mM; HEPES 25 mM pH 7.2 mit $\mathrm{NaOH}$ einstellen

Direkt vor Trypsinierung Zugabe von: Trypsin 5 mg/ml; DNase Lsg. 2\%

\section{Dissoziations-Lösung:}

HBSS; $\mathrm{MgSO}_{4} \times 7 \mathrm{H}_{2} \mathrm{O} 12 \mathrm{mM}$ 
Direkt vor Benutzung Zugabe von: DNase Lsg. 2\%

Medium:

Minimum essential medium (MEM); Glucose $5 \mathrm{mg} / \mathrm{ml}$; $\mathrm{NaHCO}_{3} 0,2$ $\mathrm{mg} / \mathrm{ml}$; Transferrin $0,1 \mathrm{mg} / \mathrm{ml}$

\section{Platierungs-Medium:}

Medium; FBS $10 \%$; L-Glutamin 2 mM; Insulin 25 mg/ml

\section{Wachstums-Medium:}

Medium; FBS 5 \%; L-glutamine 0,5 mM; B-27 supp. (50X, w/o AO)

$20 \mu \mathrm{l} / \mathrm{ml}$; Ara-C $2 \mu \mathrm{M}$; Penicillin/Streptomycin (10 kU/20 kU) $100 \mu \mathrm{g} / \mathrm{ml}$

Insulin Lösung:

$\mathrm{HCl}(10 \mathrm{mM}) ;$ Insulin $12,5 \mathrm{mg} / \mathrm{ml}$

\section{Cytosine Arabinoide Lösung:}

$\mathrm{H}_{2} \mathrm{O}$; Ara-C $4 \mathrm{mM}$

\section{Kulturmedium I (EPI I):}

DMEM; FBS 5\%

\section{Kulturmedium II (EPI II):}

DMEM; FBS 10\%; B-27 supp. (50X, w/o AO) $20 \mu \mathrm{l} / \mathrm{ml}$;

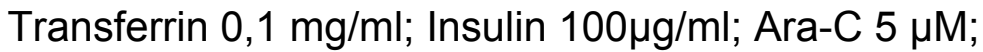

Penicillin/Streptomycin (10 kU/20 kU) 100 mg/ml

\section{ATP-Messung}

\section{Testlösung}

NADP 1 mM; Glucose 100 mM; $M$ Cl$_{2} 20$ mM; TEA 91,5 mM

\section{G-6-P-Dehydrogenase}

Stammlösung 1:20 verdünnen 


\section{Statistik}

Die hier vorgestellten Ergebnisse sind jeweils als Mittelwerte \pm Standardabweichung angegeben. Die Signifikanz der durch Pharmaka induzierten Veränderungen gegenüber unbehandelten Kontrollen wurde je nach Versuchsanordnung mit dem gepaarten oder ungepaarten, 2-seitigen t-Test nach Student bestimmt. Signifikante Änderungen sind in den Diagrammen mit * $(P<0.05)$ und ** $(P<0.01)$ angegeben. 


\section{Ergebnisse}

\section{Redoxmodulation der Hypoxie-Antwort}

\section{Modulation der Hypoxie-Antwort durch $\mathrm{H}_{2} \mathrm{O}_{2}$}

Bei vorhergehenden Versuchen (Hepp et al., 2005) wurde gezeigt, dass die Hypoxie-Antwort, d.h. eine HSD, in akuten hippokampalen Schnitten durch eine Oxidation der Sulfhydrylgruppen durch z.B. DTNB verzögert auftritt, während eine Reduktion durch z.B. DTT das Auftreten der HSD beschleunigte und bei längerer Applikation auch teilweise zu spontan auftretenden SD Episoden führte. Der den DTNB Effekten zugrunde liegende Mechanismus wurde als eine Aktivierung von $\mathrm{Ca}^{2+}$-abhängigen BK-Kanälen identifiziert (Hepp et al., 2005).

Um diese neuroprotektive Wirkung genauer zu untersuchen, wurde die Wirkung von $\mathrm{H}_{2} \mathrm{O}_{2}$ in verschiedenen Konzentrationen auf die Hypoxie induzierte SD untersucht.

In akuten hippokampalen Hirnschnitten wurden in einer Interfacekammer HSD durch den Wechsel der Begasung von Carbogen auf $\mathrm{N}_{2}\left(95 \% \mathrm{~N}_{2}-5 \% \mathrm{CO}_{2}\right)$ ausgelöst. Die Veränderungen in den Parametern der Messungen an Schnitten unter dem Einfluss von $\mathrm{H}_{2} \mathrm{O}_{2}$ wurden jeweils auf die zuvor am selben Schnitt gemachten Kontrollmessungen bezogen. Es wurden die Dauer bis zum Auftreten der HSD $(\Delta t)$, die Amplitude der Veränderung des extrazellulären DC-Potentials $(\Delta \mathrm{V})$ und die Dauer der HSD $\left(\mathrm{t} \frac{1}{2}\right)$, gemessen auf der Höhe der halbmaximalen Amplitude (siehe Abb. 13, A). Unter den Kontrollbedingungen traten die HSD 137,5 \pm 55,5 s nach dem Wechsel auf $\mathrm{N}_{2}$-Begasung auf. Die Amplitude betrug -17,9 \pm 3,7 $\mathrm{mV}$ und sie hatten eine mittlere Dauer von 49,7 $\pm 10,5 \mathrm{~s}(\mathrm{n}=120)$.

Es hat sich gezeigt, dass zur Verzögerung der $\mathrm{HSD}$ eine $\mathrm{H}_{2} \mathrm{O}_{2}$ Konzentration von mindestens $1 \mathrm{mM}$ nötig war (Abb. 13). Dabei trat die HSD nach $143,1 \pm 24,1$ s auf. Amplitude und die Dauer der HSD blieben mit $-17,1 \pm 4,3 \mathrm{mV}$ bzw. 47,6 $\pm 13,0$ s unverändert $(n=9)$.

Eine Erhöhung der $\mathrm{H}_{2} \mathrm{O}_{2}$ Konzentration auf $5 \mathrm{mM}(\mathrm{n}=7)$ erhöhte die Latenz weiter auf 154,1 \pm 43,8 $\mathrm{s}$, ohne einen Einfluss auf Amplitude $(-15,1 \pm 3,6 \mathrm{mV})$ und Dauer $(46,7 \pm 24,5 \mathrm{~s})$ zu haben. Ein kombinierter Einsatz 
von $5 \mathrm{mM} \mathrm{H}_{2} \mathrm{O}_{2}$ mit dem Eisenchelator Deferoxamin $(500 \mu \mathrm{M})$ hatte keinen weiteren Effekt auf die Latenz (175,4 $\pm 17,9$ s), verkürzte jedoch die Dauer der HSD geringfügig auf $43,0 \pm 6,6 \mathrm{~s}$. Die Amplitude blieb unter diesen Bedingungen bei -14,1 $\pm 4,1 \mathrm{mV}(\mathrm{n}=6)$. Der kombinierte Einsatz der Radikalfänger Ascorbinsäure $(1 \mathrm{mM})$ und Trolox $(750 \mu \mathrm{M})(\mathrm{n}=9)$ sowie die Inhibition der Superoxid Dismutase (SOD) durch $1 \mathrm{mM}$ Di-Ethyldithiocarbamat $($ DEDTC $)(n=9)$ hatten keinen Einfluss auf Amplitude $(-16,1 \pm 4,6 \mathrm{mV}$ bzw. $-16,0 \pm 3,7 \mathrm{mV})$, Latenz $(148,0 \pm 27,7 \mathrm{~s}$ bzw. 137,1 $\pm 27,2 \mathrm{~s})$ oder die Dauer der HSD (50,9 $\pm 12,7 \mathrm{~s}$ und 53,2 \pm 18,7 s)(Abb. 13, C). Im Gegensatz $\mathrm{zu}$ der externen $\mathrm{H}_{2} \mathrm{O}_{2}$ Anwendung beschleunigte eine Anregung der intrinsischen Superoxid Produktion durch $50 \mu \mathrm{M}$ Xanthin (X) mit $25 \mathrm{mU}$ Xanthinoxidase (XO) $(n=8)$ das Auftreten einer HSD auf 89,5 $\pm 19,4 \mathrm{~s}$, ohne die Amplitude $(-15,5 \pm$ 4,3 mV) oder Dauer (56,0 \pm 4,6 s) signifikant zu verändern (Abb. 13, $B$ und $C$ ). Wurde der Abbau von $\mathrm{H}_{2} \mathrm{O}_{2}$ durch eine Inhibition der Glutathion Peroxidase mit $2 \mathrm{mM}$ Mercaptobernsteinsäure verhindert, führte das zu einem beschleunigten Auftreten der HSD (188,3 $\pm 61,0 \mathrm{~s})$, einer Amplitude von 15,6 $\pm 3,1 \mathrm{mV}$ und einer auf $56,2 \pm 19,3$ s verlängerten Dauer der HSD Episoden $(n=7)$.

Während eine Zugabe von $\mathrm{H}_{2} \mathrm{O}_{2}$ eine gewisse neuroprotektive Wirkung aufwies und das Auftreten einer HSD verzögerte, war die intrinsische ROSProduktion offenbar nicht ausreichend, um einen signifikanten Einfluss auf die Hypoxie-Antworten zu haben. 
A

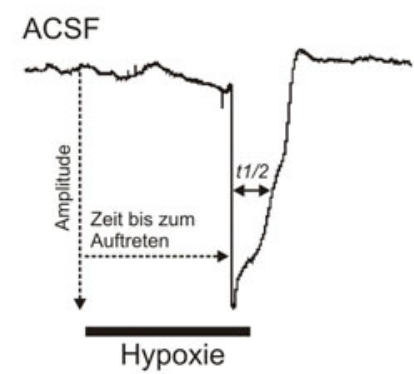

B
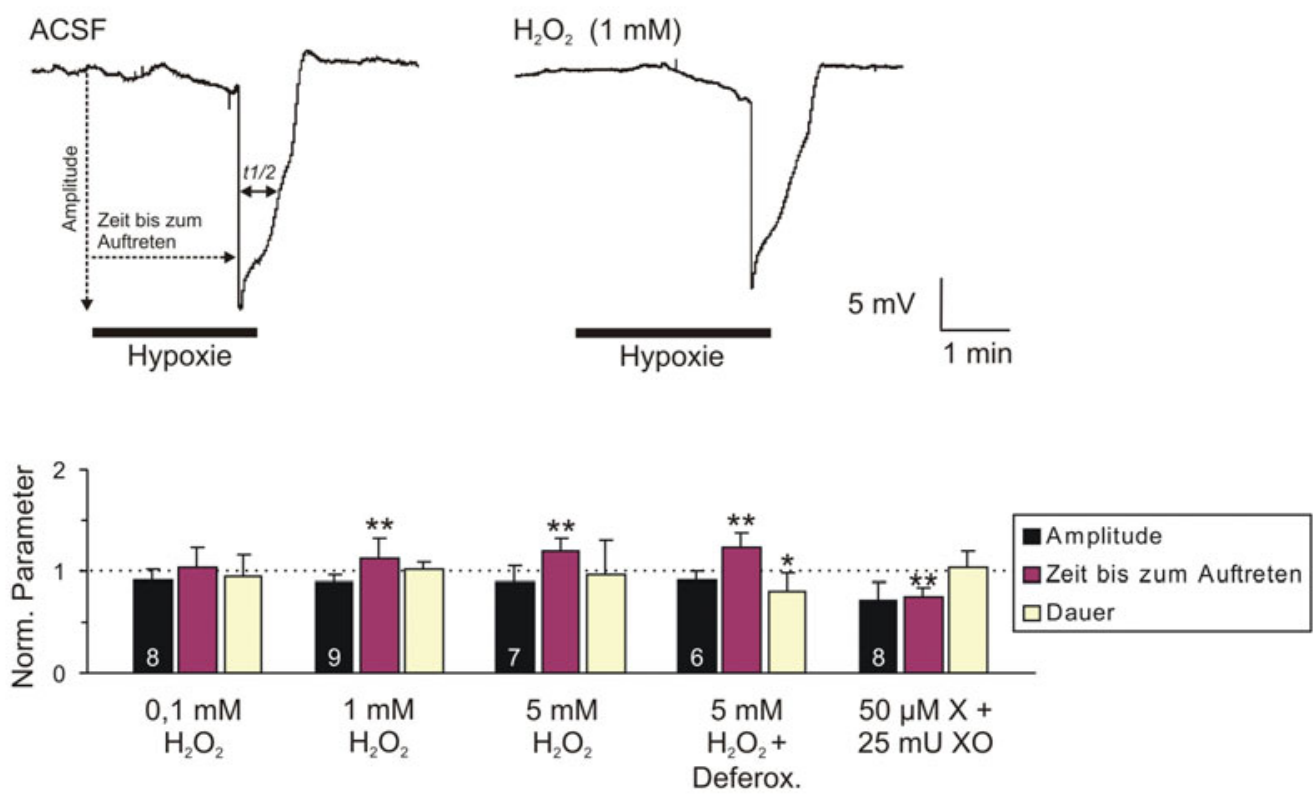

C

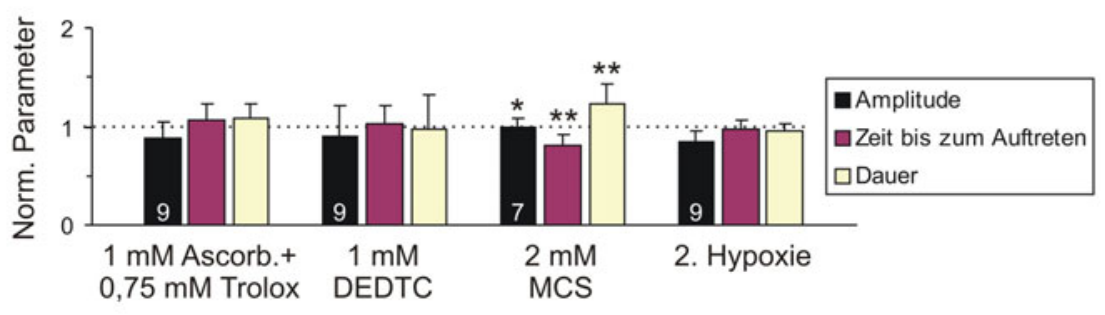

\section{Abb. 13: Redoxmodulation der Hypoxie-Antworten}

Bei mit $1 \mathrm{mM} \mathrm{H}_{2} \mathrm{O}_{2}$ vorbehandelten akuten hippokampalen Schnitten trat eine HSD verzögert auf, was auf eine verringerte Anfälligkeit der Hirnschnitte gegenüber Hypoxie vermuten lässt. Dauer und Amplitude der HSD blieben unverändert (A). Die Wirkung von $\mathrm{H}_{2} \mathrm{O}_{2}$ auf die Latenz der HSD war dosisabhängig (B). Eine Erhöhung der endogenen ROSProduktion beschleunigte das Auftreten der HSD. Der Einsatz von Radikalfängern sowie eine Inhibition der SOD hatte keinen Effekt auf die gemessenen HSD Parameter. Eine Inhibition der Glutathionperoxidase hingegen beschleunigte das Auftreten einer HSD und hatte einen positiven Effekt auf die Dauer und Amplitude (C).

\section{Einfluss der mitochondrialen Funktion auf die Hypoxie-Antwort}

Um die Rolle der Mitochondrien als mögliche Hypoxiesensoren sowie ihren Beitrag zu einer Hypoxie-Antwort genauer zu untersuchen, wurden die Mitochondrienfunktion und die Atmungskette durch den gezielten Einsatz der verschiedenen Blocker gestört. 
In Kontrollmessungen trat eine HSD in 154,1 \pm 59,7 s nach dem Umschalten der Begasung von Carbogen auf $\mathrm{N}_{2}$ auf. Die Amplitude des DC-Shifts betrug $-16,4 \pm 5,4 \mathrm{mV}$ und sie hatte eine mittlere Dauer von 47,2 $\pm 11,3 \mathrm{~s}(\mathrm{n}=158)$. Die Veränderungen in den HSD Parametern der Messungen an Hirnschnitten unter dem Einfluss von mitochondrialen Blockern wurden jeweils auf die zuvor am selben Schnitt gemachten Kontrollmessungen bezogen. Des Weiteren wurden die gemittelten Ergebnisse mit Messungen an Schnitten, die mit den Lösungsmitteln DMSO bzw. Ethanol der jeweiligen Pharmaka behandelt wurden, verglichen, um Effekte der Lösungsmittel selbst auszuschließen.

Durch eine Entkopplung durch $1 \mu \mathrm{M}$ FCCP konnte keine spontane SD ausgelöst werden. Das Auftreten einer HSD wurde durch $1 \mu \mathrm{M}$ FCCP jedoch um $31,0 \pm 11,6 \%$ beschleunigt und ihre Dauer um 28,0 $\pm 25,0 \%$ verkürzt. Unter diesen Bedingungen verringerte sich die Amplitude der HSD um $28,3 \pm 15,5 \%(n=7)$.

Eine Inhibition der $\mathrm{F}_{0} \mathrm{~F}_{1}$ ATPase mit Oligomycin (OMC; $10 \mu \mathrm{g} / \mathrm{ml}$ ) hatte keinen Effekt auf die gemessenen HSD Parameter (Abb. 14). In der Anwesenheit von mitochondrialen Entkopplern kann die ATP-Synthase ihre Funktion umkehren und unter ATP Verbrauch Protonen in die Matrix pumpen um das Membranpotential aufrechtzuhalten (Duchen, 1999; Nicholls und Budd, 2000). Um diesen Effekt zu kompensieren, wurde FCCP zusammen mit OMC gegeben. Unter diesen Umständen wurde die Auslösung einer HSD immer noch um $28,0 \pm 15,4 \%$ beschleunigt $(n=7)$. In einem weiteren Versuch wurden die Hirnschnitte erst 15 min nur mit OMC und dann 20 - 25 min gleichzeitig mit FCCP und OMC inkubiert, um die unterschiedlichen Diffusionsgeschwindigkeiten von FCCP und OMC, die sich aus den unterschiedlichen Molekulargewichten (254 bzw. $791 \mathrm{~g} / \mathrm{mol}$ ) ergaben, zu berücksichtigen. Die Reaktion auf diese Behandlung unterschied sich kaum von FCCP ohne OMC (Abb. 14). 
A

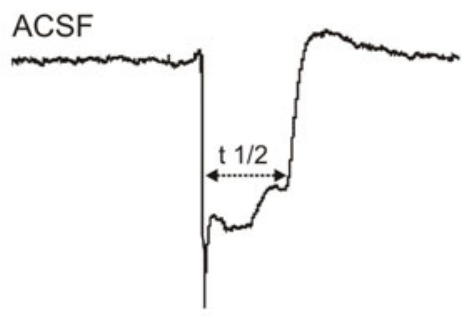

Hypoxie
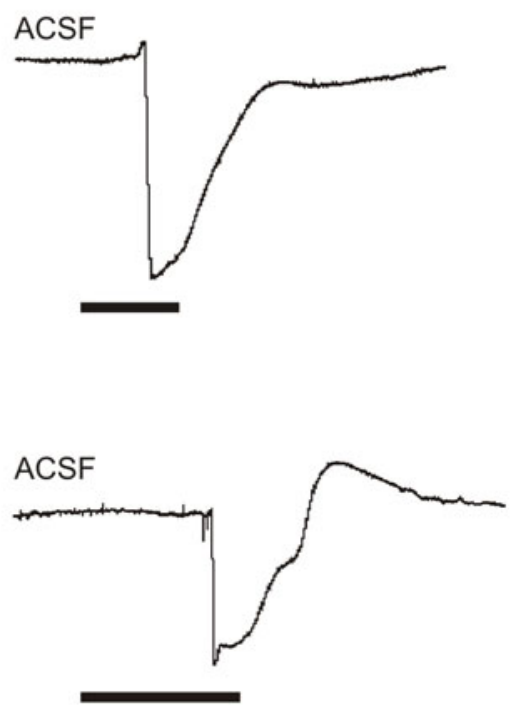

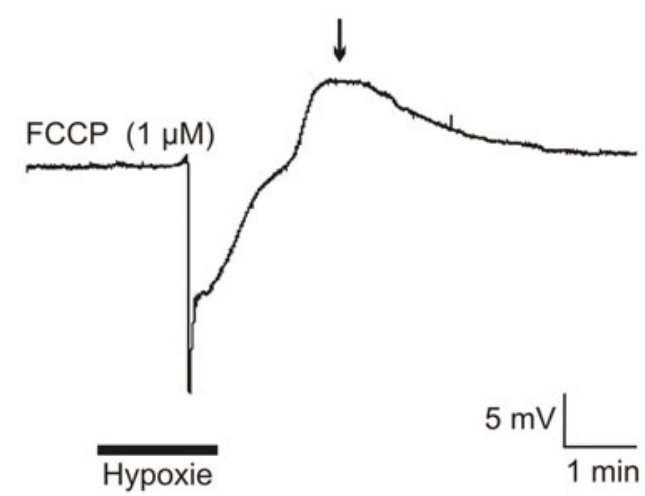

Oligomycin $(10 \mu \mathrm{g} / \mathrm{ml})$
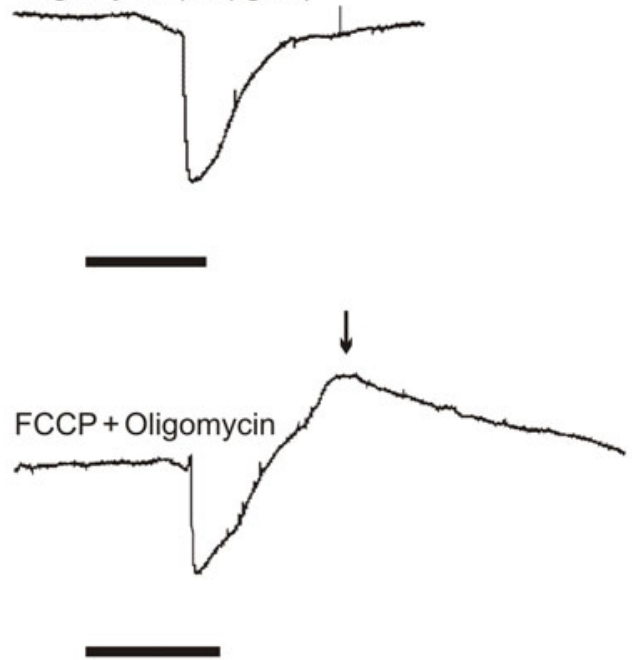

B

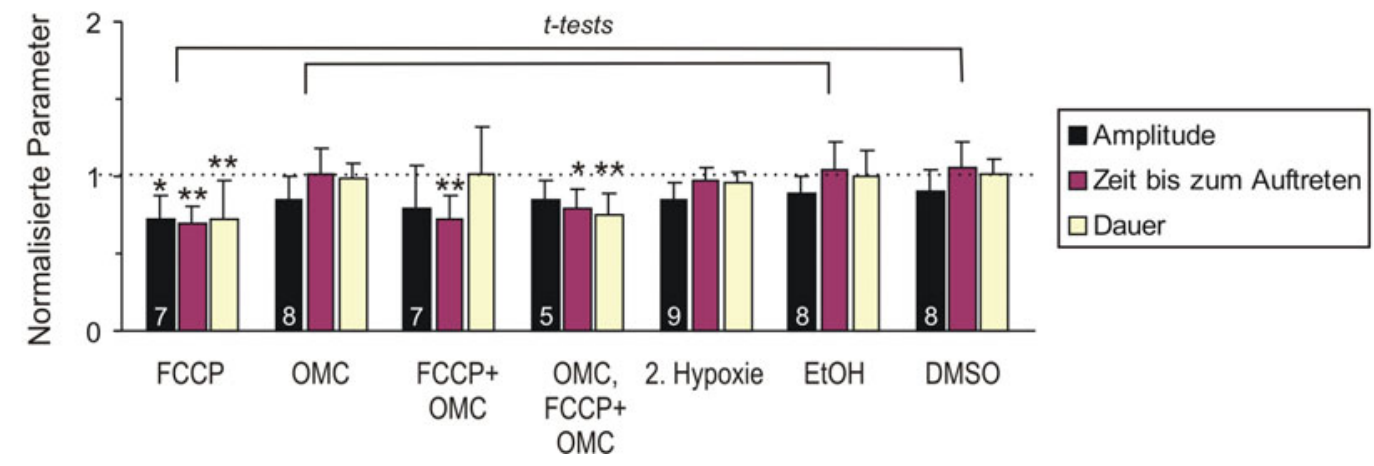

\section{Abb. 14: Modulation von HSD durch mitochondriale Entkopplung und}

\section{Blockade der ATP-Synthase}

Mitochondriale Entkopplung beschleunigt das Auftreten einer HSD, während OMC keinen Effekt hat. FCCP führt während der Reoxygenierung zu einem transienten positiven DC-Potentialanstieg (A). OMC und die Lösungsmittel DMSO und Ethanol ohne gelöste 
Wirkstoffe hatten keinen Effekt auf die gemessenen HSD Parameter (B).

Das Auftreten der HSD beschleunigte sich um 20,9 $\pm 12,8 \%$ und die Dauer wurde um 24,9 \pm 14,3\% leicht verkürzt, während die HSD Amplitude nicht verändert wurde $(n=5)$.

Ein Verbrauch von zellulärem ATP durch die Inhibition der $\mathrm{F}_{0} \mathrm{~F}_{1}$ ATPase hatte keinen Effekt auf eine Hypoxie-Antwort, ein Zusammenbruch des Protonengradienten durch FCCP und die dadurch erfolgte Störung der mitochondrialen Funktion führte zu starken Veränderungen der gemessenen Parameter. Daher wurden die Effekte einer gestörten mitochondrialen Atmung genauer untersucht.

Eine Blockade von Komplex I durch $20 \mu \mathrm{M}$ Rotenon $(n=10)$ oder $25 \mu \mathrm{M}$ DPI $(n=8)$, welches aber noch weitere Effekte, z.B. auf den Krebs-Zyklus oder die NADPH Oxidase hat, beschleunigte das Auftreten der HSD um 26,4 $\pm 19,3 \%$ bzw. 16,7 $\pm 20,0 \%$. Beide Wirkstoffe verkürzten die Dauer der HSD um $21,4 \pm 18.9 \%$ bzw. 16,5 $\pm 18,7 \%$, hatten jedoch keinen ausgeprägten Effekt auf die Amplitude der HSD (Abb. 15). Es kam bei Rotenon und DPI während der Reoxygenierung zu einem ausgeprägten transienten positiven Ausschlag des DC-Potentials (siehe Abb. 15, $\downarrow$ ). Inhibition von Komplex II durch $1 \mathrm{mM}$ 3-NPA hatte keinen Effekt auf die Amplitude oder die Latenz, verlängerte aber die Dauer der HSD um $72,1 \pm 66,4 \%(n=11)$. Durch Antimycin A (AMC; $20 \mu \mathrm{M}$ ), einem Blocker von Komplex III, beschleunigte sich das Auftreten der HSD um 17,7 $\pm 19,3 \%(n=8)$, während sich die Dauer der HSD um 24,3 $\pm 25,8 \%$ verkürzte. Wie auch Rotenon hatte Antimycin A keinen Effekt auf die Amplitude, erzeugte aber während der Reoxygenierung einen ausgeprägten transienten positiven Ausschlag des DC-Potentials (Abb. 15). 
A
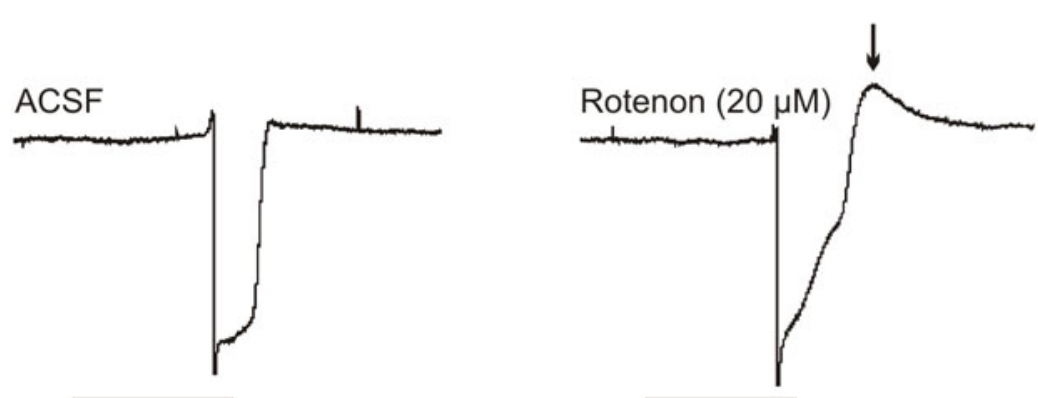

Hypoxie

Hypoxie
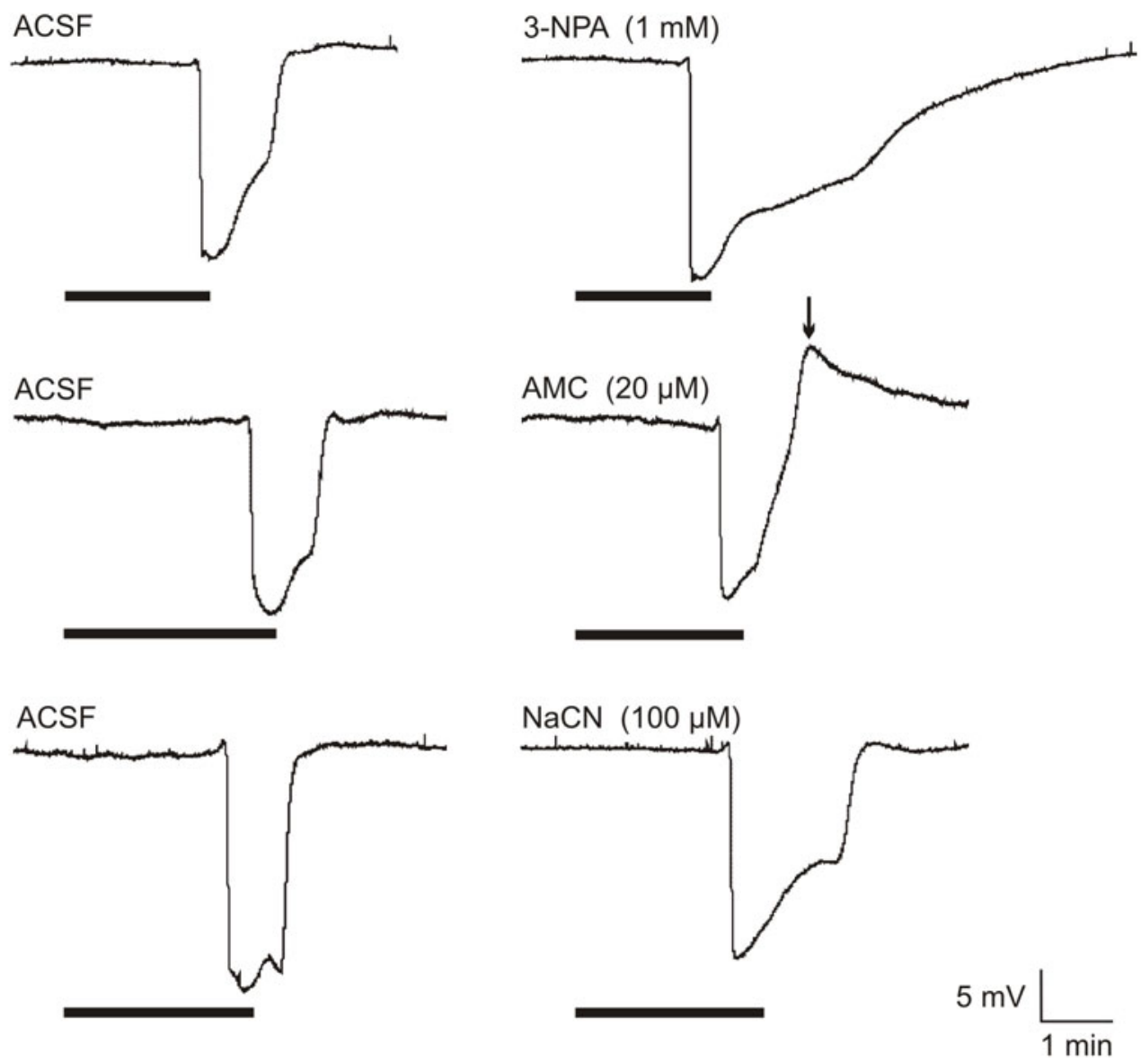

$\mathrm{B}$

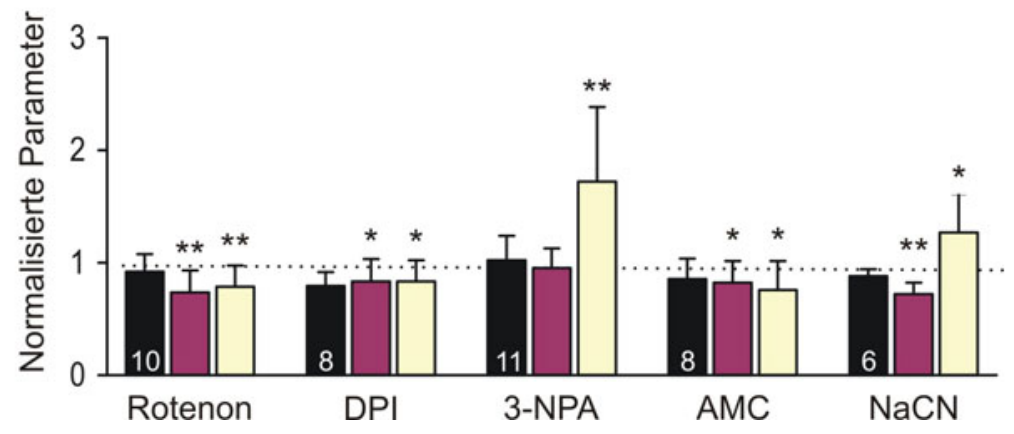

Amplitude

$\square$ Zeit bis zum Auftreten $\square$ Dauer

\section{Abb. 15: Modulation von HSD durch gezielte Atmungskettenblockade}

In akuten hippokampalen Hirnschnitten wurden HSD durch Zugabe von Rotenon, 3-NPA, Antimycin A, Cyanid und DPI moduliert. Bei Blockade der protonenpumpenden Komplexe I, III sowie, schwach ausgeprägt 
IV kam es während der Reoxygenierung zu einem transienten positiven Anstieg des DC-Potentials $(\mathbf{A}, \downarrow)$.

B: Zusammenfassung der Einflüsse der mitochondrialen Blocker auf eine HSD.

Eine Inhibition von Komplex IV durch $100 \mu$ M Cyanid $(n=6)$ beschleunigte das Auftreten der HSD um 27,8 \pm 10,0\% und verlängerte die Dauer um $26,7 \pm 33,3 \%$, ohne einen Effekt auf die Amplitude bewirken. Es kam hierbei ebenfalls zu einem transienten positiven DC-Potential Anstieg während der Reoxygenierung, dieser war aber nur schwach ausgeprägt.

Eine Kombination von Rotenon $(20 \mu \mathrm{M})$ mit AMC $(20 \mu \mathrm{M})$ konnte spontane SD Episoden auslösen ( $n=3$ von 6 ). Falls das nicht der Fall war, wurde bei einer HSD die Latenz um 23,3 \pm 9,6\% verkürzt und die Dauer um 24,8 \pm 6,8\% verkürzt. Des Weiteren wurde die Amplitude um 21,6 \pm 9,6\% verkleinert.

Um die Möglichkeit von spontanen SD Episoden durch Modulation der Mitochondrien zu überprüfen, wurden einige Wirkstoffe in höheren Konzentrationen eingesetzt. So löste $1 \mathrm{mM}$ Cyanid trotz $\mathrm{O}_{2}$ Verfügbarkeit nach 251,3 \pm 34,4 s eine SD mit einer Amplitude von -11,2 $\pm 1,1 \mathrm{mV}$ und einer Dauer von $147 \pm 57$ s aus $(n=7)$. Die Hirnschnitte zeigten in diesen Versuchen aber nur eine langsame und unvollständige Erholung.

Hochdosiertes FCCP $(10 \mu \mathrm{M})$ führte ebenfalls zu normoxischen SD Episoden ( $n=12$ von 14), die aber erst nach $1189 \pm 342 \mathrm{~s}$ auftraten und eine auffällig kurze Dauer von 20,9 \pm 9,2 s aufwiesen. Die mittlere Amplitude ähnelte mit $-16,9 \pm 4,9 \mathrm{mV}$ der einer normalen HSD.

\section{Intrinsische optische Signale}

Zur genaueren Charakterisierung und Unterscheidung der durch den Einfluss von Pharmaka ausgelösten HSD wurden die mit einer SD einhergehenden intrinsischen optischen Signale an hippokampalen Hirnschnitten aufgezeichnet. Dabei wurde die Intensivierung der Lichtreflexion quantifiziert und das betroffene hippokampale Areal gemessen (siehe Material \& Methoden, Seite 25). 
Bereits einige Minuten vor dem Auftreten der Depolarisation der Neurone und Gliazellen kommt es zu einer moderaten Abnahme der Lichtreflexion. Zeitgleich mit der negativen extrazellulären DC-Potentialverschiebung steigt die Lichtreflexion des Gewebes sprunghaft an (Aitken et al., 1999; Müller und Somjen, 1999). Es hat sich gezeigt, dass sich die IOS von kaliuminduzierten normoxischen SD und HSD gleichen (Aitken et al., 1999). Durch Cyanid, Azid oder FCCP ausgelöste SD wiesen in ihren IOS und elektrischen Signalen aber deutliche Unterschiede zu Hypoxie-induzierten SD auf (Abb. 16).

Unter Kontrollbedingungen erhöhte sich die Lichtreflexion während einer HSD um 11,6 $\pm 3,3 \%$. Ihr Maximum erreichte sie $44 \mathrm{~s}$ nach dem Beginn der HSD und sie breitete sich mit einer Geschwindigkeit von 6,5 $\pm 3,2 \mathrm{~mm} / \mathrm{min}$ aus $(n=14)$. Bei den Cyanid-, Azid- und FCCP-induzierten SD trat die Intensivierung der Reflexion ebenfalls gleichzeitig mit der Verschiebung des DC-Potentials auf, sie erreichten ihr Maximum von 14,5 $\pm 4,9 \%, 12,9 \pm 3,0 \%$ bzw. $21,8 \pm 7,4 \%$ aber erst nach 122, 70 und $70 \mathrm{~s}(\mathrm{n}=7,8$ und 9). Die mit Pharmaka behandelten Hirnschnitte erholten sich von der SD nicht vollständig und langsamer als von der Kontroll-HSD, offenbar weil die Hirnschnitte noch einen Teil der Pharmaka enthielten, die falls überhaupt reversibel, nur langsam auswaschbar waren. Wenn die Hirnschnitte nach dem Einsetzen der HSD noch für weitere 5 Minuten unter anoxischen Bedingungen gehalten wurden, kam es auch zu einer langsamen und unvollständigen Erholung nach der Wiederherstellung der Sauerstoffversorgung. Unter Cyanid und Azid Einfluss wurde ein größeres Gewebeareal betroffen als es bei einer $\mathrm{N}_{2}$ induzierten HSD der Fall war. Eine FCCP induzierte SD breitete sich nicht weiter als die dazugehörigen Kontrollen aus, zeigte jedoch die größte Intensität der IOS. Die Ausbreitungsgeschwindigkeiten aller hier gezeigten SD bzw. HSD unterschieden sich nicht voneinander. 
A
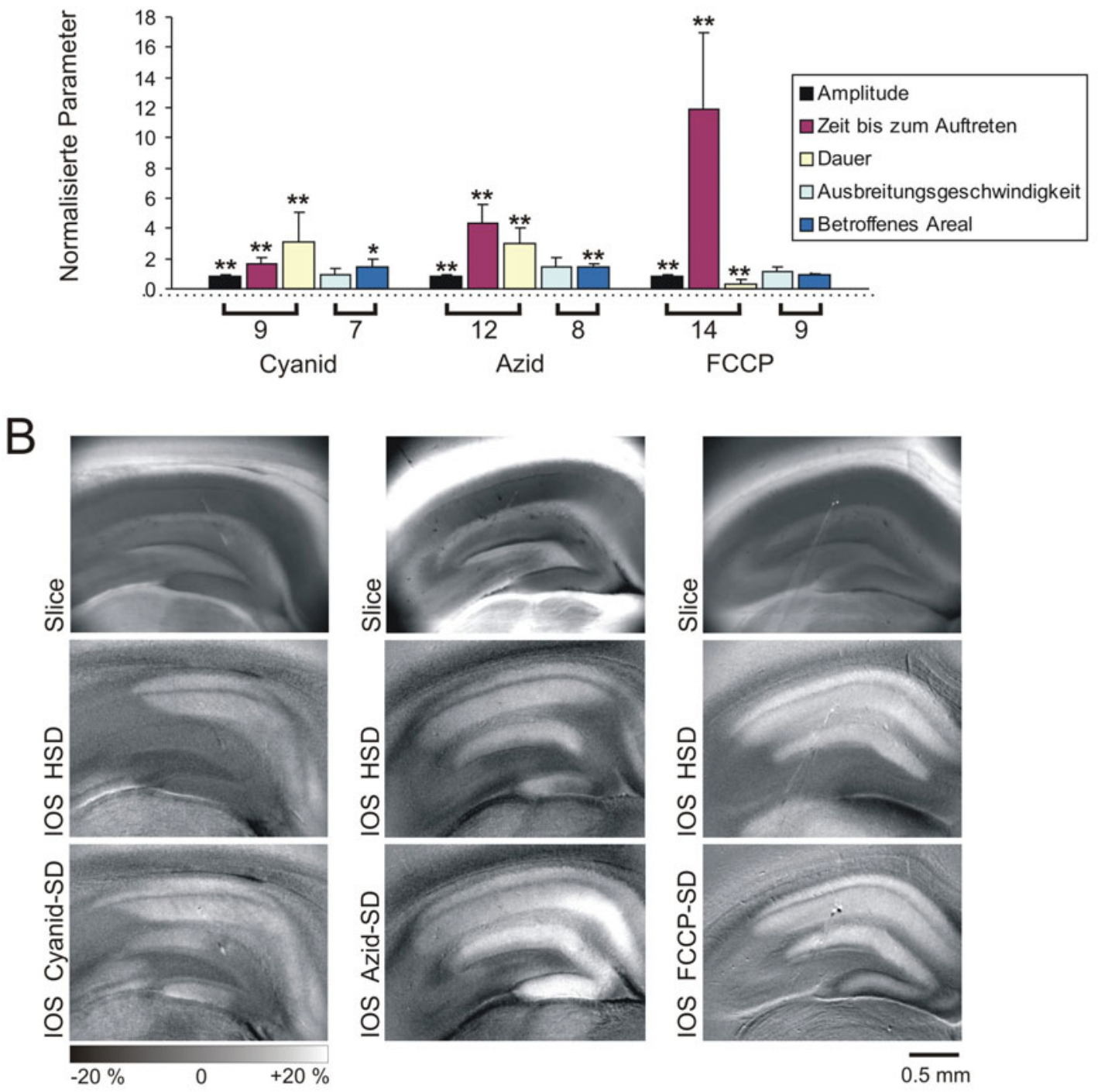

C

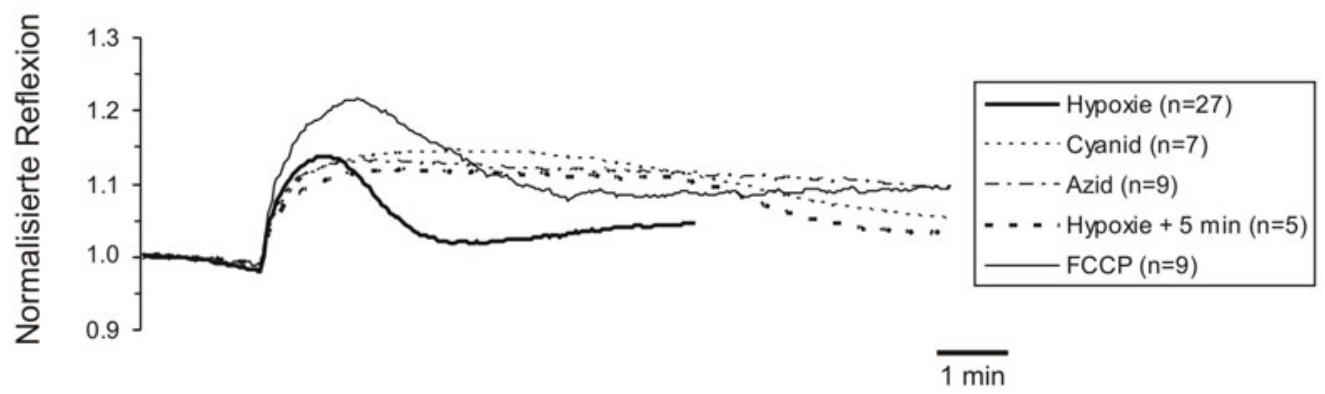

Abb. 16: Vergleich der elektrophysiologischen und optischen Charakteristika von Hypoxie- und Pharmaka-induzierten SD

A: Vergleich der charakteristischen elektrophysiologischen SDParameter, der Ausbreitungsgeschwindigkeit und der Größe des betroffenen Areals. Signifikante Unterschiede der Parameter zu einer 
jeweils zuvor durchgeführten Kontrollmessung sind mit einem * versehen. Die Zahlen unter den Balken geben die Anzahl der durchgeführten Versuche an.

B: maximale Ausbreitung der IOS unter Cyanid- (1 mM), Azid- (2 mM) und FCCP-Einfluss $(10 \mu \mathrm{M})$ (untere Reihe) im Vergleich zur Kontrolle (mittlere Reihe). Die obere Reihe zeigt ein Transmissionsbild der jeweiligen Hirnschnitte. Die Änderung der Gewebe Reflexion wurde auf das erste Bild der Aufnahme bezogen und eine Änderung in Graustufen von $-20 \%$ bis $+20 \%$ Reflexionsänderung angezeigt.

C: Zeitverlauf und Ausmaß der IOS. Angezeigt ist der gemittelte Verlauf der Reflexionsänderung unter den verschiedenen Versuchsbedingungen.

\section{Optische Quantifizierung mitochondrialer Parameter und des Redox-Status}

Die Untersuchungen der Wirkung der mitochondrialen Blocker auf die Hypoxie-Antworten lieferten erstaunliche Ergebnisse. Einige Wirkstoffe, wie z.B. Rotenon oder AMC beschleunigten das Auftreten der HSD, verkürzten aber auch ihre Dauer, was zu einer schnelleren Erholung der Hirnschnitte führte. Dieser Vorgang beinhaltet ATP verbrauchende Mechanismen, wie z.B. die $\mathrm{Na}^{+} / \mathrm{K}^{+}$ATPase zur Wiederherstellung des lonengleichgewichts und des Membranpotentials (Rosenthal und Sick, 1992). Um die Effekte der einzelnen mitochondrialen Blocker genauer zu verstehen, wurden ihre Wirkungen auf das mitochondriale Membranpotential $(\Delta \psi \mathrm{m})$, den mitochondrialen Metabolismus, den Redox-Zustand und den ATP-Gehalt untersucht.

\section{Messung des mitochondrialen Membranpotentials $(\Delta \Psi \mathrm{m})$ mit Rh123}

Die Energiegewinnung durch die oxidative Phosphorylierung ist abhängig von einem Protonengradienten über die innere Mitochondrienmembran. Dieser Gradient wird durch die Atmungskette aufgebaut und erhalten. Dadurch ergibt sich ein Membranpotential von -150 bis $-180 \mathrm{mV}$ gegenüber dem Cytosol 
(Foster et al., 2006). Der positiv geladene Farbstoff Rhodamin 123 (Rh123) akkumuliert in den Mitochondrien, wo seine eigene Fluoreszenz durch die hohe Konzentration gedämpft (quenching) wird (Abb. 18). Bei einer Depolarisation der inneren Membran wird er teilweise an das Cytosol abgegeben, wodurch es durch den Wegfall des Eigen-Quenchings zu einem Anstieg der Fluoreszenzintensität kommt.

Die Messungen des mitochondrialen Membranpotentials wurden auf Einzelzellebene in Zellkulturen oder in Verbindung mit NADH-Messungen an akuten hippokampalen Hirnschnitten durchgeführt. Die folgenden Ergebnisse wurden in Hirnschnitten gemessen.

Eine Inhibition der Atmungskette führte in der Regel zu einem Anstieg der Rh123 Fluoreszenz (Abb. 17). Die Blockade von Komplex I durch $20 \mu \mathrm{M}$ Rotenon steigerte die Rh123 Fluoreszenz um 22,8 $\pm 8,2 \% \quad(n=5)$. DPI $(25 \mu \mathrm{M})$ führte zu einem starken Anstieg um 35,7 \pm 7,9\% $(n=5)$, während $1 \mathrm{mM}$ 3-NPA $(\mathrm{n}=6)$ nur eine schwache Depolarisation zur Folge hatte $(4,8 \pm 2,0 \%)$. Antimycin $A(20 \mu M)$, ein Blocker für Komplex III, steigerte die Fluoreszenz um 15,4 $\pm 5,4 \%(n=5)$. Cyanid wurde in niedrigen $(100 \mu M)$ und hohen (1 $\mathrm{mM}$ ) Konzentrationen getestet und führte dosisabhängig zu einem Anstieg von 12,2 $\pm 9,0 \%(n=6)$ bzw. 34,2 $\pm 11,3 \%(n=5)$. Der Einsatz von Oligomycin $(10 \mu \mathrm{g} / \mathrm{ml})$ zur Blockade der $\mathrm{F}_{0} \mathrm{~F}_{1}$-ATPase verringerte als einziger Wirkstoff die Rh123 Fluoreszenz um -2,6 $\pm 1,9 \%(n=7)$. Einen sehr starken Anstieg der Fluoreszenz erhielt man mit 35,3 \pm 14,7\% $(n=6)$ durch die Protonophore FCCP $(1 \mu \mathrm{M})$. Diese beiden Wirkstoffe haben damit auch den dynamischen Bereich des Rh123 dargestellt, da FCCP zu einer maximalen Depolarisation der Mitochondrien führt und durch Oligomycin eine maximale Hyperpolarisation eintritt. 


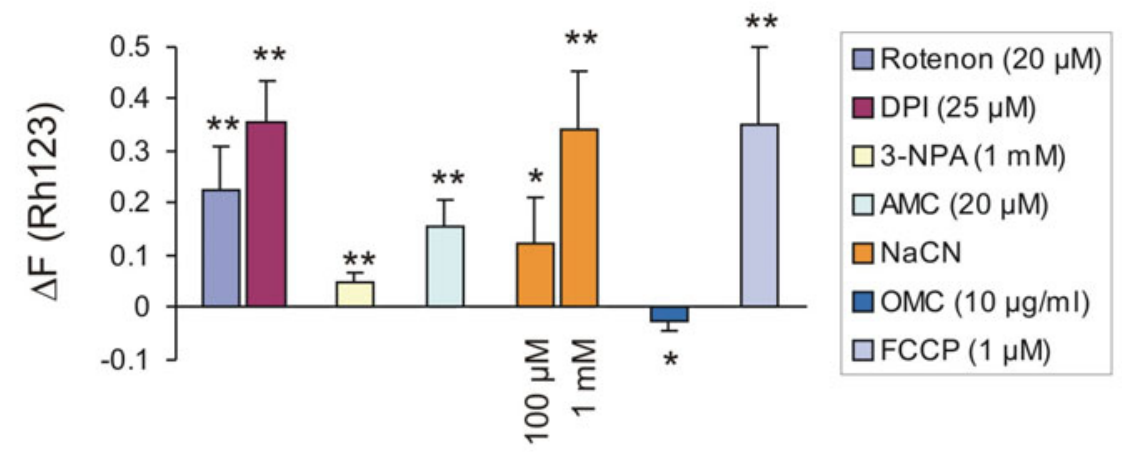

B

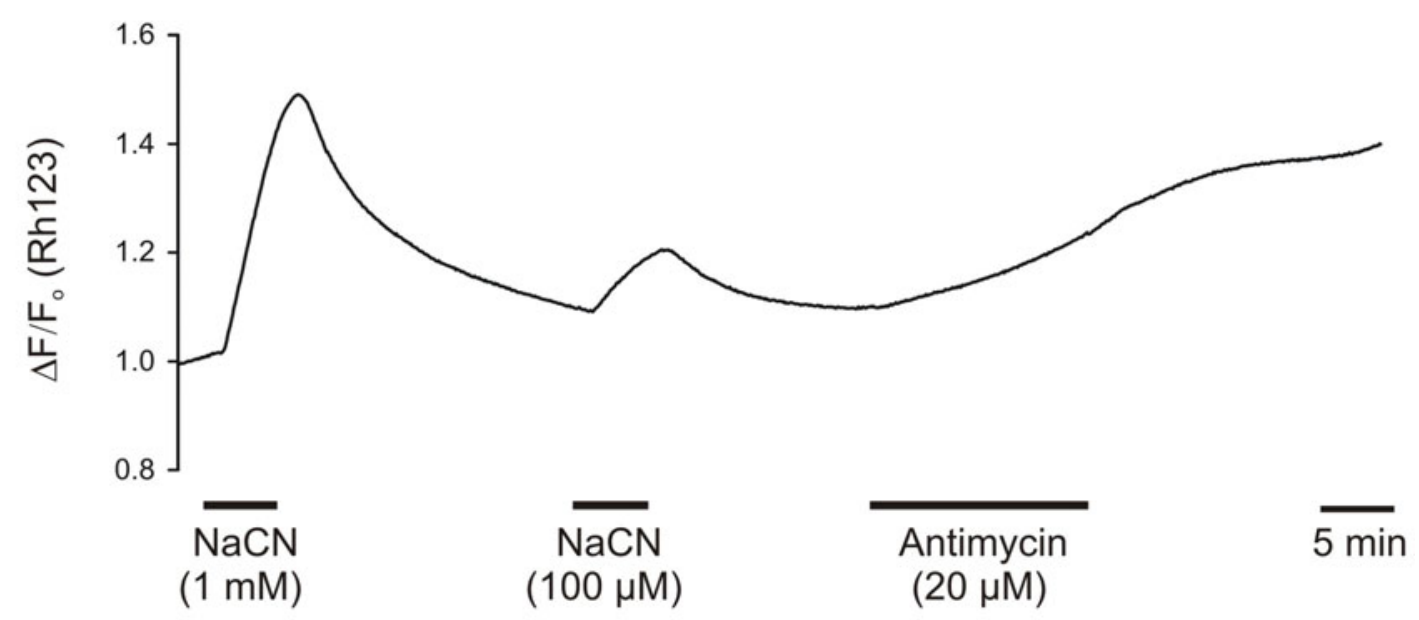

\section{Abb. 17: Wirkung der Mitochondrien-Inhibitoren auf das mitochondriale \\ Membranpotential}

Akute hippokampale Hirnschnitte wurden mit Rh123 angefärbt und die Änderungen im mitochondrialen Membranpotential in einer Region im stratum radiatum in der CA1 Region gemessen. Ein Anstieg der Intensität der Rh123 Fluoreszenz zeigt eine Depolarisation der inneren Mitochondrienmembran an. Die gemessenen Veränderungen wurden auf einen Grundzustand vor der Pharmakazugabe normalisiert.

A: Übersicht über die Auswirkung der genutzten Inhibitoren auf das mitochondriale Membranpotential. Aufgezeigt sind die Mittelwerte der Messungen von 5 - 7 Hirnschnitten.

B: Wirkung von Cyanid und AMC auf das mitochondriale Membranpotential. Cyanid ließ sich gut auswaschen, während AMC zu einer irreversiblen Depolarisation führte. 

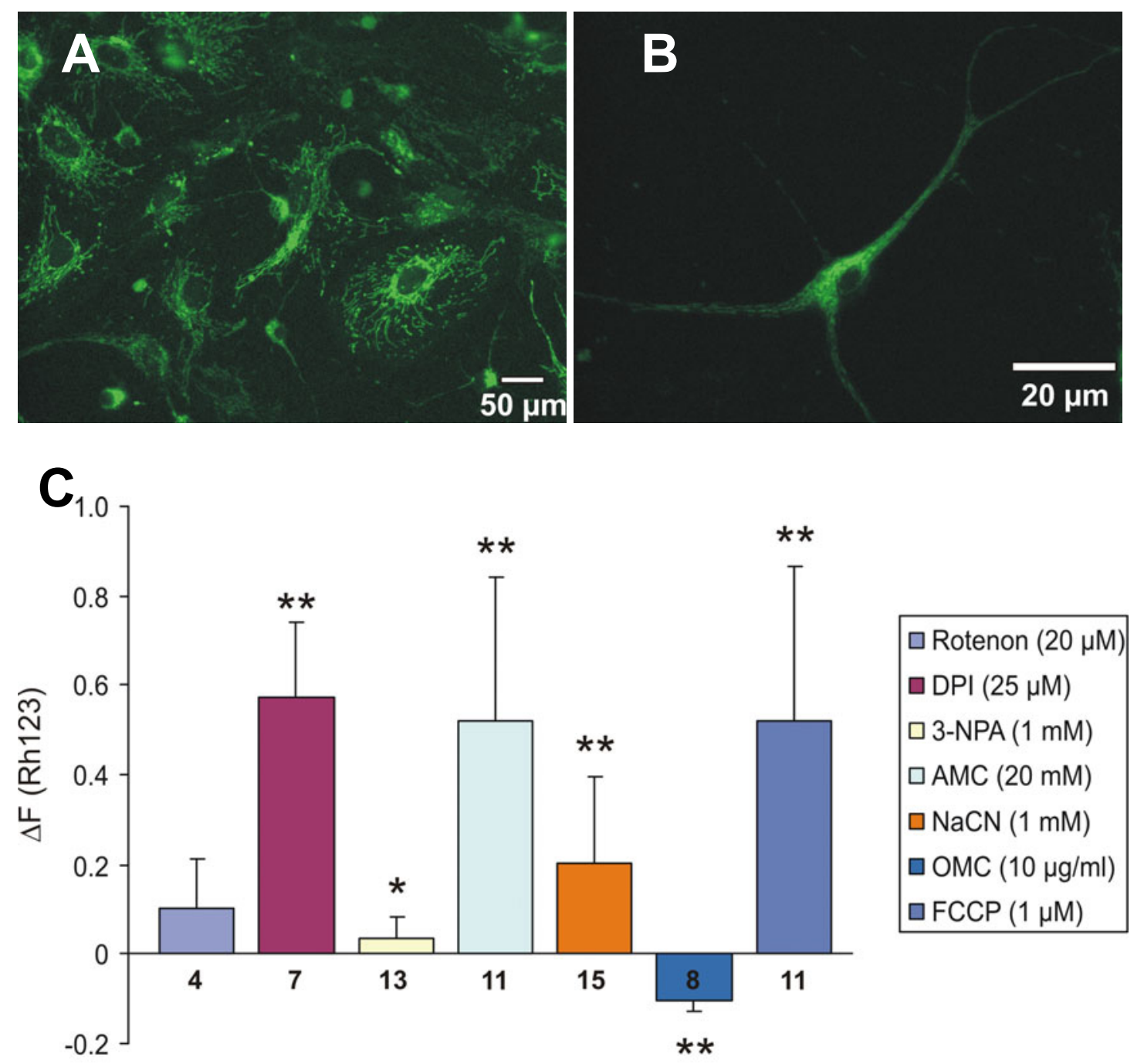

\section{Abb. 18: Detektion von $\Delta \psi \mathrm{m}$ in Zellkultur}

Die Veränderung des mitochondrialen Membranpotentials als Reaktion auf Inhibitoren der Atmungskette wurde in mit Rh123 beladenen kultivierten Neuronen gemessen. Die Auswirkungen der Blocker unterschieden sich nur geringfügig von denen, die in hippokampalen Hirnschnitten gemessen wurden (Abb.17).

Bei optischen Messungen in Hirnschnitten ist es nicht möglich, zwischen Neuronen und Gliazellen zu trennen. Mit Rh123 beladene kultivierte Neurone zeigten in ihren Reaktionen auf die Mitochondrienblocker jedoch nur eine geringfügige Abweichung von den in Hirnschnitten gemessenen Werte (Abb. 18). 


\section{Autofluoreszenz von NADH und FAD}

Veränderungen in der Autofluoreszenz der Coenzyme NADH und FAD sind ein direkter Indikator für den mitochondrialen Metabolismus und den RedoxZustand (Mills und Jöbsis, 1972; Shuttleworth et al., 2003). Da die reduzierte Form von $\mathrm{NADH}$ und das oxidierte FAD autofluoreszente Eigenschaften haben, zeigen die beiden Stoffe auf Veränderungen der Atmungskettenaktivität gegensätzliche Reaktionen. Eine Steigerung der NADH Fluoreszenz zeigt eine Reduktion an, während eine Steigerung der FAD Fluoreszenz eine Oxidation anzeigt (Abb. 19). Eine Inhibition des mitochondrialen Metabolismus führt also zu entgegengesetzten Reaktionen dieser beiden Parameter. Cyanid führte zu einem Anstieg der Fluoreszenz von NADH und einer Abschwächung der Fluoreszenz von FAD, was auf eine Inhibition der mitochondrialen Respiration deutet. Antimycin A steigerte den NADH Gehalt in den Hirnschnitten, hatte aber kaum einen Einfluss auf FAD. FCCP führte erwartungsgemäß zu einem gesteigerten Verbrauch von NADH und einem Anstieg von FAD, da eine Entkopplung der Atmungskette durch Protonophoren die mitochondriale Respiration steigert (Nicholls et al., 2007). Die Mechanismen die bei DPI und Oligomycin zu dem Absinken von NADH und der Steigerung von FAD führen sind noch nicht völlig aufgeklärt. 
A

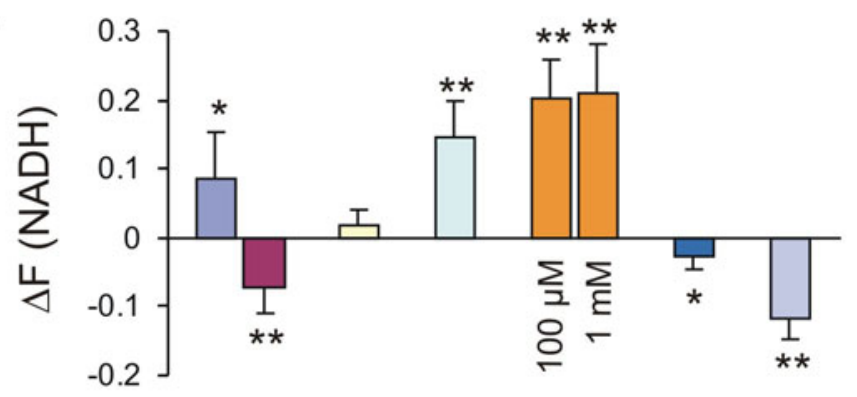

Rotenon $(20 \mu \mathrm{M})$

口 DPI $(25 \mu \mathrm{M})$

$\square$ 3-NPA (1mM)

$\square$ AMC $(20 \mu \mathrm{M})$

$\square \mathrm{NaCN}$

$\mathrm{OMC}(10 \mu \mathrm{g} / \mathrm{ml})$

$\square \operatorname{FCCP}(1 \mu \mathrm{M})$

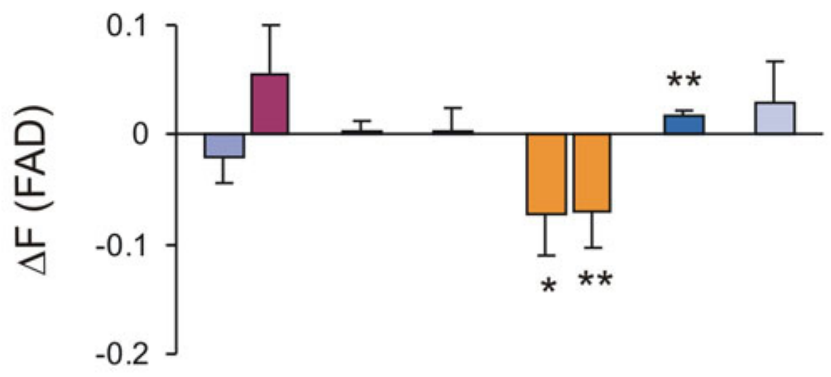

B

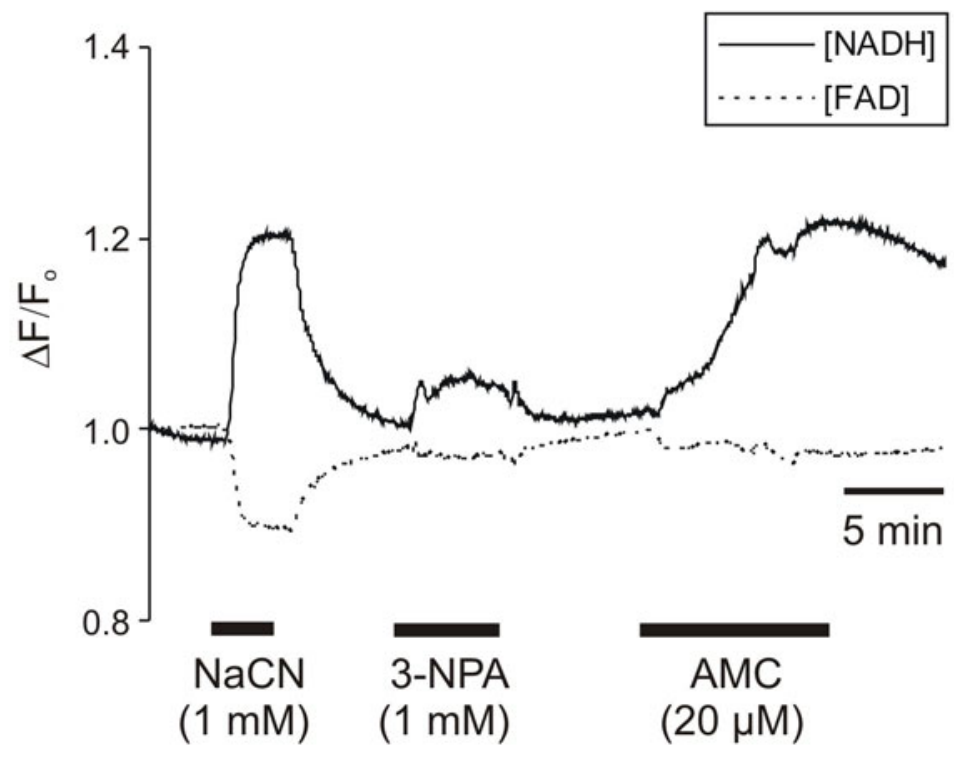

Abb. 19: Auswirkung der Atmungsketten-Modulatoren auf den mitochondrialen Metabolismus

Die Veränderung des mitochondrialen Metabolismus durch die Zugabe der verschiedenen Atmungsketten-Modulatoren wurde anhand der Autofluoreszenz von NADH und FAD gemessen. Die Änderungen in der Autofluoreszenz der beiden Coenzyme wurden gleichzeitig bei 
$366 \mathrm{~nm}$ bzw. $460 \mathrm{~nm}$ in einer Region in der CA1 Region im stratum radiatum von hippokampalen Hirnschnitten gemessen. Die gemessenen Veränderungen wurden auf einen Grundzustand vor der Pharmakazugabe normalisiert.

A: Übersicht über die Auswirkung der verschiedenen Inhibitoren auf den mitochondrialen Metabolismus. Aufgezeigt sind die Mittelwerte von 4 - 6 Hirnschnitten. B: Die Inhibition der mitochondrialen Atmungskette führt zu einem Anstieg der Fluoreszenz von NADH und einer Schwächung der Fluoreszenz von FAD.

Zur besseren Übersicht und Vergleichbarkeit der Werte von NADH und FAD sind die Ergebnisse dieser Messungen hier in Tabellenform wiedergegeben.

Tabelle 6: Wertetabelle Autofluoreszenz von NADH und FAD

\begin{tabular}{|c|c|c|c|c|c|c|c|c|}
\hline \multicolumn{9}{|c|}{ NADH } \\
\hline & $\begin{array}{c}\text { Rot } \\
(20 \mu \mathrm{M})\end{array}$ & $\begin{array}{c}\text { DPI } \\
(25 \mu \mathrm{M})\end{array}$ & $\begin{array}{l}\text { 3-NPA } \\
(1 \mathrm{mM})\end{array}$ & $\begin{array}{l}\text { AMC A } \\
(20 \mu M)\end{array}$ & $\begin{array}{c}\mathrm{NaCN} \\
(100 \mu \mathrm{M})\end{array}$ & $\begin{array}{c}\mathrm{NaCN} \\
(1 \mathrm{mM})\end{array}$ & $\begin{array}{c}\text { OMC } \\
(10 \mu \mathrm{g} / \mathrm{ml})\end{array}$ & $\begin{array}{l}\text { FCCP } \\
(1 \mu \mathrm{M})\end{array}$ \\
\hline$\Delta \mathrm{F}$ & $8.5 \%$ & $-7.2 \%$ & $1.9 \%$ & $14.8 \%$ & $20.1 \%$ & $21.1 \%$ & $-2.7 \%$ & $-11.6 \%$ \\
\hline SD & $7.0 \%$ & $3.8 \%$ & $2.4 \%$ & $5.2 \%$ & $5.9 \%$ & $7.2 \%$ & $1.7 \%$ & $3.1 \%$ \\
\hline$n$ & 6 & 5 & 4 & 5 & 4 & 6 & 5 & 6 \\
\hline \multicolumn{9}{|c|}{ FAD } \\
\hline & $\begin{array}{c}\text { Rot } \\
(20 \mu \mathrm{M})\end{array}$ & $\begin{array}{c}\text { DPI } \\
(25 \mu \mathrm{M})\end{array}$ & $\begin{array}{l}\text { 3-NPA } \\
\text { (1 } \mathrm{mM})\end{array}$ & $\begin{array}{l}\text { AMC A } \\
(20 \mu \mathrm{M})\end{array}$ & $\begin{array}{c}\mathrm{NaCN} \\
(100 \mu \mathrm{M})\end{array}$ & $\begin{array}{l}\mathrm{NaCN} \\
(1 \mathrm{mM})\end{array}$ & $\begin{array}{c}\mathrm{OMC} \\
(10 \mu \mathrm{g} / \mathrm{ml})\end{array}$ & $\begin{array}{l}\text { FCCP } \\
(1 \mu \mathrm{M})\end{array}$ \\
\hline$\Delta \mathrm{F}$ & $-2.0 \%$ & $5.5 \%$ & $0.4 \%$ & $0.3 \%$ & $-7.3 \%$ & $-7.0 \%$ & $1.7 \%$ & $2.8 \%$ \\
\hline SD & $2.4 \%$ & $4.6 \%$ & $0.9 \%$ & $2.3 \%$ & $3.6 \%$ & $3.3 \%$ & $0.6 \%$ & $3.9 \%$ \\
\hline$n$ & 5 & 5 & 4 & 5 & 4 & 6 & 5 & 6 \\
\hline
\end{tabular}

\section{Messungen des Redox-Potentials mit redoxsensitiven Farbstoffen}

Zum Nachweis der Membranpermeabilität von $\mathrm{H}_{2} \mathrm{O}_{2}$ und der Darstellung einer intrinsischen ROS-Produktion wurden ursprünglich ROS sensitive Farbstoffe wie Dihydroethidium (HEt) (Abb. 20, A) oder Fluorescein-Varianten benutzt. Dies erwies sich aber als äußerst unpraktikabel, da diese Farbstoffe cytotoxisch sind und leicht irreversibel durch Luftsauerstoff oder UV-Beleuchtung oxidieren. HEt wurde leicht aus den Zellen ausgewaschen wodurch sich keine stabile baseline einstellen ließ. Des Weiteren war eine Oxidation von HEt irreversibel, was eine Messung von dynamischen 
Vorgängen unmöglich machte. Aussagekräftige Messungen waren somit praktisch nicht durchführbar.

A

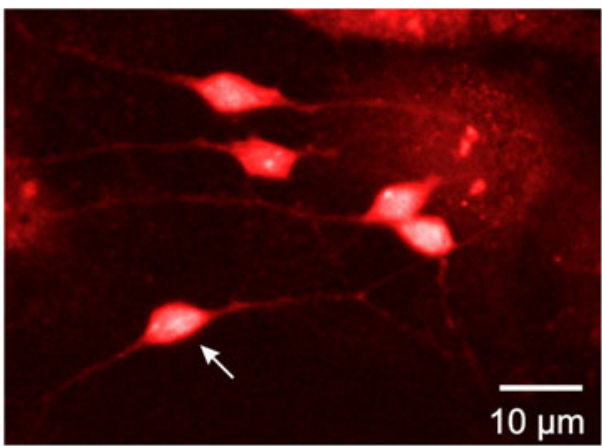

B

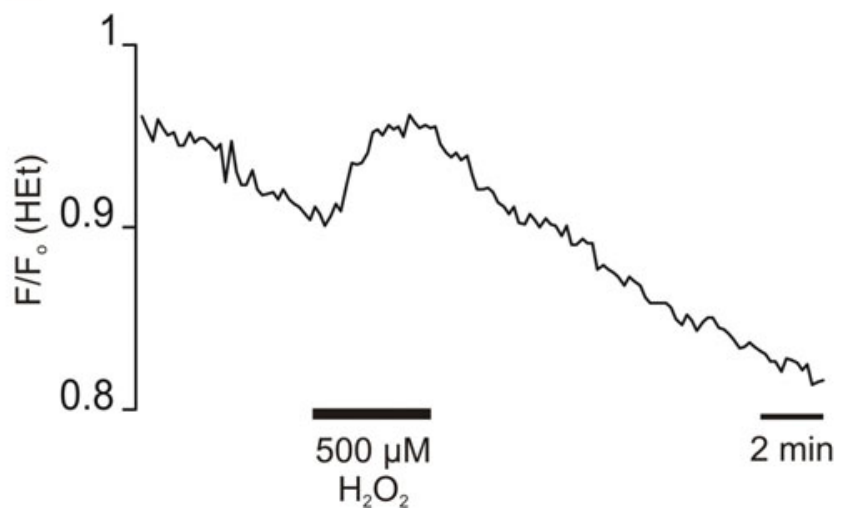

\section{Abb. 20: $\mathrm{H}_{2} \mathrm{O}_{2}$ oxidiert ROS sensitive Farbstoffe irreversibel}

Kultivierte hippokampale Neurone wurden mit HEt $(10 \mu \mathrm{M}, 30 \mathrm{~min})$ angefärbt (A). Der Pfeil markiert die Zelle, in deren Soma die in (B) dargestellte Spur aufgezeichnet wurde. $\mathrm{H}_{2} \mathrm{O}_{2}(500 \mu \mathrm{M})$ führte zu einer Oxidation und damit zu einer Intensivierung der Fluoreszenz. Diese Oxidation war irreversibel. Die Intensität des Farbstoffs nahm kontinuierlich $a b$, was darauf schließen lässt, dass er leicht ausgewaschen wird und/oder eine starke Tendenz zum Photobleaching hat (B).

Eine bei weitem überlegene Methode stellte die Transfektion von neuronalen Zellkulturen mit dem redoxsensitiven roGFP dar.

\section{Dynamische Messungen der ROS Bildung mit roGFP transfizierten Zellen}

Bis zu 5\% der Elektronen, die die Atmungskette durchlaufen, entweichen normalerweise dem System und tragen so zur Bildung von ROS bei. Ziel dieses Versuchsblockes war es, zu bestimmen, inwiefern eine mitochondriale Blockade oder Modulation diese ROS-Produktion beeinflusst. Mit dem neuartigen redoxsensitiven roGFP konnten dynamische Messungen des Redox-Zustandes transfizierter Zellen durchgeführt werden (Abb. 21).

Da diese Methode in unserem Labor neu etabliert wurde, werden hier auch einige Versuche zum Beweis der Funktion des GFPs aufgezeigt. 


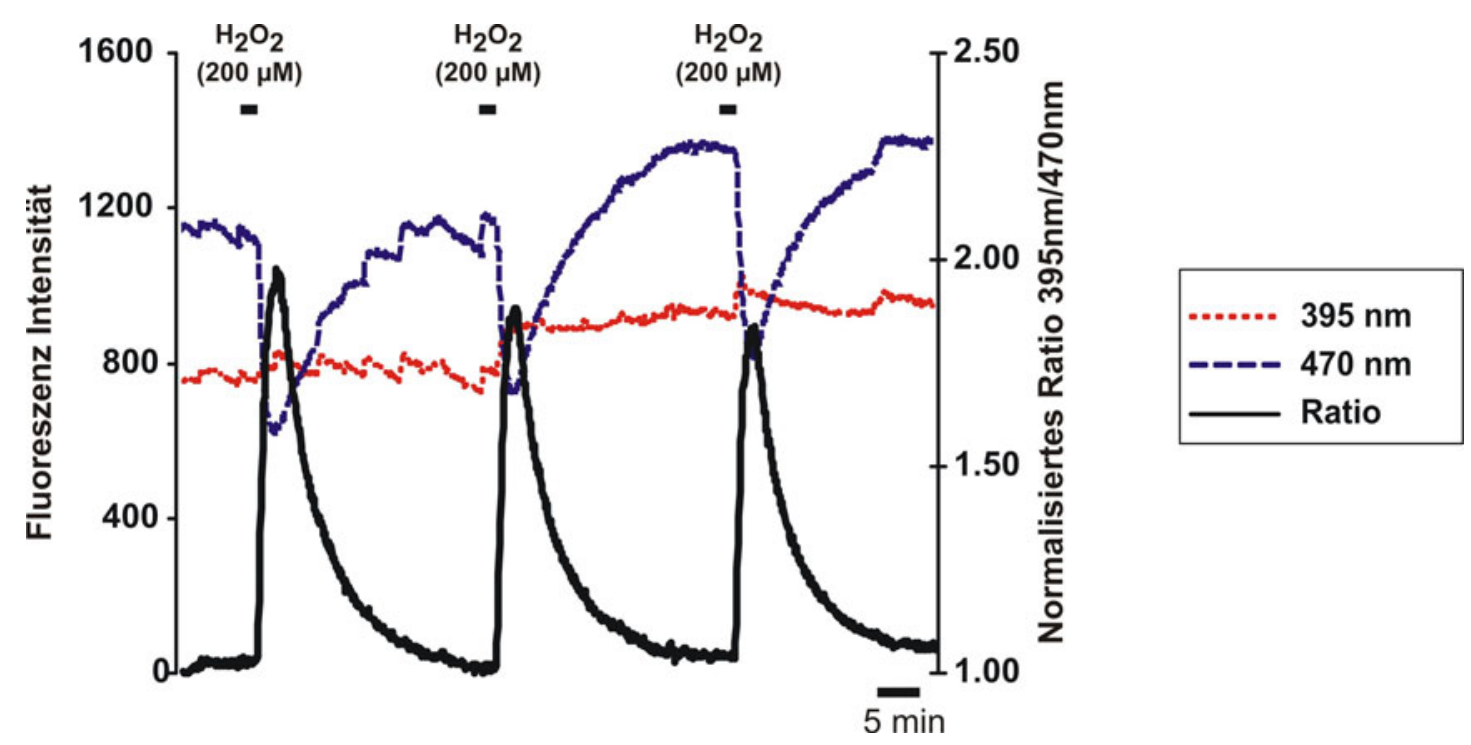

\section{Abb. 21: Ratiometrische Messungen von ROS mit roGFP}

Kultivierte hippokampale Neurone wurden mit roGFP transfiziert und wiederholt mit $200 \mu \mathrm{M} \mathrm{H}_{2} \mathrm{O}_{2}$ behandelt. Durch eine Oxidation verringert sich das Maximum bei $470 \mathrm{~nm}$, während sich das Maximum bei $395 \mathrm{~nm}$ intensiviert, wodurch ratiometrische Messungen möglich werden. Die Oxidation des GFPs ist reversibel, so dass dynamische Messungen möglich sind.

Das. roGFP zeigte eine generelle Redox-Änderung des Cytosols an, ohne eine ausgeprägte Affinität zu Superoxid, Wasserstoffperoxid oder HydroxylRadikalen zu zeigen (Abb. 22). Die durch Oxidation induzierte Bildung der Disulfidbrücken zwischen den Cystein-Resten an der Oberfläche des Proteins (Abb. 11) führt zu einer Protonierung des Chromophors. 
A
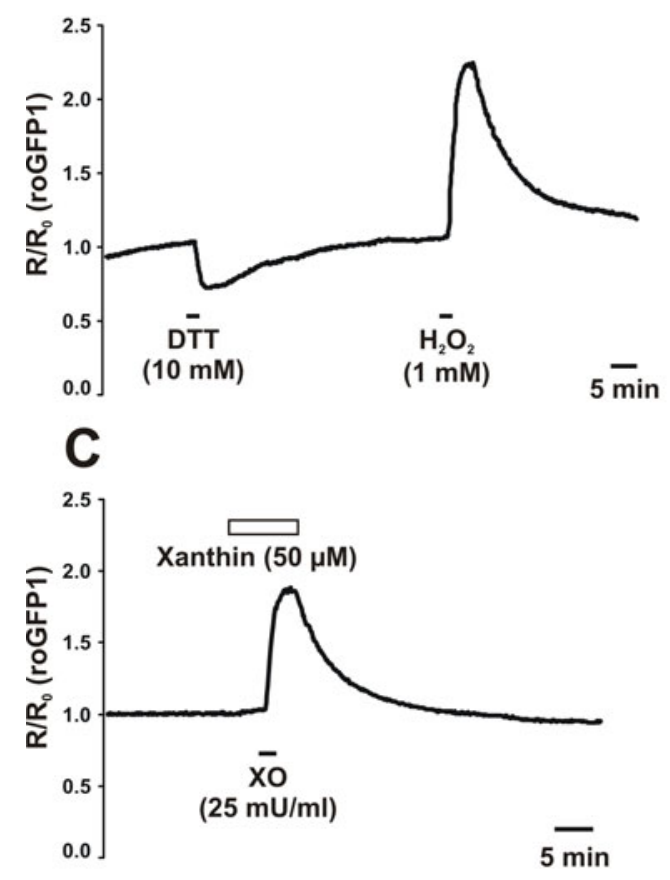

\section{B}
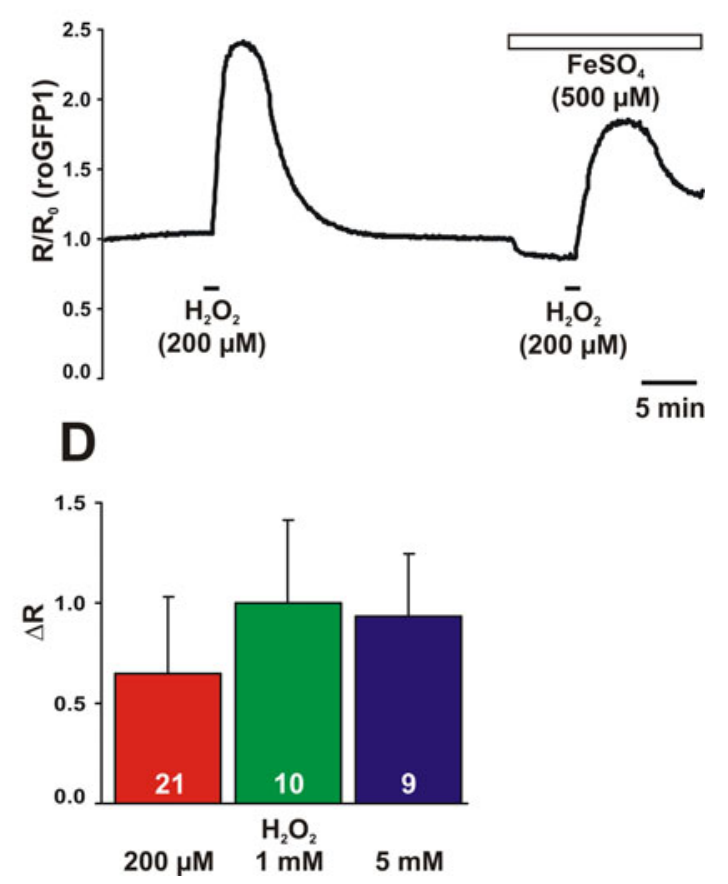

\section{Abb. 22: roGFP reagiert auf unterschiedliche ROS}

In lebenden Zellen liegt roGFP größtenteils reduziert vor, wodurch die Reaktion auf oxidierende Einflüsse stärker als auf reduzierende Reagenzien wie z.B. DTT ausfiel (A). Kultivierte Neurone wurden mit Hydroxyl-Radikalen aus der Reaktion von $\mathrm{H}_{2} \mathrm{O}_{2}$ mit $\mathrm{FeSO}_{4}(500 \mu \mathrm{M})$ (B) und Superoxid aus der Reaktion von Xanthin $(50 \mu \mathrm{M})$ mit Xanthinoxidase $(25 \mathrm{mU} / \mathrm{ml})$ (C) behandelt. $1 \mathrm{mM} \mathrm{H}_{2} \mathrm{O}_{2}$ führte zu einer vollständigen Oxidierung des roGFPs. Höhere Konzentrationen hatten keinen weiteren Effekt (D).

Aufgrund der reduzierenden Verhältnisse im Cytosol lag das GFP im Grundzustand größtenteils reduziert vor (Abb. 22, A). Eine Zugabe von $1 \mathrm{mM}$ $\mathrm{H}_{2} \mathrm{O}_{2}$ führte zu einer maximalen Oxidation des GFPs, während $10 \mathrm{mM}$ DTT eine maximale Reduktion erreichten (Hanson et al., 2004). Eine genaue Bestimmung des Redoxpotentials der Zellen hätte nur unter gleichzeitiger Messung des pH-Wertes der Zellen sowie einer Kalibrierung mit Lösungen mit bekanntem Redoxpotential unter Zuhilfenahme von redoxsensitiven Elektroden durchgeführt werden können. Da dies im Rahmen dieser Arbeit nicht möglich war, wird der Redox-Zustand der Zellen mit dem Grad der Oxidation des roGFPs beschrieben. Dabei geben die gemittelten Werte von 
$1 \mathrm{mM} \mathrm{H}_{2} \mathrm{O}_{2}(100 \pm 30,6 \%)$ und $10 \mathrm{mM}$ DTT $(0 \pm 9,2 \%)$ den Wirkungsbereich des GFPs vor. Nach dieser Definition lag das roGFP in ungestörten Zellen zu $28,2 \%$ oxidiert vor (Abb. 23).

Messungen an mit roGFP transfizierten Neuronen zeigten, das eine Blockade der Mitochondrienfunktion nicht zwangsläufig eine erhöhte ROS-Produktion nach sich zog. So führte die Inhibition von Komplex I durch $20 \mu \mathrm{M}$ Rotenon zwar zu einer leicht verstärkten Oxidation von roGFP auf 29,8 $\pm 0,8 \%$, eine Blockade durch $25 \mu \mathrm{M}$ DPI jedoch zu einer Reduktion auf 26,3 $\pm 1,6 \%$.

Inhibition von Komplex II durch 1 mM 3-NPA führte zu einer erhöhten ROSProduktion $(36,9 \pm 4,5 \%)$. Antimycin $(20 \mu \mathrm{M})$ oxidierte roGFP leicht auf $32,3 \pm 5,4 \%$. Eine stärkere Reaktion wurde durch eine Blockierung von Komplex IV durch $1 \mathrm{mM} \mathrm{NaCN}(33,3 \pm 5,0 \%)$ erzielt.

Obwohl die mitochondriale Respiration durch den Einsatz des Protonophors FCCP $(1 \mu \mathrm{M})$ stimuliert wird (Cotton et al., 1981), sank der Grad der Oxidation auf $29,8 \pm 2,5 \%$. Der Blocker der $F_{0} F_{1}$-ATPase Oligomycin $(10 \mu \mathrm{g} / \mathrm{ml})$ führte zu einer verstärkten ROS-Produktion und oxidierte GFP auf 38,5 $\pm 8,5 \%$. Glutamat in den Konzentrationen $50 \mu \mathrm{M}$ bzw. $1 \mathrm{mM}$ steigerte den Oxidationsgrad auf $35,5 \pm 5,4 \%$ bzw. $37,5 \pm 15,4 \%$. 
A

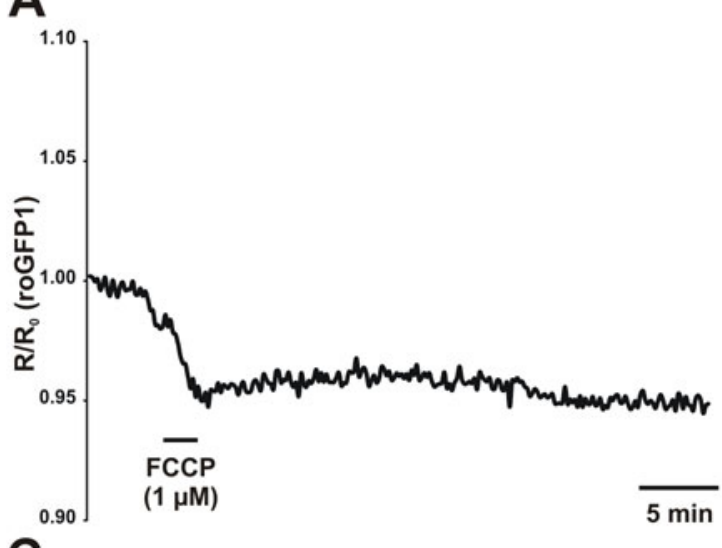

B

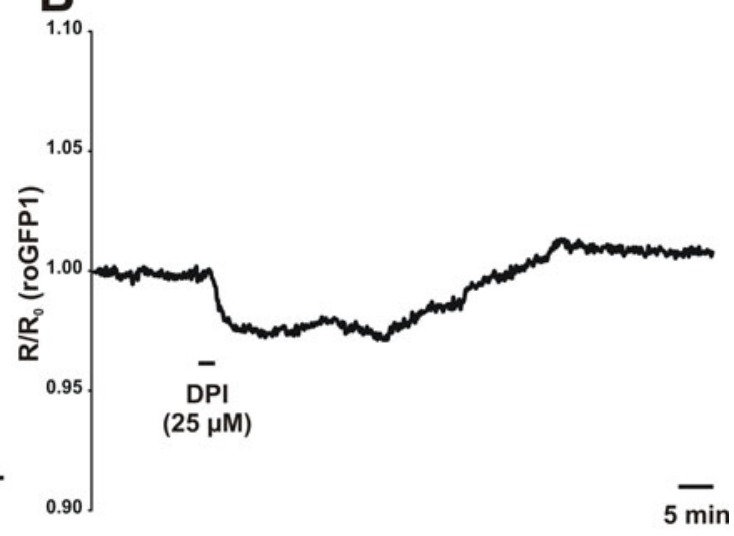

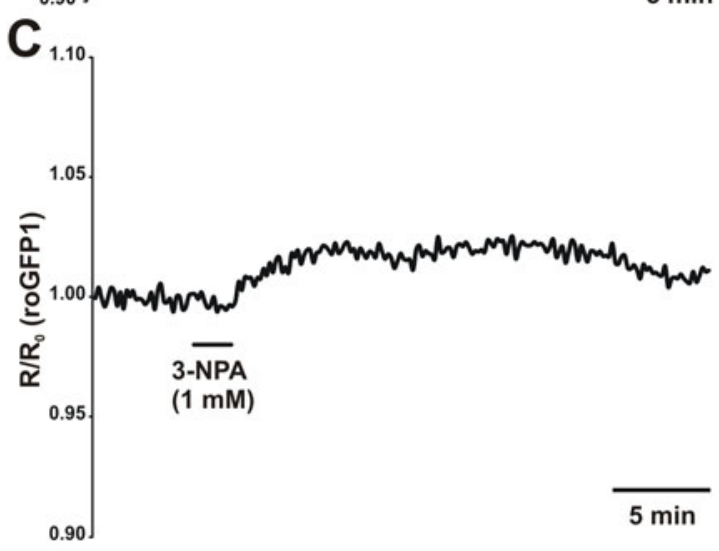

D 1.40

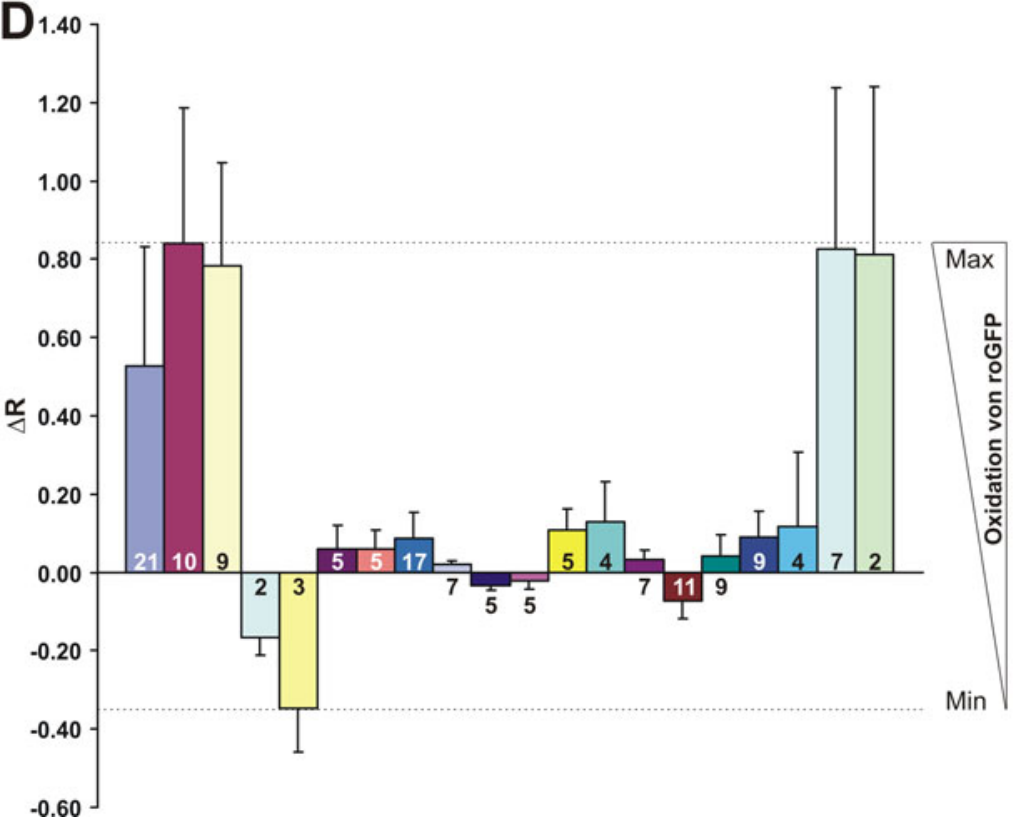

$\square \mathrm{H}_{2} \mathrm{O}_{2}(200 \mu \mathrm{M})$

- $\mathrm{H}_{2} \mathrm{O}_{2}(1 \mathrm{mM})$

$\square \mathrm{H}_{2} \mathrm{O}_{2}(5 \mathrm{mM})$

$\square$ DTT (2 mM)

$\square$ DTT (10 mM)

- $\mathrm{NaCN}(100 \mu \mathrm{M})$

$\square \mathrm{NaCN}(100 \mu \mathrm{M})\left(5^{\prime}\right)$

$=\mathrm{NaCN}(1 \mathrm{mM})$

$\square \operatorname{Rot}(20 \mu \mathrm{M})$

- FCCP $(1 \mu \mathrm{M})$

- DPI $(25 \mu \mathrm{M})$

口3-NPA (1 mM)

$\square$ OMC $(10 \mu \mathrm{g} / \mathrm{ml})$

- AMC (20 $\mu \mathrm{M})$

- Hypoxie durch $\mathrm{N}_{2}$

- Reoxygenierung nach $\mathbf{N}_{2}$

- Glu $(50 \mu \mathrm{M})$

• Glu (1 mM)

$\square \times x O$

$\square \mathrm{H}_{2} \mathrm{O}_{2}$ in Fe-Sulfat

\section{Abb. 23: Wirkung der mitochondrialen Blocker auf roGFP}

Entkopplung der Atmungskette durch $1 \mu \mathrm{M}$ FCCP (A) sowie die Inhibition von Komplex I mit $25 \mu \mathrm{M}$ DPI (B) führte zu einer Reduktion des roGFPs, während $1 \mathrm{mM}$ 3-NPA (C), ein Blocker von Komplex II zu einer ROS-Produktion führte. (D) gibt einen Überblick über die Reaktionen von roGFP auf die verschiedenen Blocker und ROS. 


\section{A}
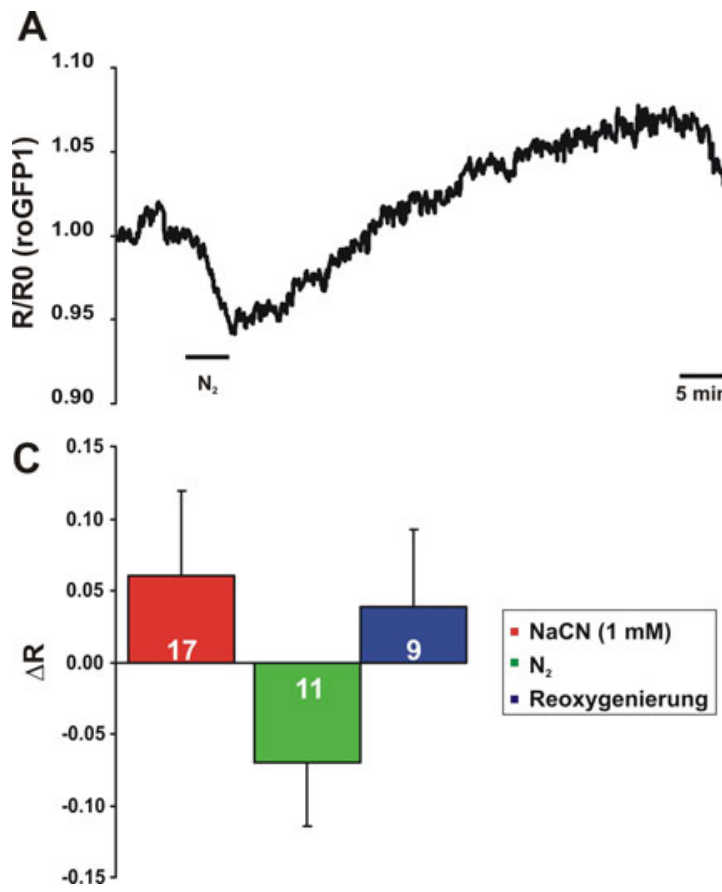

B

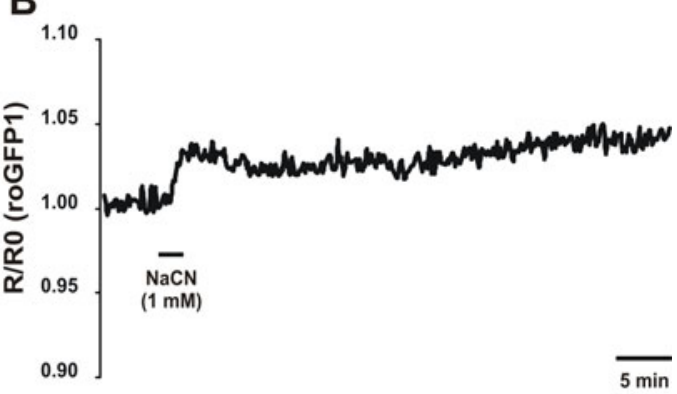

\section{Abb. 24: Ratiometrische Messungen von roGFP auf Sauerstoffentzug und chemische Anoxie.}

Um einen hypoxischen Zustand zu erreichen, wurde $95 \% \mathrm{~N}_{2}-5 \% \mathrm{CO}_{2}-$ begaste ACSF (1 $\mathrm{mM} \mathrm{Na}_{2} \mathrm{SO}_{3}$ ) eingesetzt. Dadurch wurde das cytosolische roGFP reduziert. Bei der Reoxygenierung durch einen Wechsel auf reguläre ACSF kam es zu einer überproportionalen Oxidation des roGFPs (A). Eine Inhibition von Komplex IV der Atmungskette in Anwesenheit von $\mathrm{O}_{2}$ durch $1 \mathrm{mM} \mathrm{NaCN}$ führte zu einer Oxidation (B). Hypoxische Zustände reduzieren roGFP, während chemische Anoxie und Reoxygenierung nach einer Hypoxie zu einer ROS-Produktion führen (C).

Bei einer durch Umschalten der Sauerstoffversorgung von Carbogen auf $\mathrm{N}_{2}$ ausgelösten Anoxie kam es zu einer biphasischen Reaktion. Durch das Fehlen von Sauerstoff ging die ROS-Produktion auf 21,7 $\pm 4,3 \%$ zurück. Bei der Reoxygenierung kam es zu einer kurzfristig erhöhten ROS-Produktion auf $31,5 \pm 4,5 \%$, die nach einigen Minuten wieder auf das Grundniveau zurück sank. Somit zeigten $\mathrm{N}_{2}$, der Auslöser einer anoxischen Hypoxie, und $1 \mathrm{mM}$ Cyanid, was in Anwesenheit von $\mathrm{O}_{2}$ eine chemische Anoxie ausgelöst hat, bei der ROS-Produktion entgegengesetzte Reaktionen. 


\section{ATP Messungen}

Die Wirkung der mitochondrialen Inhibition auf den zellulären ATP-Gehalt hippokampaler Schnitte durch die verschiedenen Blocker wurde nach der Methode von Lamprecht und Trautschold (1974) gemessen und mit unbehandelten Kontrollschnitten verglichen. Diese Messmethode beruht auf der photometrischen Bestimmung der $\mathrm{NADPH}_{2}$ Bildung (siehe Material und Methoden, Seite 29).

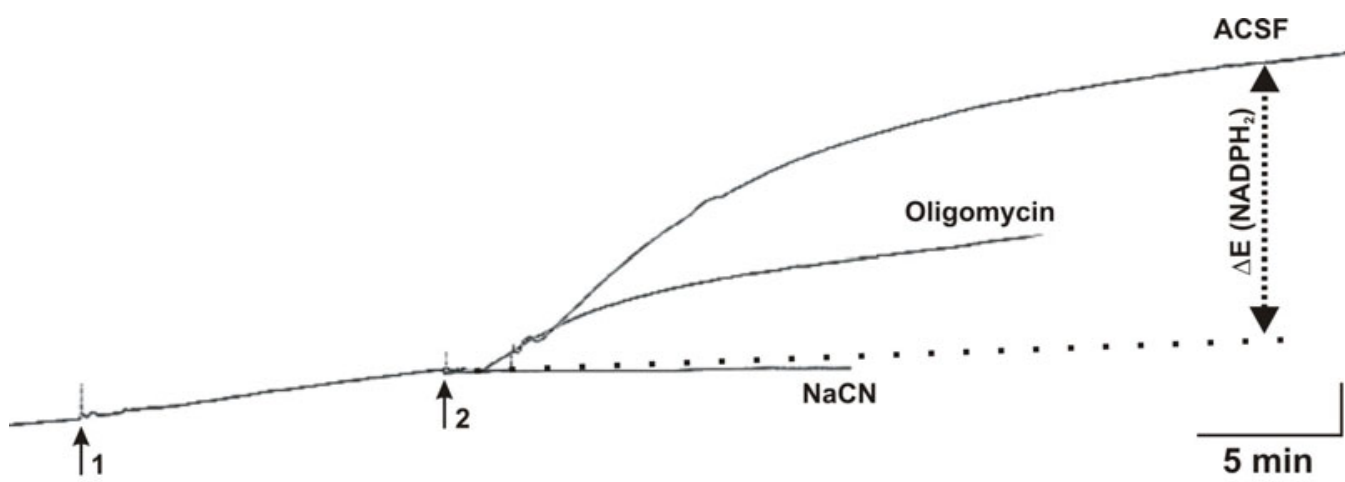

\section{Abb. 25: Aufzeichnung der Bestimmung des ATP-Gehaltes}

Gezeigt sind die Extinktionsänderungen von $\mathrm{NADPH}_{2}(\lambda: 366 \mathrm{~nm})$ bei den Proben eines unbehandelten Kontrollschnittes und von Schnitten, die je $25 \mathrm{~min}$ mit Oligomycin $(10 \mu \mathrm{g} / \mathrm{ml})$ und $\mathrm{NaCN}(1 \mathrm{mM})$ behandelt wurden. $\uparrow$ zeigen die Zeitpunkte an, bei denen Glucose-6-P-PhosphatDehydrogenase (1) und Hexokinase (2) zugegeben wurden.

Die Kontrollschnitte hatten einen mittleren ATP-Gehalt von 11,4 $\pm 3,8 \mathrm{nmol}$ ATP / mg Protein. Überraschenderweise hatte eine Blockade der Atmungskette nur einen schwachen Einfluss auf den zellulären ATP-Gehalt. Eine signifikante Reduktion wurde durch die Blockade von Komplex I durch $20 \mu \mathrm{M}$ Rotenon und Komplex IV durch $1 \mathrm{mM}$ NaCN erreicht, wobei der ATPGehalt durch Rotenon auf 55,2\% (6,3 \pm 1,9 nmol ATP / mg Protein) abgesenkt wurde, während $\mathrm{NaCN}$, vermutlich durch wiederholt aufgetretene SD-Episoden während der Inkubationszeit, den ATP-Gehalt der Hirnschnitte fast vollständig auf 1,5\% (0,2 $\pm 0,3 \mathrm{nmol}$ ATP / mg Protein) der Kontrolle reduzierte. Eine Kombination von Oligomycin und FCCP reduzierte den ATPGehalt signifikant auf $70,7 \%(8,1 \pm 1,6 \mathrm{nmol}$ ATP / mg Protein) und damit 
stärker als die einzelnen Wirkstoffe, die eine Reduktion auf 72,1\% bzw. 80,8\% (8,2 $\pm 2,7$ bzw. 9,2 $\pm 3,3 \mathrm{nmol}$ ATP / mg Protein) bewirkten.

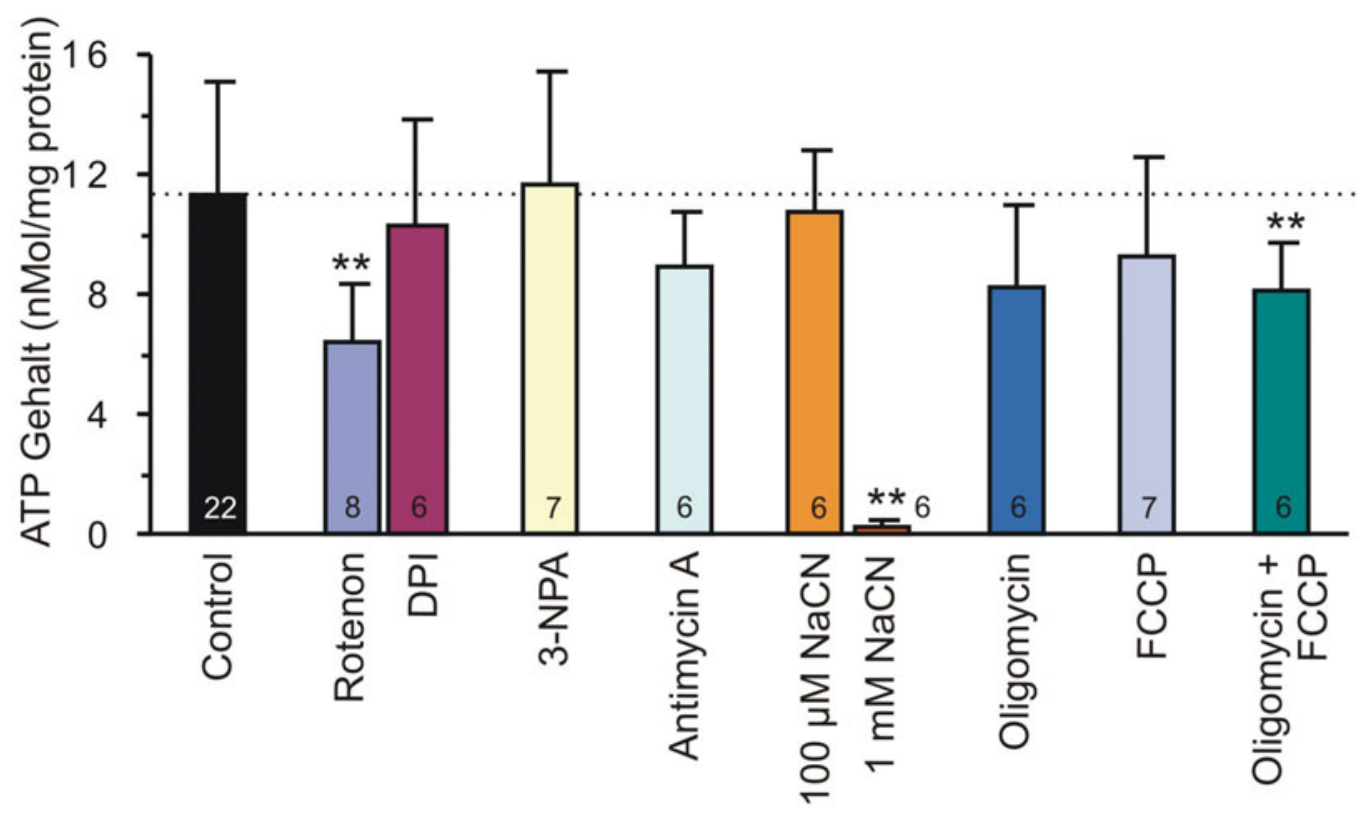

\section{Abb. 26: Zusammenfassung der Auswirkungen der verschiedenen Mitochondrienblocker auf den ATP-Gehalt}

Die Hirnschnitte wurden jeweils für 25 min mit den angegeben Pharmaka vorbehandelt und bezüglich des veränderten ATP-Gehaltes mit unbehandelten Kontrollschnitten verglichen. Die Anzahl der untersuchten Hirnschnitte ist an den jeweiligen Balken angegeben.

Eine Behandlung mit Antimycin A zeigte eine Tendenz zur Reduktion, was aber nicht für eine statistische Signifikanz ausreichte. $25 \mu \mathrm{M}$ DPI reduzierte den ATP-Gehalt auf 90\% (10,3 $\pm 3,5 \mathrm{nmol}$ ATP / mg Protein) und hatte so nur einen minimalen Effekt auf den ATP-Gehalt der untersuchten Hirnschnitte. Eine Behandlung mit $1 \mathrm{mM}$ 3-NPA führte sogar zu einem geringen Anstieg des ATP-Gehaltes auf 102\% (11,7 $\pm 3,8 \mathrm{nmol}$ ATP / mg Protein). 


\section{Identifizierung redoxsensitiver molekularer Angriffspunkte}

Die Membrangängigkeit von $\mathrm{H}_{2} \mathrm{O}_{2}$ und die Modulation der Hypoxie-Antwort weist auf eine mögliche Signalfunktion niedriger ROS Konzentrationen hin. Um die Ziele dieser Signalfunktion sowie die Angriffspunkte oxidativen Stresses durch erhöhte ROS Konzentrationen genauer zu charakterisieren, wurde die Wirkung von $\mathrm{H}_{2} \mathrm{O}_{2}$ in verschiedenen Konzentrationen auf einige Parameter der mitochondrialen und zellulären Funktion untersucht.

\section{Modulation der synaptischen Plastizität und Funktion durch $\mathrm{H}_{2} \mathrm{O}_{2}$}

Entgegen den Ergebnissen von Untersuchungen an Schaffer Kollateralen und CA1 Pyramidenzellsynapsen in Ratten und Meerschweinchen (Pellmar, 1986; Pellmar, 1995; Fowler, 1997) wurden bei den hier durchgeführten Untersuchungen an akuten hippokampalen Schnitten keine Beeinträchtigung der grundlegenden synaptischen Funktionen oder der paired pulse Faszilitierung, einem funktionellen Test der kurzzeitigen Plastizität (Zucker, 1989), festgestellt. Dabei ist zu beachten, dass in den Untersuchungen von Pellmar (1995) population spikes im stratum pyramidale ausgewertet wurden und nicht wie hier EPSPs im stratum radiatum.

Input output Kurve

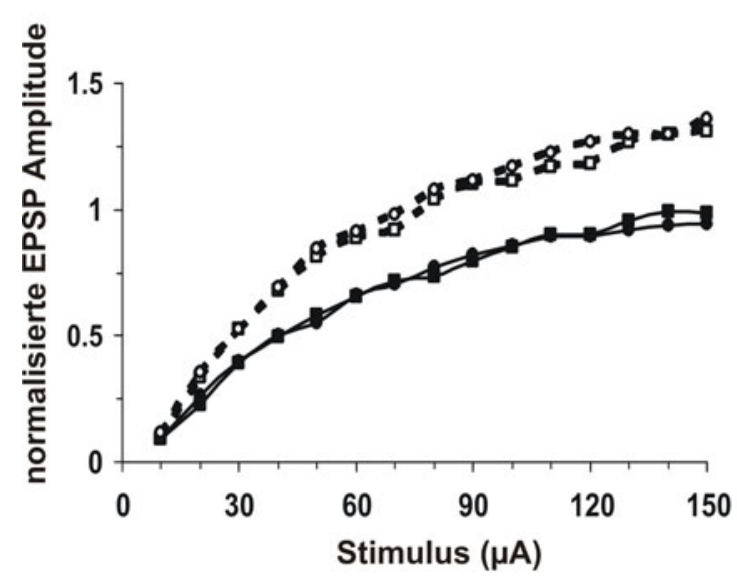

$$
\begin{array}{|ll|}
\hline \rightarrow-\text { Control-1 } & \overrightarrow{-}-\mathrm{H}_{2} \mathrm{O}_{2}-1 \\
-\square-\text { Control-2 } & -\circ-\mathrm{H}_{2} \mathrm{O}_{2}-2 \\
\hline
\end{array}
$$

Paired pulse

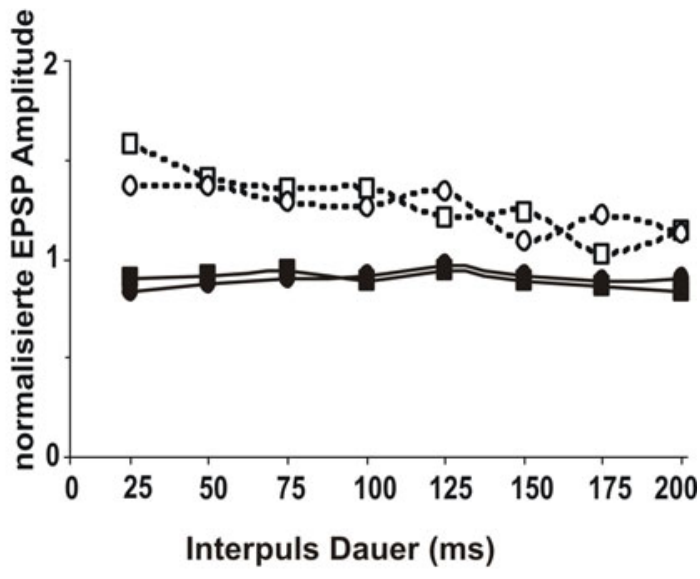

$$
\begin{aligned}
& \rightarrow-\text { Control-1 } \rightarrow \mathrm{H}_{2} \mathrm{O}_{2}-1 \\
& \text {..... Control-2 …. } \mathrm{H}_{2} \mathrm{O}_{2}-2
\end{aligned}
$$

Abb. 27: Die synaptische Funktion und Plastizität werden durch $\mathrm{H}_{2} \mathrm{O}_{2}$ nicht beeinflusst 
Orthodrom evozierte Feldpotentiale zeigen, dass bei Ableitungen im Bereich der Dendriten im S.R. selbst hohe $\mathrm{H}_{2} \mathrm{O}_{2}$ Konzentrationen (5 mM) keinen nennenswerten Einfluss auf grundlegende synaptische Funktionen oder die kurzzeitige Plastizität (paired pulse Faszilitierung) haben.

\section{Mitochondriale Ziele von extrazellulär appliziertem $\mathrm{H}_{2} \mathrm{O}_{2}$}

Eine externe Applikation von $\mathrm{H}_{2} \mathrm{O}_{2}$ führte in mit Rh123 $(6,25 \mu \mathrm{g} / \mathrm{ml} ; 30 \mathrm{~min})$ inkubierten akuten hippokampalen Schnitten zu einer schwachen Depolarisation der mitochondrialen Membran. Diese Wirkung auf $\Delta \psi m$ war dosisabhängig und reversibel, wobei die Erholung mit zunehmender Konzentration offenbar langsamer geschah (Abb. 28).

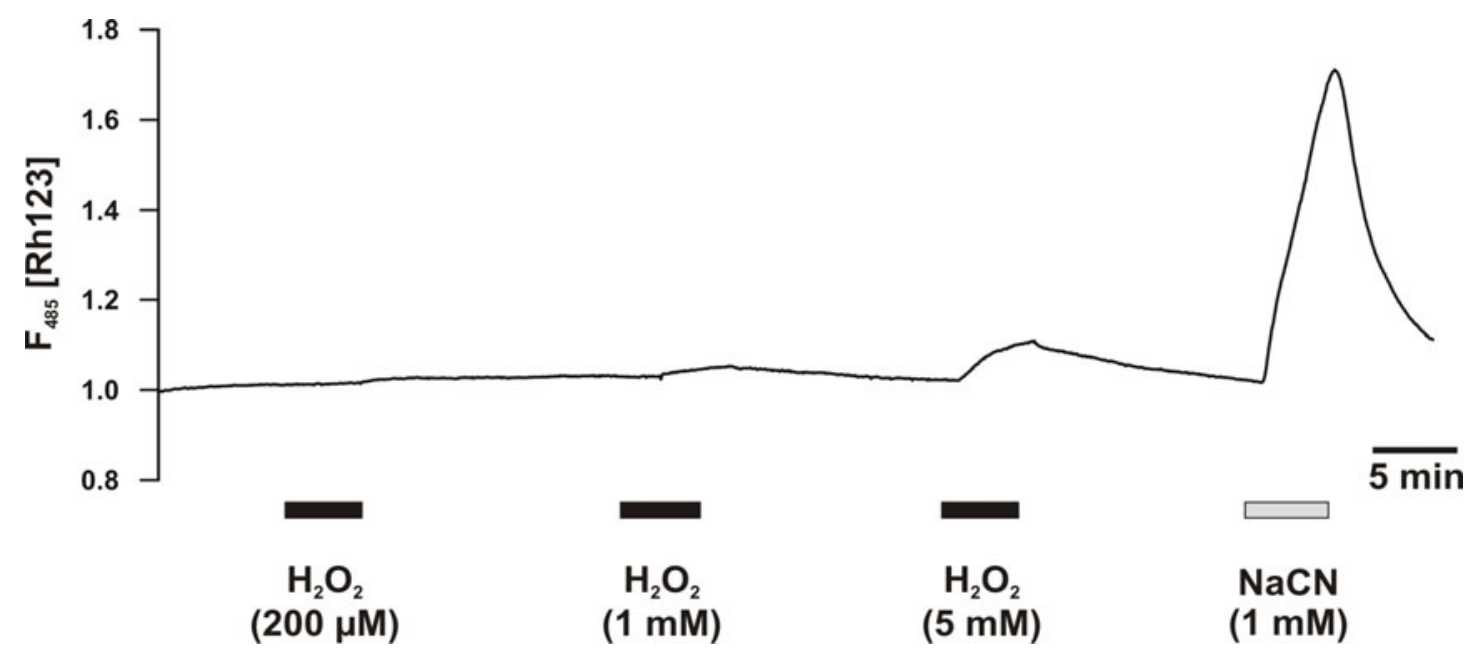

Abb. 28: Wirkung von $\mathrm{H}_{2} \mathrm{O}_{2}$ auf das mitochondriale Membranpotential

$\mathrm{H}_{2} \mathrm{O}_{2}$ führte in akuten hippokampalen Hirnschnitten zu einer schwachen dosisabhängigen reversiblen Depolarisation der Mitochondrien.

Der mitochondriale Metabolismus, angezeigt durch die Veränderung der Autofluoreszenz von $\mathrm{NADH}$ und $\mathrm{FAD}$, wurde durch steigende $\mathrm{H}_{2} \mathrm{O}_{2}$ Konzentrationen offenbar nur unwesentlich beeinflusst. Es kam zu einer dosisabhängigen Verringerung der NADH Fluoreszenz, während sich die FAD Fluoreszenz gegensätzlich verhielt. 

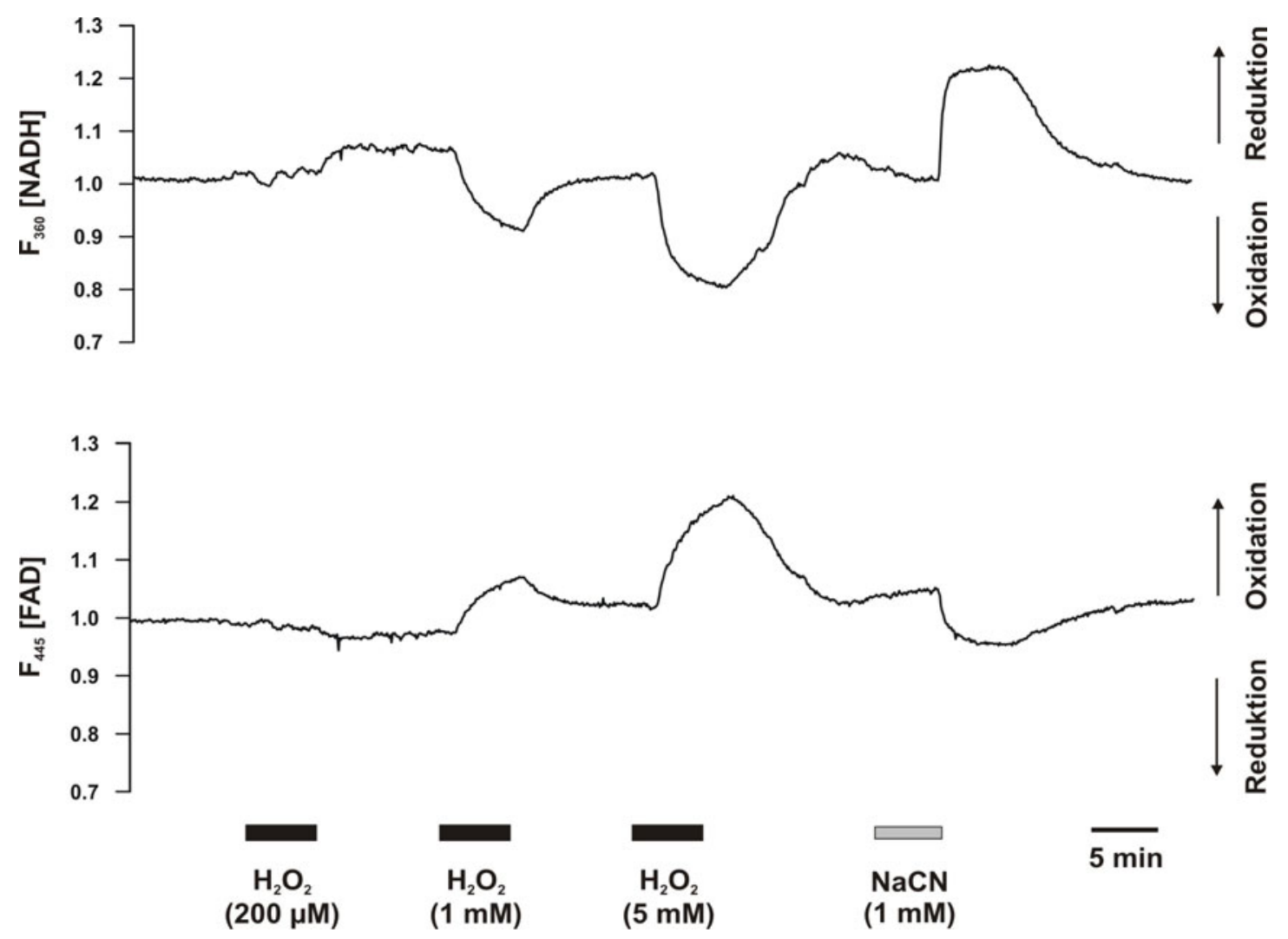

Abb. 29: Auswirkung von $\mathrm{H}_{2} \mathrm{O}_{2}$ auf den mitochondrialen Metabolismus

$\mathrm{H}_{2} \mathrm{O}_{2}$ führte zu einer dosisabhängigen reversiblen Verringerung der Fluoreszenz von NADH. FAD zeigte eine gegensätzliche Reaktion.

Da Mitochondrien auf $\mathrm{H}_{2} \mathrm{O}_{2}$ mit einer Depolarisation reagieren, sollte der NADH-Spiegel steigen und FAD absinken. Da das Gegenteil eintrat, scheinen $\mathrm{NADH}$ und FAD offenbar direkt durch $\mathrm{H}_{2} \mathrm{O}_{2}$ oxidiert zu werden.

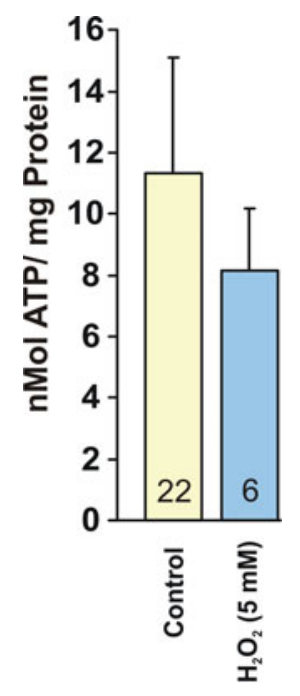

Abb. 30: Wirkung von $\mathrm{H}_{2} \mathrm{O}_{2}$ auf den ATP-Gehalt

Akute hippokampale Hirnschnitte wurden 25 min mit $5 \mathrm{mM} \mathrm{H}_{2} \mathrm{O}_{2}$ behandelt. Es zeigte sich eine Tendenz zur Reduzierung von intrazellulärem ATP, die aber nicht ausreichte, um statistische Signifikanz zu erreichen $(P=0,058)$. 
Eine Behandlung von akuten hippokampalen Hirnschnitten mit einer hohen $\mathrm{H}_{2} \mathrm{O}_{2}$-Konzentration (5 mM, $25 \mathrm{~min}$ ) führte nur zu einem Absinken des ATPGehaltes auf $71,9 \%$ der Kontrolle $(8,2 \pm 2,0 \mathrm{nmol}$ ATP / mg Protein) $(n=6)$.

\section{Messung des intrazellulären Calciums mit Fluo-3}

Um auch die Effekte von $\mathrm{H}_{2} \mathrm{O}_{2}$ auf intrazelluläre Signalwege zu testen, wurden optische Messungen der intrazellulären $\mathrm{Ca}^{2+}$ Konzentration $\left(\left[\mathrm{Ca}^{2+}\right]_{i}\right)$ durchgeführt.

Kultivierte hippokampale Neurone wurden mit dem Calcium Indikator Fluo-3 (5 $\mu \mathrm{M}$ ) beladen und mit ansteigenden $\mathrm{H}_{2} \mathrm{O}_{2}$ Konzentrationen behandelt. Das führte in zu einem Anstieg von $\left[\mathrm{Ca}^{2+}\right]_{\mathrm{i}}$ (Abb. 31). Der Anstieg und die Erholung auf das Ausgangsniveau verliefen langsam, waren von der gegebenen Dosis abhängig und konnten bei niedrigen $\mathrm{H}_{2} \mathrm{O}_{2}$-Dosen ohne signifikante Änderungen mehrfach wiederholt werden. Bei der Zugabe von $200 \mu \mathrm{M}, 1 \mathrm{mM}$ und $5 \mathrm{mM} \mathrm{H}_{2} \mathrm{O}_{2}$ erhöhte sich die Fluoreszenz um 20,4 $\pm 6,6 \%(\mathrm{n}=15)$; $28,2 \pm 9,1 \%(n=17)$ bzw. $26,6 \pm 15,7 \%(n=17)$.

Dieser Anstieg von $\left[\mathrm{Ca}^{2+}\right]_{i}$ blieb in $\mathrm{Ca}^{2+}$-freiem ACSF erhalten (Abb. 31). Die Zugabe von $200 \mu \mathrm{M}, 1 \mathrm{mM}$ und $5 \mathrm{mM} \mathrm{H}_{2} \mathrm{O}_{2}$ führten unter diesen Bedingungen zu Steigerungen der Fluo-3 Fluoreszenz von 14,8 $\pm 7,8 \%$; $35,3 \pm 13,3 \%$ bzw. $30,9 \pm 15,9 \%(n=41)$. 

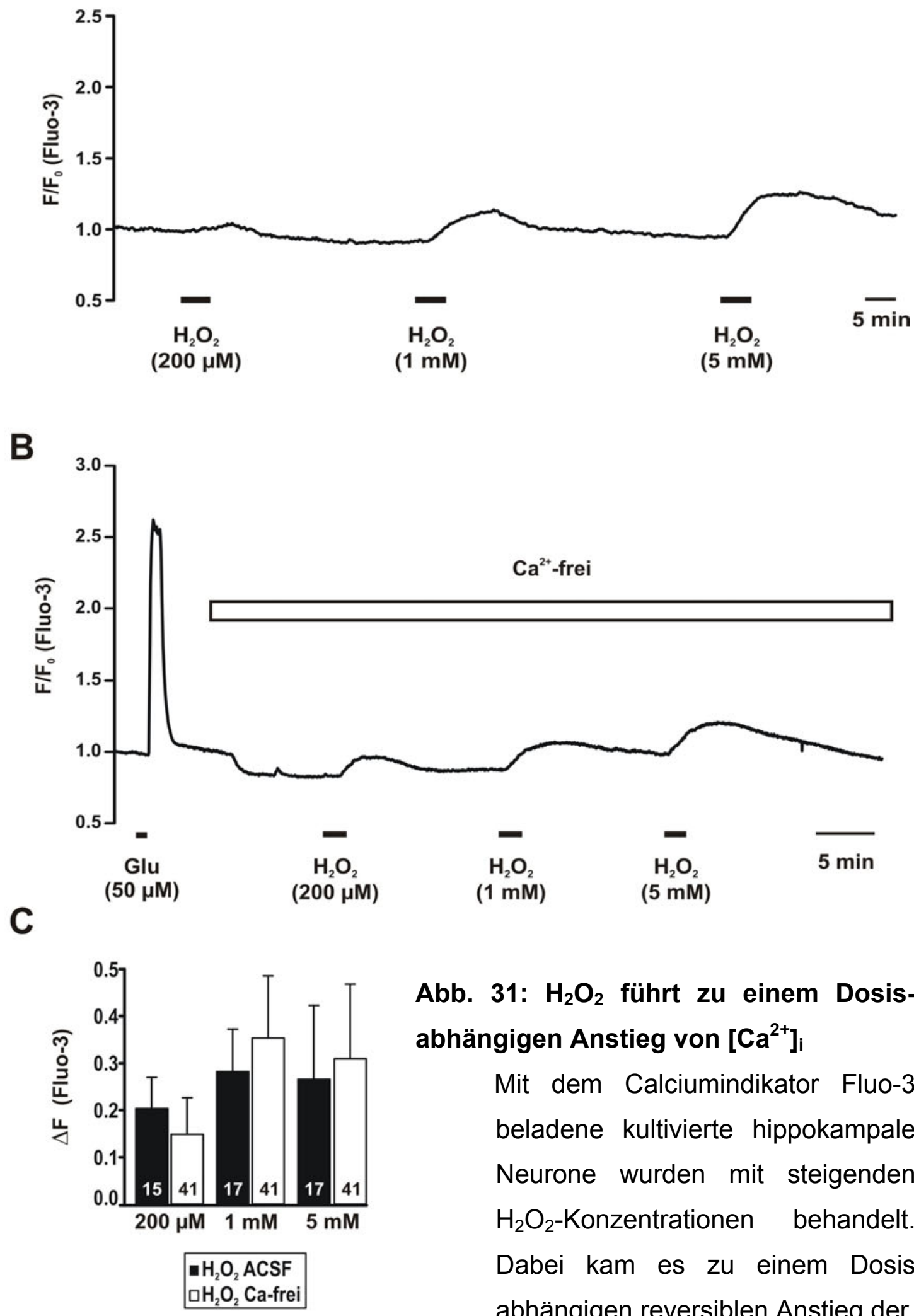

Abb. 31: $\mathrm{H}_{2} \mathrm{O}_{2}$ führt zu einem Dosisabhängigen Anstieg von $\left[\mathrm{Ca}^{2+}\right]_{i}$

Mit dem Calciumindikator Fluo-3 beladene kultivierte hippokampale Neurone wurden mit steigenden $\mathrm{H}_{2} \mathrm{O}_{2}$-Konzentrationen behandelt. Dabei kam es zu einem Dosis abhängigen reversiblen Anstieg der 
intrazellulären Calcium-Konzentration (A). Dieser Anstieg konnte auch in $\mathrm{Ca}^{2+}$-freiem Medium beobachtet werden (B), was auf intrazelluläre Quellen schließen lässt. Die Reaktionen der Zellen auf die jeweiligen $\mathrm{H}_{2} \mathrm{O}_{2}$-Konzentrationen in normalem und $\mathrm{Ca}^{2+}$-freiem ACSF unterschieden sich nicht signifikant voneinander (C). Die Zahlenwerte an den Balken geben die Anzahl der durchgeführten Versuche an.

Die gemessenen Veränderungen des Calcium-Spiegels in normalen und $\mathrm{Ca}^{2+}$-freiem ACSF unterschieden sich nicht signifikant voneinander (Abb. 31, C). Das führte zu dem Schluss, dass die Quelle des $\mathrm{H}_{2} \mathrm{O}_{2}$-induzierten Anstiegs des $\left[\mathrm{Ca}^{2+}\right]_{i}$ intrazelluläre Speicher sein müssen.

Zur genaueren Identifizierung der intrazellulären $\mathrm{Ca}^{2+}$ Speicher wurden die Zellen vor der Zugabe $\mathrm{H}_{2} \mathrm{O}_{2}$ mit verschiedenen Modulatoren vorbehandelt. Eine Behandlung der Zellen mit $1 \mu \mathrm{M}$ FCCP führte durch den Zusammenbruch des mitochondrialen Membranpotentials zu einer Freisetzung von $\mathrm{Ca}^{2+}$ aus den Mitochondrien (Balakrishnan, 2006) und somit zu einem Anstieg von $\left[\mathrm{Ca}^{2+}\right]$, was aber keinen Einfluss auf das Ausmaß des Anstiegs von $\left[\mathrm{Ca}^{2+}\right]_{i}$ bei einer gleichzeitig erfolgten Zugabe von $\mathrm{H}_{2} \mathrm{O}_{2}$ hatte $(95,9 \pm 30,6 \%$ der Kontrolle; $n=6)$.

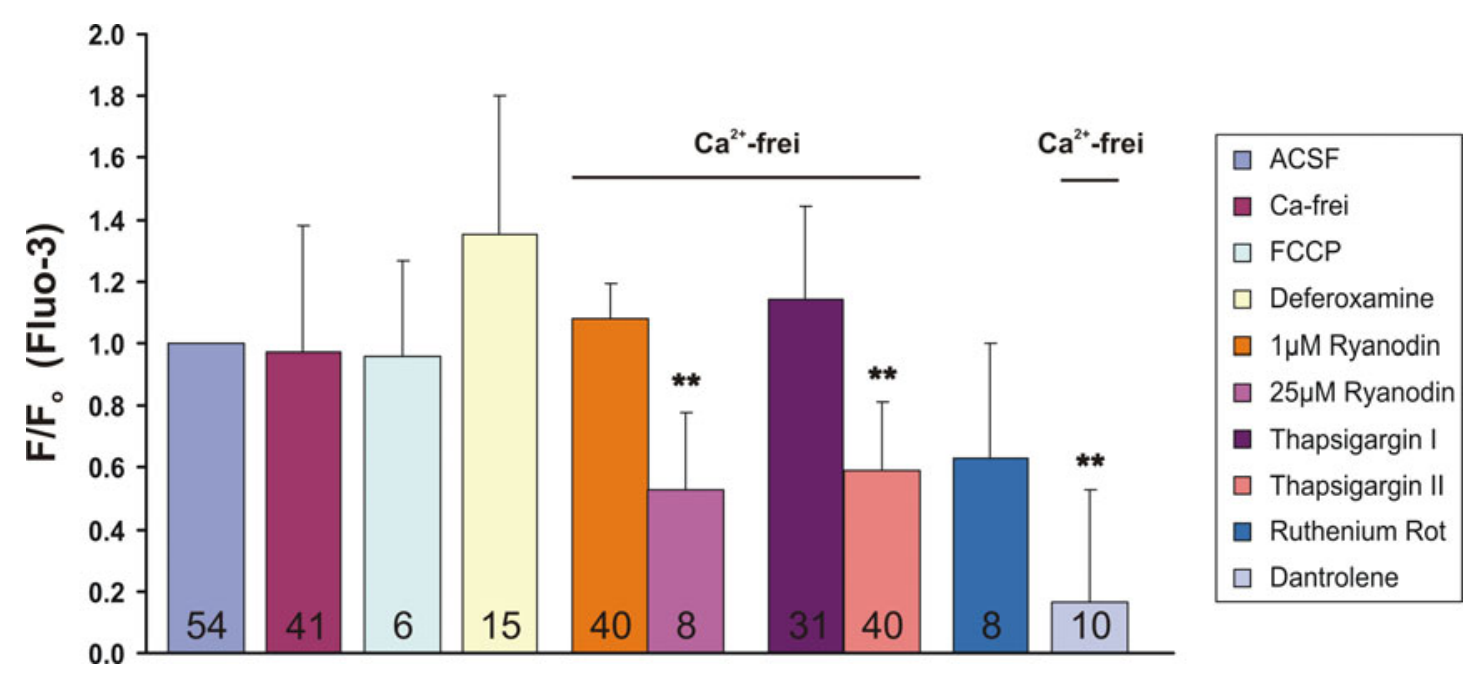

Abb. 32: $\mathrm{H}_{2} \mathrm{O}_{2}$ aktiviert Ryanodin Rezeptoren

Die durch $\mathrm{H}_{2} \mathrm{O}_{2}$ hervorgerufenen Änderungen im intrazellularen Calcium-Spiegel konnten durch die verschiedenen Modulatoren der intrazellulären $\mathrm{Ca}^{2+}$-Speicher modifiziert werden. Mit dem Calciumindikator Fluo-3 beladene kultivierte hippokampale Neurone 
wurden in Anwesenheit der verschiedenen Modulatoren der intrazellulären $\mathrm{Ca}^{2+}$-Speicher mit $200 \mu \mathrm{M} \quad \mathrm{H}_{2} \mathrm{O}_{2}$ behandelt. Das pharmakologische Profil der durch $\mathrm{H}_{2} \mathrm{O}_{2}$ induzierten $\mathrm{Ca}^{2+}$-Transienten lässt auf eine Aktivierung der Ryanodin-Rezeptoren und eine Abgabe von $\mathrm{Ca}^{2+}$ aus dem Endoplasmatischen Retikulum (ER) schließen.

Durch die Behandlung der Zellen mit dem Eisenchelator Deferoxamin $(500 \mu M)$ intensivierte sich die Fluo-3 Fluoreszenz auf 135,2 $\pm 44,8 \%(n=15)$, was darauf hindeutet, dass ein Teil des Peroxids in der eisenkatalysierten Fenton-Reaktion zu Hydroxyl Radikalen reagiert und sich so die effektive $\mathrm{H}_{2} \mathrm{O}_{2}$ Konzentration vermindert.

In niedrigen Konzentrationen $(<20 \mu \mathrm{M})$ wirkt Ryanodin als Agonist der Ryanodin-gesteuerten $\mathrm{Ca}^{2+}$-Kanäle im ER, wodurch die Kanäle im offenen Zustand gehalten werden. Bei höheren Konzentrationen werden diese Kanäle durch Ryanodin blockiert (Bidasee et al., 1995). Der durch $\mathrm{H}_{2} \mathrm{O}_{2}$ induzierte Anstieg der Fluo-3 Fluoreszenz erhöhte sich in Anwesenheit von $1 \mu \mathrm{M}$ Ryanodin auf 107,8 $\pm 11,7 \%(n=40)$ und verminderte sich bei $25 \mu \mathrm{M}$ Ryanodin auf $52,8 \pm 25,1 \%(n=8)$.

Unter der Einwirkung von Thapsigargin, einem Inhibitor der ATP-abhängigen $\mathrm{Ca}^{2+}$-Pumpe des sarkoplasmatischen bzw. endoplasmatischen Retikulums (SERCA) gab es bei einer ersten Zugabe von $\mathrm{H}_{2} \mathrm{O}_{2}$ keine signifikante Änderung von $\left[\mathrm{Ca}^{2+}\right]_{i}(113,9 \pm 30,3 \% ; n=31)$. Bei einer zweiten Zugabe von $\mathrm{H}_{2} \mathrm{O}_{2}$ wurde die Intensität des $\mathrm{Ca}^{2+}$-Transienten signifikant auf $58,9 \pm 22,3 \%$ vermindert $(n=40)$, was durch die Blockade der Wiederaufnahme von $\mathrm{Ca}^{2+}$ in das ER durch Thapsigargin und die somit entleerten Speicher erklärt werden kann (Kostyuk und Verkhratsky, 1994). Ruthenium Rot, ein Blocker der Ryanodin-sensitiven $\mathrm{Ca}^{2+}$-Kanäle sowie der mitochondrialen $\mathrm{Ca}^{2+}$-Aufnahme und Abgabe, reduzierte die Calcium-Signale auf $62,9 \pm 37,2 \%(n=8)$. Die stärkste Reduktion der $\mathrm{Ca}^{2+}$-induzierten Transienten wurde durch Dantrolen hervorgerufen $(16,6 \pm 37,2 \% ; n=8)$. 


\section{Intrazelluläre Ableitungen aus Gliazellen}

Während den Messungen an Zellkulturen zeigte sich, das DTT (2 mM) bei Gliazellen ein Zurückziehen der Ausläufer bewirkt (Abb. 33). Bei neuronalen Zellen lies sich nichts Vergleichbares feststellen. Der Effekt trat 7-10 min nach DTT Zugabe ein, und innerhalb von 35-40 min hatten die Zellen alle Ausläufer eingezogen und waren fast vollständig abgekugelt. Um eine Beeinträchtigung der Funktion der Gliazellen durch DTT zu verifizieren, wurden außerdem intrazelluläre Ableitungen mit scharfen Elektroden an Gliazellen der CA1 Region in akuten hippokampalen Schnitten in einer Submersionskammer durchgeführt. Das mittlere Membranpotential der Zellen betrug -89,7 $\pm 5,6 \mathrm{mV}$ $(n=6)$. Der Eingangswiderstand der Zellen war zu niedrig, um verlässlich gemessen zu werden. Als Antwort auf die DTT (2 mM) Zugabe zeigten die Gliazellen eine langsame aber gleichmäßige Depolarisation, welche im Mittel nach 15-20 $\mathrm{min}$ bei 19,2 \pm 7,5 $\mathrm{mV}$ lag. 
A

Control

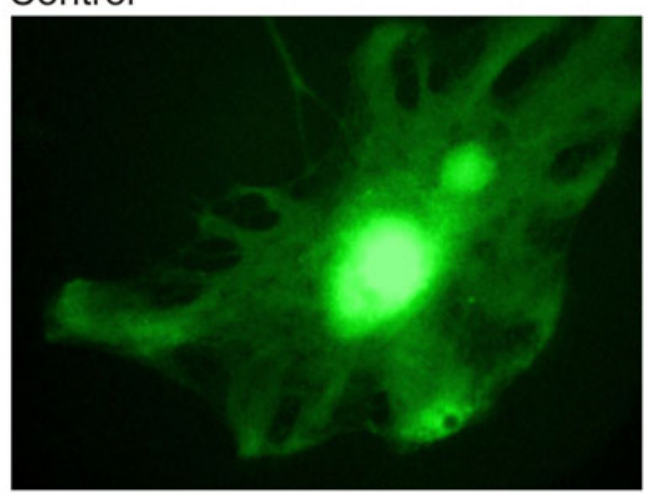

$20 \min$ DTT

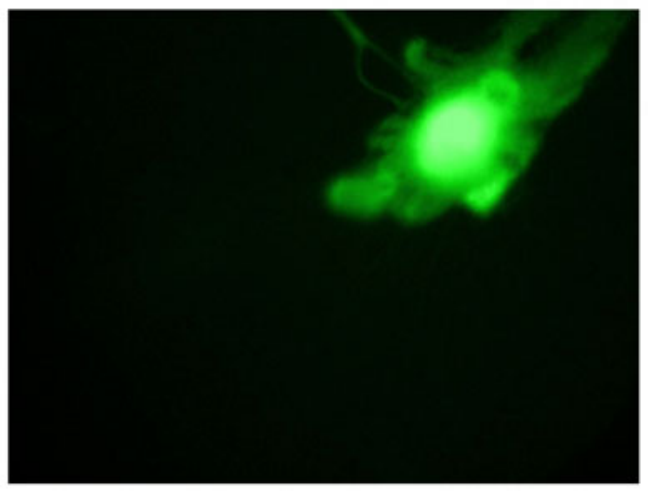

$10 \min$ DTT

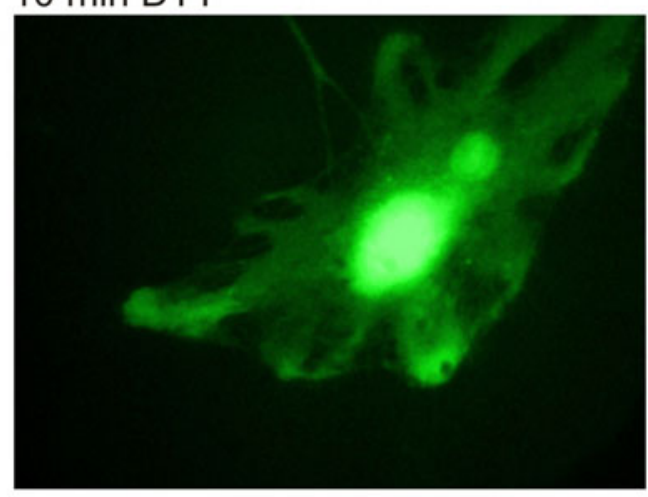

30 min DTT

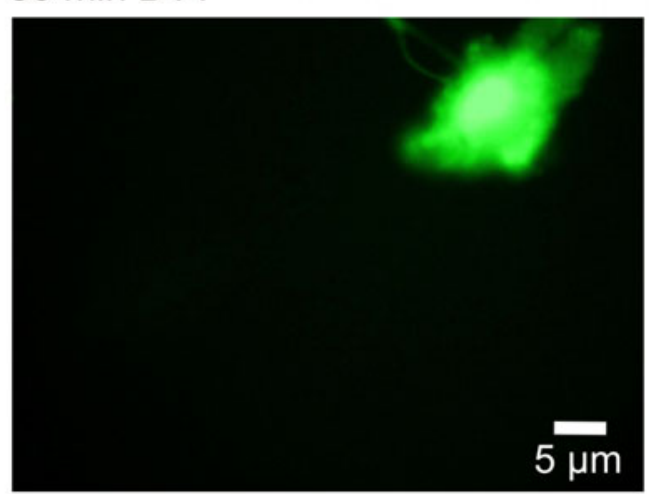

B

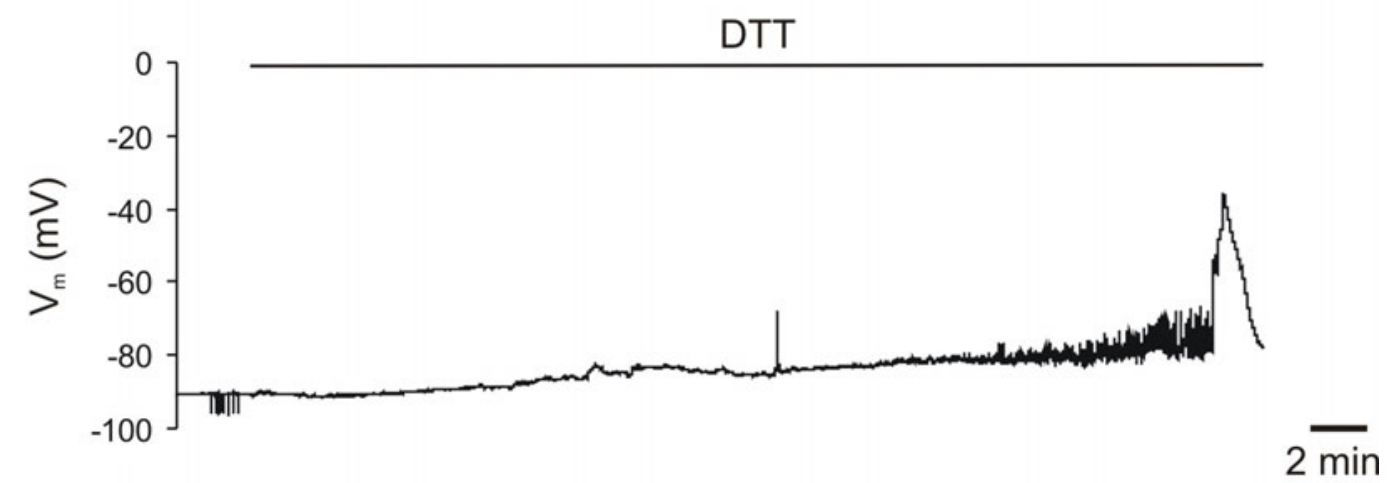

Abb. 33: Gliazellen depolarisieren unter DTT Einfluss und ziehen ihre Ausläufer zurück

Gliazellen in einer Mischkultur aus hippokampalen Neuronen und Gliazellen wurden mit Fluo-3 (5 $\mu \mathrm{M}, 30 \mathrm{~min}$ ) angefärbt und 2 mM DTT ausgesetzt. Als Reaktion begannen sie kurz nach der DTT Zugabe ihre Ausläufer zurückzuziehen (A) und hatten sich nach 30-40 min fast vollständig abgekugelt. Intrazelluläre Ableitungen mit scharfen Elektroden aus Gliazellen in akuten hippokampalen Hirnschnitten zeigten einem langsamen Verlust des Membranpotentials der 
Gliazellen. Zusätzlich kam es nach 35 min zu einer Depolarisation auf $-20 \mathrm{mV}$, was vermutlich auf eine spontane SD durch DTT zurückzuführen war (B).

Die durch die DTT Zugabe hervorgerufenen spontanen synchronisierten Spike-Entladungen von Neuronen führten durch den Anstieg des extrazellulären $\mathrm{K}^{+}$in Gliazellen zu einer langsamen transienten Depolarisation von $\leq 20 \mathrm{mV}$. In der Regel führte eine andauernde DTT Gabe nach 30-40 min zur Auslösung einer spontanen SD, wobei es in den betroffenen Zellen zu der charakteristischen massiven Depolarisation kam. 


\section{Diskussion}

Im Rahmen dieser Arbeit wurden die Effekte von oxidativem Stress auf Hypoxie-Antworten, mitochondriale Funktion, Redox-Status und CalciumSpiegel an akuten hippokampalen Schnitten sowie primären gemischten Neuron-Glia Zellkulturen untersucht.

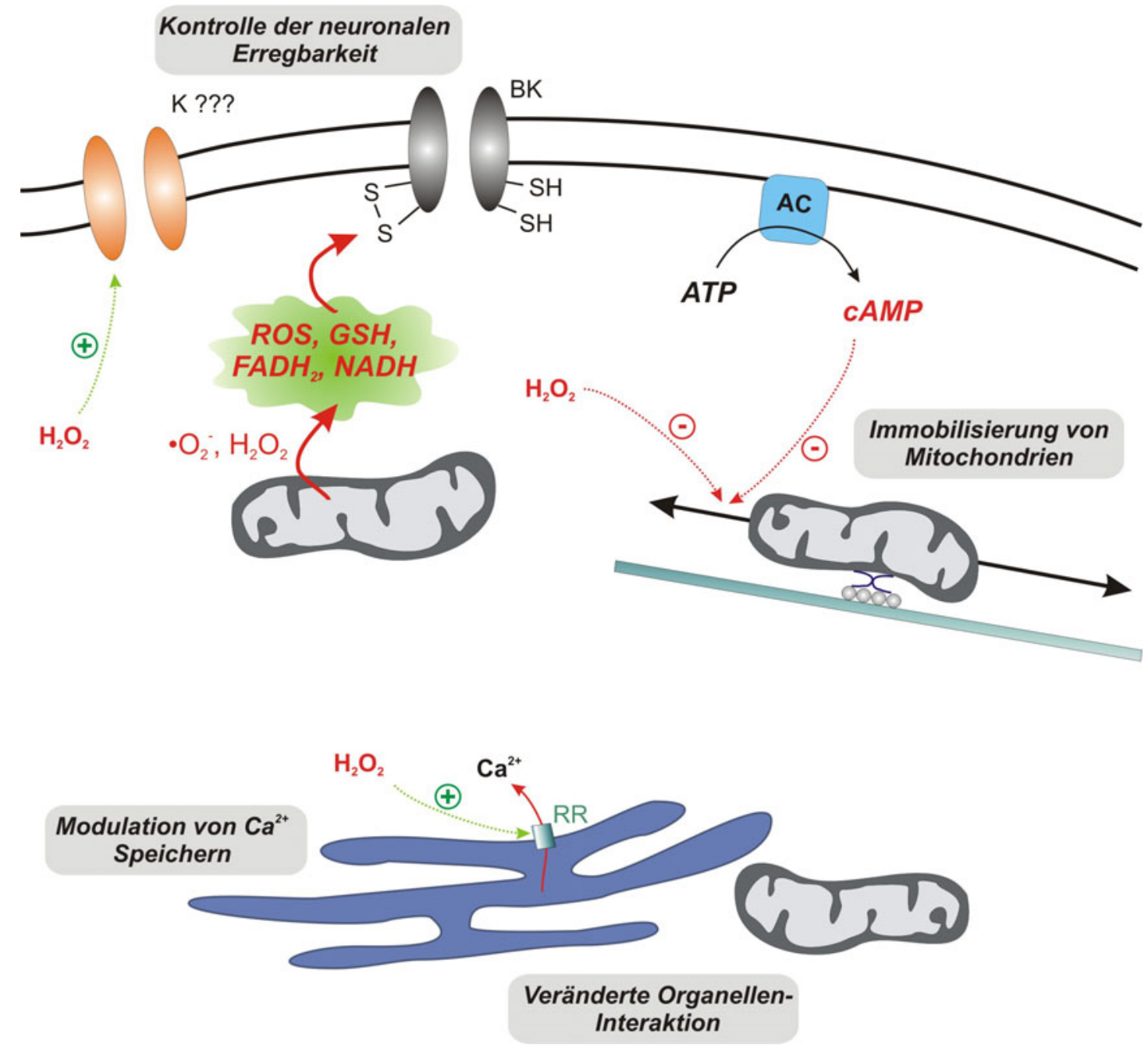

\section{Abb. 34: Intrazelluläre Redox-Targets}

Es konnte gezeigt werden, das $\mathrm{H}_{2} \mathrm{O}_{2}$ intrazelluläre $\mathrm{Ca}^{2+}$ Speicher moduliert, die neuronale Erregbarkeit über eine Steigerung der $\mathrm{K}^{+}$Leitfähigkeit kontrolliert, den Transport von Mitochondrien stoppt (Gerich und Müller, unveröffentlichte Daten), den cytosolischen RedoxStatus durch eine Oxidation von NADH und $\mathrm{FADH}_{2}$ moduliert und den zellulären ATP-Gehalt reduziert. 
Es ist zu bedenken, dass sich der Redox-Status aus verschiedenen Komponenten zusammensetzt. Im Rahmen dieser Arbeit wurden die Verhältnisse der Wasserstoff Carrier NADH/NAD und $\mathrm{FADH}_{2} / \mathrm{FAD}$ und der ROS Gehalt untersucht. Auf weitere Faktoren wie z.B. Reaktive StickstoffSpezies (NOS) oder das Verhältnis von reduziertem zu oxidiertem Glutathion konnte aber im Rahmen dieser Arbeit nicht näher eingegangen werden. Des Weiteren können voraussichtlich auch noch weitere redoxsensitive Targets identifiziert werden, was zu einer genaueren Aufklärung der beteiligten Mechanismen führen wird.

\section{Modulation der Hypoxie-Antwort durch $\mathrm{H}_{2} \mathrm{O}_{2}$}

Wie schon zuvor gezeigt werden konnte (Hepp et al., 2005), kann eine Hypoxie-Antwort durch eine Modulation der Sulfhydrylgruppen beeinflusst werden. Eine Oxidation durch DTNB verzögert das Auftreten einer HSD, während eine Reduktion mittels DTT die HSD beschleunigt und ggf. sogar eine spontane SD auslöst. Die Mechanismen, die in einer durch DTT hervorgerufenen Beschleunigung einer HSD wirken, sind noch nicht ausreichend untersucht worden, um sie vollständig zu charakterisieren, es konnte aber gezeigt werden, dass die Verzögerung der HSD durch DTNB über die Aktivierung von calciumabhängigen Kaliumkanälen mit großer Leitfähigkeit (BK-Kanäle) bewirkt wird (Hepp et al., 2005).

Eine durch Oxidation gesteuerte neuroprotektive Wirkung ist eher ungewöhnlich und unerwartet, da die Neurone des Zentralnervensystems durch die hohe metabolische Aktivität, einen hohen Anteil an mehrfach ungesättigten Fettsäuren (Coyle und Puttfarcken, 1993), nur schwach ausgeprägten Schutzmechanismen und in einigen Hirnregionen durch einen hohen Eisengehalt gegenüber oxidativen Stress besonders empfindlich sind (Halliwell, 1992). Oxidativer Stress gilt als Auslöser oder Begleiterscheinung einiger neurodegenerativen Erkrankungen wie unter anderem Alzheimer (Zhu et al., 2007), Chorea Huntington (Trushina und McMurray, 2007) und Parkinson (Nakabeppu et al., 2007).

Der Effekt von DTNB ließ sich auch durch die extrazelluläre Applikation von $\mathrm{H}_{2} \mathrm{O}_{2}$ erzielen, wobei selbst bei hohen Konzentrationen die Amplitude der 
HSD unverändert blieb und keine funktionelle Beeinträchtigung der Hirnschnitte zu erkennen war (Abb. 13). Umso bedeutender erscheint die Verzögerung der HSD durch Sulfhydryloxidanten, da hier eine Schädigung des Hippokampus als Ursache ausgeschlossen werden kann. Allerdings wirken oxidierende Bedingungen nicht grundsätzlich verzögernd auf das Auftreten einer HSD. Eine Stimulation der endogenen Superoxid-Produktion durch Xanthin/Xanthinoxidase hatte jedoch den gegenteiligen Effekt und beschleunigte vielmehr das Auftreten einer HSD (Abb. 13).

Eine Inhibition der mitochondrialen Funktion erhöhte die Anfälligkeit hippokampaler Schnitte gegenüber Hypoxie, was sich durch eine Verkürzung der Latenz einer HSD zeigte. Der Einfluss der Blockade der Atmungskette bzw. der Mitochondrien variierte stark zwischen den einzelnen Ansatzpunkten der Blocker. Durch hochkonzentriertes FCCP $(10 \mu \mathrm{M}), \mathrm{NaCN}(1 \mathrm{mM})$ und Azid (2 mM) ließ sich selbst bei fortgeführter Sauerstoffversorgung eine normoxische SD auslösen (Abb. 16). Durch die Messung des mitochondrialen Metabolismus über die Autofluoreszenz von NADH und FAD, die Messung des mitochondrialen Membranpotentials (Rh123 Fluoreszenz) und des ATPGehaltes in akuten hippokampalen Schnitten konnte eine erfolgreiche Modulation der Mitochondrienfunktion durch die mitochondrialen Blocker eindeutig nachgewiesen werden. Keiner der Blocker verringerte die Amplitude der HSD maßgeblich. Das lässt darauf schließen, dass die benutzten Blocker über den Untersuchungszeitraum (25 min Einwirkzeit und 3-8 Minuten Hypoxie) keinen negativen Einfluss auf die Vitalität der Hirnschnitte und die Synchronisation der massiven Depolarisation hatten.

\section{Einfluss der mitochondrialen Inhibition auf den zellulären}

\section{ATP-Gehalt}

Eine Inhibition der mitochondrialen Atmungskette in einem beliebigen Komplex hat Auswirkungen auf die Funktion der gesamten Kaskade und somit auch auf den mitochondrialen Metabolismus, ROS-Produktion sowie ATP-Produktion und Gehalt der betroffenen Zellen (Nicholls und Budd, 2000; Adam-Vizi, 2005). Dabei kann eine Inhibition von Komplex I oder II weitgehend durch den jeweils anderen kompensiert werden, was bei einer 
Inhibition von Komplex III und IV nicht möglich ist. Selbst wenn bei einer Inhibition von Komplex I durch z.B. Rotenon die Verwendung von NADH als Elektronenquelle verhindert wird, können noch in Komplex II Elektronen von $\mathrm{FADH}_{2}$ in die Atmungskette eingebracht werden. Umgekehrt bleibt die Funktion von Komplex I durch eine Blockade von Komplex II durch z.B. 3-NPA unbeeinflusst. Dabei ist $z u$ beachten, dass eine Blockade von Komplex I größere Auswirkungen hat. Bei der vollständigen Oxidation eines Moleküls Glucose werden $10 \mathrm{NADH}$ gebildet, aber nur $2 \mathrm{FADH}_{2}$ (Berg et al., 2003). Es steht also weitaus mehr NADH zur Verfügung als $\mathrm{FADH}_{2} . \mathrm{Da}$ Komplex I als Protonenpumpe dient, wird bei der Verwendung von NADH als Elektronendonor potentiell auch mehr ATP gebildet. Dies könnte erklären, warum Rotenon das Auftreten einer HSD beschleunigt, zu einer stärkeren Depolarisation der Mitochondrien führt und die zellulären NADH und FAD Konzentrationen stärker beeinflusst als 3-NPA. Die Verlängerte Dauer einer HSD in der Anwesenheit von 3-NPA deutet darauf hin, dass die Erholung während der Reoxygenierung durch 3-NPA gestört wird. Der genaue Mechanismus, der diesem Effekt zugrunde liegt, ist noch nicht völlig geklärt. Eine mögliche Erklärung ist, dass die Effekte von Rotenon zumindest teilweise reversibel sind (Läuger et al., 1944), 3-NPA jedoch irreversibel wirkt (Coles et al., 1979). Des Weiteren könnten auch sekundäre Effekte von 3-NPA beteiligt sein.

Das Auftreten einer HSD wurde durch den Entkoppler FCCP sowie jene Blocker beschleunigt, die auf die Komplexe I, III und IV der Atmungskette wirken, welche als Protonenpumpen fungieren. Die Wirkstoffe FCCP, Rotenon, AMC und Cyanid greifen so in die Aufrechterhaltung des Protonengradienten und damit potentiell auch in die ATP-Produktion ein. Ein gesteigerter ATP-Verbrauch bzw. ein niedriger ATP-Gehalt im betroffenen Gewebe (Hansen, 1985) kann jedoch als alleiniger Auslöser einer HSD ausgeschlossen werden. Ein verringerter ATP-Gehalt begünstigt zwar das Auftreten einer HSD (Allen et al., 2005) und im Verlauf einer HSD sinkt der ATP-Spiegel im Gewebe deutlich (Lipton, 1999), da durch den Sauerstoffmangel kein neues ATP gebildet werden kann und das vorhandene schnell verbraucht wird. 
Bei den hier gezeigten Versuchen hatten die benutzten Blocker bis auf $1 \mathrm{mM}$ Cyanid nur einen geringen Effekt auf den ATP-Gehalt (Abb. 26). Der ATPSpiegel wurde in diesen Versuchen zu dem Zeitpunkt gemessen, in dem eine HSD ausgelöst worden wäre, und die stärkste Verminderung, durch $20 \mu \mathrm{M}$ Rotenon, senkte den ATP-Gehalt auf 55\%. Einen klaren Zusammenhang zwischen Wirkung auf den ATP-Gehalt und verfrühter Hypoxie-Reaktion konnte dennoch nicht beobachtet werden. So beschleunigte $100 \mu \mathrm{M}$ Cyanid das Auftreten einer HSD am deutlichsten, hatte aber praktisch keinen Effekt auf den ATP-Gehalt der Hirnschnitte (Abb. 15 und 26). Oligomycin (10 $\mu \mathrm{g} / \mathrm{ml})$ zeigte eine deutliche Tendenz, den ATP-Spiegel zu verringern, hatte jedoch keinen Einfluss auf die Latenz einer HSD (Abb. 14). Die Ausnahme bildete $1 \mathrm{mM}$ Cyanid, das zu einem fast vollständigen Verbrauch von ATP führte (Abb. 26). Diese völlige ATP-Verarmung ist aber offensichtlich durch spontan auftretende SD-Episoden während der Einwirkzeit hervorgerufen worden, die im Mittel bereits nach 4 Minuten Cyanid auftraten (Gerich et al., 2006). Die These, dass vermehrter ATP-Verbrauch der Auslöser einer HSD ist, wird auch dadurch entkräftet, dass FCCP, Rotenon, DPI und AMC auch die Erholung des Gewebes nach einer Reoxygenierung beschleunigen. Dieser Vorgang benötigt ATP zur Wiederherstellung des lonengleichgewichts der Zellen durch aktiven Transport, vor allem durch die $\mathrm{Na}^{+} / \mathrm{K}^{+}$-ATPase (Rosenthal und Sick, 1992). Ein vollständiger Verbrauch von ATP würde daher zu einer stark verlangsamten oder einer ausbleibenden Erholung der Hirnschnitte führen. Dies konnte bei spontan auftretenden SDs in der Anwesenheit von hohen FCCP- und Cyanid-Konzentrationen sowie einer HSD, bei der die Sauerstoffzufuhr nach der regulären Zeit noch weitere 5 Minuten unterbrochen blieb, beobachtet werden.

Der Zusammenbruch des Protonengradienten über die Mitochondrienmembran durch den Einsatz von FCCP führt dazu, die $\mathrm{F}_{0} \mathrm{~F}_{1}$-ATPase in dem Versuch, das Membranpotential stabil zu halten, ihre Arbeitsrichtung umkehrt und ATP verbraucht. Die kombinierte Zugabe von Oligomycin und FCCP stoppt diesen Effekt (Sipos et al., 2003). Da die Verkürzung der Latenz einer HSD mit FCCP Einwirkung auch bei gleichzeitiger Oligomycin Zugabe bestehen blieb, kann eine Auswirkung durch 
einen erhöhten mitochondrialen ATP Verbrauch durch die umgekehrt laufende $\mathrm{F}_{0} \mathrm{~F}_{1}$-ATPase ausgeschlossen werden (Abb. 14).

In den hier durchgeführten Versuchen zum ATP-Gehalt akuter hippokampaler Hirnschnitte wurde die gesamte hippokampale Region untersucht. Eine Unterscheidung zwischen den unterschiedlichen hippokampalen Arealen fand nicht statt. Außerdem konnte mit unserem Versuchsansatz nicht zwischen mitochondrial und glykolytisch entstandenem ATP unterschieden werden (Kasischke et al., 2004). Es besteht also die Möglichkeit, dass eine Reduktion der mitochondrialen ATP-Produktion durch eine Intensivierung der Glykolyse teilweise kompensiert wurde (Nicholls und Budd, 2000), was insbesondere bei hippokampalen Neuronen gegeben zu sein scheint (Allen et al., 2005).

Zusammengefasst deuten diese Ergebnisse darauf hin, dass die HypoxieAnfälligkeit akuter hippokampaler Schnitte durch diverse Faktoren wie z.B. mitochondriale Depolarisation oder anderen Fehlfunktionen, nicht jedoch einem erhöhtem ATP Verbrauch befördert wird.

\section{Modulation des cytosolischen Redox-Status}

\section{Auswirkung mitochondrialer Inhibition}

Eine Inhibition der mitochondrialen Funktion verändert den zellulären RedoxZustand durch eine erhöhte Produktion von ROS (Cadenas, 2004; Foster et al., 2006) und durch eine verändertes Verhältnis von NADH zu NAD ${ }^{+}$sowie $\mathrm{FADH}_{2}$ zu FAD (Chance et al., 1979; Foster et al., 2006). Die Auswirkungen einer solchen Inhibition sind je nach Position des Blocks sehr unterschiedlich und variieren je nach untersuchtem Gewebe stark untereinander. Generell liegen durch eine Blockade des Elektronentransports die beteiligten Proteine hinter dem Block oxidiert vor, während die vor dem Block durch die aufgestauten Elektronen reduziert werden, was ein Entweichen von Elektronen aus der Atmungskette erleichtert und zur Erhöhten ROSProduktion führt (Adam-Vizi, 2005). Das Insektizid Rotenon setzt direkt am Anfang der Atmungskette an und blockiert in Komplex I den Elektronentransfer vom Eisen-Schwefel Cluster auf das Ubichinon (AdamVizi, 2005; Foster et al., 2006) wodurch die Nutzung von NADH verhindert wird. Dies führte in den hier gezeigten Experimenten zu einem Anstieg der 
NADH Autofluoreszenz (Abb. 19) und einer mitochondrialen Depolarisation (Abb. 17) sowie zu einer schwach erhöhten ROS-Produktion (Abb. 23). Antimycin A, ein Blocker von Komplex III der Atmungskette (Chen et al., 2003) zeigte eine vergleichbare Reaktion, die jedoch in allen der hier aufgeführten Parametern deutlicher ausfiel als bei Rotenon (Abb. 19, 17 und 23). Ebenso verhielt es sich mit Cyanid, welches Komplex IV blockiert und durch Elektronen-Rückfluss Superoxid an Komplex III freisetzt (Chen et al., 2003). Die Wirkung von Cyanid auf Mitochondrienmembranpotential, NADHGehalt und ROS-Produktion fiel noch stärker aus, als es bei Rotenon und Antimycin der Fall war (Abb. 19, 17 und 23). Zum Teil könnte dies auf mangelnde Kompensation einer Blockade von Komplex IV oder auch dem geringeren Molekulargewicht und der damit einhergehenden erleichterten Diffusion von Cyanid in das Gewebe beruhen.

DPI blockiert ebenfalls Komplex I, hat jedoch die Flavinmononucleotid-Gruppe als Ansatzpunkt (Adam-Vizi, 2005). Die Wirkung von DPI zeigt eine starke Depolarisation der Mitochondrien (Abb. 17), einen reduzierten NADH-Spiegel (Abb. 19) sowie eine verringerte ROS-Produktion (Abb. 23) und ähnelt mit diesen Effekten der Wirkung von FCCP (Abb. 19, 17 und 23). Dies deutet auf eine erhöhte mitochondriale Respiration hin, was ja eine bekannte Folge einer mitochondrialen Entkopplung ist (Duchen, 1999; Schuh et al., 2005), wodurch sich auch die ROS-Produktion erhöhen sollte. Diese Reaktion wurde auch von uns (Gerich et al., 2006) vorhergesagt und in anderen Arbeiten gezeigt (Boveris und Chance, 1973; Bindokas et al., 1996), es hat sich aber gezeigt, dass ein moderat depolarisiertes mitochondriales Membranpotential eine gewisse neuroprotektive Wirkung hat, indem es einem Calcium Einstrom entgegenwirkt und eine ROS-Produktion abschwächt (Margos und Korde, 2004). Durch eine Applikation von FCCP sank die ROS-Produktion leicht ab, was durch das depolarisierte mitochondriale Membranpotential erklärt werden kann. Der genaue Mechanismus ist aber noch nicht vollständig geklärt.

DPI ist ein unspezifischer Inhibitor von Komplex I und wirkt wahrscheinlich auch über nicht-mitochondriale Mechanismen. Neben Komplex I hemmt DPI auch andere Enzymsysteme, die Flavoproteine beinhalten, wie die NADPHOxidase (Cross und Jones, 1986; Li und Trush, 1998), die Xanthinoxidase sowie die Stickstoffmonoxid-Synthetase (Pou et al., 1999; Chakraborty und 
Massey, 2002) und greift auch in den Pentose-Phosphat-Weg ein (Riganti et al., 2004). So deutet das DPI-induzierte Absinken der ROS-Produktion unter normoxischen Bedingungen z.B. auf eine Blockade der XO hin.

Der irreversible Blocker 3-NPA inhibiert Komplex II, wobei die eigentliche Inhibition erst nach langer Einwirkung (2 Stunden) einsetzt und dann, untersucht in kultivierten SK-N-SH Neuroblastoma-Zellen, zu einer Degeneration und Zelltod führt (Wang et al., 2001). Zuerst stimuliert 3-NPA die Succinat-abhängige zelluläre Respiration, was keinen Einfluss auf den NADH Gehalt der Zellen haben sollte, aber eine verstärkte Oxidation von $\mathrm{FADH}_{2}$ zu FAD (Abb. 19) bewirkt und zu einer erhöhten Produktion von ROS, offenbar durch einen Rückfluss von Elektronen von Komplex II nach Komplex I (Abb. 23), sowie ATP (Abb. 26) führt (Wang et al., 2001). Die anfängliche Stimulation des mitochondrialen Metabolismus durch 3-NPA zeichnete sich in den hier gezeigten Versuchen ab, die Versuche wurden aber nicht so lange durchgeführt, um eine Umkehr dieser Reaktionen im weiteren Verlauf zu erreichen.

Durch den Einsatz von Oligomycin, einem Blocker der $\mathrm{F}_{0} \mathrm{~F}_{1}$-ATPase, wurden die Mitochondrien maximal hyperpolarisiert (Abb. 17), was eine Intensivierung der zellulären Respiration zur Folge hatte. Dies zeigte sich in einer Verringerung der NADH Autofluoreszenz (Abb. 19) und einem starken Anstieg der durch roGFP angezeigten ROS-Produktion (Abb. 23).

\section{Wechselseitige Auswirkung von schwerer Hypoxie und Redox- Status}

Es konnte kein direkter Zusammenhang zwischen einer beschleunigten HSD und reduzierenden Bedingungen gezeigt werden. DPI und FCCP reduzieren die ROS-Produktion und führen zu einer Verkürzung der Latenz, sie führen aber auch zu einer verstärkten Oxidation von NADH. Rotenon, Antimycin und Cyanid, die Blocker der protonenpumpenden Komplexe, beschleunigten ebenfalls das Auftreten einer HSD, jedoch war ihr Einfluss auf NADH-Spiegel und ROS-Produktion genau umgekehrt. Eine Gemeinsamkeit dieser fünf Wirkstoffe war die ausgeprägte Depolarisation der Mitochondrien (Abb. 17). Die Blocker 3-NPA und Oligomycin hatten keinen bzw. einen 
hyperpolarisierenden Effekt auf die Mitochondrienmembran und zeigten beide keinen Effekt auf die Latenz einer HSD (Abb. 17, 14 und 15).

Wie erwartet reduzierte sich während hypoxischen Episoden die ROSProduktion in betroffenen Schnitten (Abb. 23). Foster et al. (2005) konnten zeigen, das in von Hypoxie betroffenen Gewebe der Sauerstoffpartialdruck wenige Sekunden nach dem Einsetzen der Hypoxie schnell absinkt und nach ungefähr einer Minute bereits ein Minimum erreicht. Ohne Sauerstoff als Elektronenakzeptor können keine weiteren Sauerstoffradikale gebildet werden. Der NADH-Spiegel steigt im Verlauf einer Hypoxie laut Foster et al. bereits vor dem Einsetzen einer HSD an und steigt gleichzeitig mit dem Einsetzen der HSD sprunghaft an, was eine starke Reduktion und die Inhibition der zellulären Respiration anzeigt (Mills et al., 1977). Wird die Sauerstoffversorgung rechtzeitig wiederhergestellt, sinkt der NADH-Spiegel schlagartig wieder auf das Grundniveau zurück. Je länger der hypoxische Zustand anhält, desto wahrscheinlicher und ausgeprägter kommt es während der Reoxygenierung zu einer Hyperoxidation und der NADH-Spiegel fällt unter das Grundniveau (Rosenthal et al., 1995; Pérez-Pinzón et al., 1997). Zu diesem Zeitpunkt sind die Auswirkungen der Hypoxie nicht mehr reversibel und führen zu Zellschäden oder Zelltod (Foster et al., 2005). Der Mechanismus der hinter der Hyperoxidation steht ist noch nicht völlig geklärt. Der Sauerstoffpartialdruck im Gewebe steigt bei einer Hyperoxidation über das Grundniveau hinaus, was auf einen eingeschränkten mitochondrialen Metabolismus und den damit einhergehenden verringerten Sauerstoffverbrauch, z. B. durch bereits erfolgte zelluläre Schädigungen (Rosenthal et al. 1995) schließen lässt. Ebenso scheinen oxidative Schädigungen durch ROS beteiligt zu sein (Pérez-Pinzón et al., 1997). Diese Theorie deckt sich mit der hier gemachten Beobachtung, dass im Verlauf der Reoxygenierung verstärkt ROS gebildet werden (Abb. 24).

Zusammengefasst deuten auch diese Ergebnisse auf die Möglichkeit hin, dass Faktoren, die mit einer mitochondrialen Depolarisation zusammenhängen, die Hypoxie-Anfälligkeit akuter hippokampaler Schnitte erhöhen. Welche Signalwege beteiligt sind, ist aber noch unklar. 
Als einer der möglichen Ansatzpunkte eines Redox-vermittelten Signalweges wurden die über Ryanodin-Rezeptoren gesteuerten $\mathrm{Ca}^{2+}-$ Kanäle des Endoplasmatischen Retikulums identifiziert.

\section{Die Modulation intrazellulärer $\mathrm{Ca}^{2+}$ Speicher durch $\mathrm{H}_{2} \mathrm{O}_{2}$}

Eine extrazelluläre Applikation von $\mathrm{H}_{2} \mathrm{O}_{2}$ führt zu einem Anstieg von $\left[\mathrm{Ca}^{2+}\right]$. Die Hauptquelle des Calciums scheinen aber nicht die Mitochondrien zu sein, sondern das Endoplasmatische Retikulum. Eine Zugabe von FCCP führte zwar zu einem Anstieg von $\left[\mathrm{Ca}^{2+}\right]_{\mathrm{i}}$, da durch das vollständig depolarisierte mitochondriale Membranpotential die $\mathrm{Ca}^{2+}$-Aufnahme durch die Mitochondrien verhindert wird und $\mathrm{Ca}^{2+}$ an das Cytosol abgegeben wird (Duchen, 1999; Brocard et al., 2001; Maragos und Korde, 2004), dies hatte aber keinen Einfluss auf den Anstieg von $\left[\mathrm{Ca}^{2+}\right]_{i}$ durch die Zugabe von $\mathrm{H}_{2} \mathrm{O}_{2}$ (Abb. 31). Die Calcium-Antwort auf $\mathrm{H}_{2} \mathrm{O}_{2}$ war von extrazellulärem Calcium unabhängig und ließ sich deutlich durch Modulatoren der intrazellulären $\mathrm{Ca}^{2+}$-Speicher beeinflussen (Abb. 32). Ruthenium Rot und Dantrolen reduzierten massiv den Anstieg von $\left[\mathrm{Ca}^{2+}\right]$. Thapsigargin, ein Inhibitor der SERCA, welche Calcium in die intrazellulären Speicher pumpen, führte zu einer leichten Reduzierung und bei einer nachfolgenden Zugabe zu einer weiteren Halbierung der Calcium Antwort. Niedrige Konzentrationen von Ryanodin steigerten die $\mathrm{Ca}^{2+}$-Antwort, während höhere Konzentrationen zu einer Abnahme führten. Diese Wirkung entspricht genau der Wirkung von Ryanodin auf Ryanodin-Rezeptor (RyR) gesteuerte $\mathrm{Ca}^{2+}$-Freisetzung (Hernández-Fonseca und Massieu, 2005). Diese Beobachtungen führen $\mathrm{zu}$ dem Schluss, dass $\mathrm{H}_{2} \mathrm{O}_{2}$ in hippokampalen Neuronen über eine RyR-Aktivierung Calcium aus dem Endoplasmatischen Retikulum freisetzt (Suzuki et al., 1997; Xia et al., 2003), und sie identifizieren RyR in hippokampalen Neuronen als ein Ansatzpunkt der Redoxmodulation, wobei die Sensitivität in einem Bereich liegt, in dem die neuronale Erregbarkeit noch nicht moduliert wird.

Ähnliche Beobachtungen konnten unter anderem auch in Kardiomyozyten (Gen et al., 2001) oder kultivierten hippokampalen Astrozyten der Ratte (González et al., 2006) gemacht werden. In diesen Fällen wurden aber noch andere Mechanismen zur $\mathrm{Ca}^{2+}$-Freisetzung und Calciumquellen, wie z.B. 
Mitochondrien identifiziert, was aber bei den hier genutzten kultivierten Neuronen nicht zuzutreffen scheint.

Die HSD-verzögernde Wirkung von DTNB beruht auf der calciumabhängigen Aktivierung von BK-Kanälen. Die Ryanodinrezeptoren des ER enthalten hochreaktive Cysteinreste, deren Sulfhydrylgruppen gegenüber Redoxmodulation sehr anfällig sind (Hidalgo et al., 2004). Eine moderate Oxidation der Sulfhydrylgruppen aktivierte RyR maximal, während eine starke Oxidation sowie eine Reduktion der freien Thiole das Schließen der RyRgesteuerten Kanäle begünstigte (Sun et al., 2001). Dabei ist zu bedenken, dass die Inaktivierung durch eine starke Oxidation irreversibel ist und daher eher pathologische als physiologische Auswirkungen hat. In RyR aus dem Skelettmuskel des Kaninchens konnte eine Gruppe von Hyper-Reaktiven Sulfhydrylgruppen (Bezeichnung nach: Liu et al., 1994) als Redoxsensor identifiziert werden (Aracena-Parks et al., 2006).

Der durch extrazellulär gegebenes $\mathrm{H}_{2} \mathrm{O}_{2}$ hervorgerufene oxidative Stress und das dadurch gestiegene $\left[\mathrm{Ca}^{2+}\right]_{i}$ hatten keinen Effekt auf die synaptische Funktion und Plastizität (Abb. 27). Eine Auswirkung konnte erst bei der sehr hohen pathologischen Konzentration von $5 \mathrm{mM}$ gezeigt werden. Andere Arbeiten zeigten eine Inhibition der synaptischen Übertragung bei Konzentrationen über 1,5 mM (Pellmar, 1995; Fowler, 1997), wobei hier jedoch vornehmlich die somatische Komponenten (Populations-Spikes) und nicht wie in dieser Arbeit die dendritischen Anteile der EPSPs untersucht wurden. Diese Inhibition scheint ihre Ursache in einer gestiegenen extrazellulären Adenosin-Konzentration als Reaktion auf den oxidativen Stress zu haben (Masino et al., 1999). Sehr hohe $\mathrm{H}_{2} \mathrm{O}_{2}$-Konzentrationen (20 mM) führten zu einer verringerten LTP, während $1 \mu \mathrm{M} \mathrm{H}_{2} \mathrm{O}_{2}$ sogar zu einer Steigerung führte (Kamsler und Segal, 2003). 


\section{Fazit}

Es konnte gezeigt werden, dass der Redox-Status durchaus eine Modulation neuronaler und glialer Eigenschaften und Funktion bewirken kann. Dies konnte während metabolischer Störungen wie z.B. Anoxie beobachtet werden, die Sensitivität einiger beteiligten Komponenten lässt aber auch den Schluss zu, dass eine Redoxmodulation auch in der normalen Zellfunktion eine Rolle spielen kann. Die Fähigkeit einiger auftretender Faktoren, wie z.B. $\mathrm{H}_{2} \mathrm{O}_{2}$, Zellmembranen passieren zu können, deutet auf die Möglichkeit von Redox-gesteuerter Zell-Zell-Interaktion hin. Die beteiligten Signalwege müssen weiter aufgeklärt und weitere Redox-Targets identifiziert werden. Insbesondere sollte die Rolle von Glutathion in diesem Zusammenhang genauer untersucht werden.

Es ist erstaunlich, dass durch eine Oxidation eine neuroprotektive Wirkung erzielt werden kann, da die schädlichen Wirkungen einer stärkeren Oxidation hinreichend bekannt sind und gerade in neurodegenerativen Erkrankungen eine wichtige Rolle spielen.

Die Möglichkeit der Untersuchungen zellulärer Vorgänge mit optischen Methoden ist durch die Entwicklung neuartiger Hilfsmittel in jüngster Zeit extrem verbessert worden. So konnten z.B. durch das redoxsensitive roGFP dynamische Prozesse verfolgt werden, was mit den herkömmlichen Farbstoffen nicht möglich ist. 


\section{Zusammenfassung}

Mitochondrien generieren kontinuierlich geringe Mengen Superoxid, welches im Normalfall in $\mathrm{H}_{2} \mathrm{O}_{2}$ umgewandelt wird. Bei Störung der mitochondrialen Respiration kann so die Produktion reaktiver Sauerstoffspezies (ROS) ansteigen und der daraus resultierende oxidative Stress zu Zellschädigung oder Zelltod führen. Es wird aber auch eine Signalfunktion von ROS vermutet. Sie bestimmen in Abhängigkeit vom mitochondrialen Metabolismus den zellulären Redox-Status, der wiederum durch Sulfhydryl-Modulation die Aktivität cysteinhaltiger Proteine modulieren kann. Im Rahmen dieser Arbeit wurde die Signalfunktion cytosolischer Redox-Änderungen und die funktionellen Konsequenzen, die sich daraus für das intakte hippokampale Netzwerk ergeben, untersucht. Die Versuche wurden auf der Netzwerkebene (in akuten hippokampalen Hirnschnitten), auf Einzelzellebene (in kultivierten Neuronen) und auf molekularer Ebene durchgeführt. Extrazellulär appliziertes $\mathrm{H}_{2} \mathrm{O}_{2}(200 \mu \mathrm{M})$ führte zu einem Anstieg von $\left[\mathrm{Ca}^{2+}\right]$, offensichtlich durch Freisetzung aus RyR-sensitiven intrazellulären Speichern. Das mitochondriale Membranpotential, die synaptische Funktion sowie der ATP-Gehalt wurden durch $\mathrm{H}_{2} \mathrm{O}_{2}$ kaum beeinflusst. Mit einem innovativen redoxsensitiven roGFP konnten dynamische Messungen des Redox-Zustandes auf Zellebene durchgeführt und so die mitochondrialen Aktivitätsparameter systematisch mit dem Redox-Status korreliert werden. Cytosolische Redox-Änderungen konnten auch durch Modulation der mitochondrialen Respiration beeinflusst werden, was sich auf die Hypoxie-Empfindlichkeit der untersuchten Hirnschnitte auswirkte. Insbesondere eine ausgeprägte Depolarisation der Mitochondrien durch z.B. $1 \mu \mathrm{M}$ FCCP oder $1 \mathrm{mM} \mathrm{NaCN}$ erhöhte die Hypoxieempfindlichkeit deutlich und konnte trotz Anwesenheit von $\mathrm{O}_{2}$ zur Auslösung einer spreading depression (SD) führen. Ein Anstieg der endogenen Superoxid- oder Hydroxylradikal-Produktion beschleunigte das Auftreten einer durch Hypoxie induzierten spreading depression (HSD). Überraschenderweise verzögerte $\mathrm{H}_{2} \mathrm{O}_{2}(1-5 \mathrm{mM})$ das Auftreten einer HSD, ohne die Vitalität der Hirnschnitte zu beeinträchtigen, und wirkte somit potentiell neuroprotektiv. Dieser Effekt wurde offenbar durch eine Sulfhydryloxidation bewirkt. Die Identifikation weiterer beteiligter redoxsensitiver Targets steht noch aus, dürfte aber mit Hinblick auf potentielle Neuroprotektion einer Sulfhydryloxidation bei metabolischen Störungen auch klinisch durchaus bedeutsam sein. 


\section{Benutzte Abkürzungen:}

3-NPA: 3-Nitropropionic acid;

ACSF: artificial cerebrospinal fluid (artifizielle cerebrospinale Flüssigkeit);

AM: Acetoxymethyl;

Ara-C: Arabinosid-Cytosin;

ATP: Adenosintriphosphat;

DFOM: Deferoxamin mesylat;

DIV: Days in vitro;

DH: Dehydrogenase;

DMEM: Dulbecco's Modified Eagle Medium;

DPI: Diphenyleneiodonium Chlorid;

DTNB: 5,5'-Dithiobis(2-nitrobenzoic acid);

DTT: DL-Dithiothreitol;

ER: Endoplasmatisches Retikulum;

FBS: Fetal bovine serum (fötales Rinderserum);

FCCP: Carbonyl cyanide 4-(trifluoromethoxy)phenylhydrazone;

G-6-P: Glucose-6-Phosphat;

HBSS: Hank's balanced salts solution;

HK: Hexokinase;

HSD: hypoxic spreading depression (Hypoxie induzierte spreading depression);

IOS: intrinsische optische Signale;

LTP: long term potentiation;

MEM: Minimal essential medium;

ROS: reaktive oxygen spezies (reaktive Sauerstoff Spezies);

RT: Raumtemperatur;

RyR: Ryanodin-Rezeptor;

SD: spreading depression;

SERCA: Sarko-Endoplasmatisches Retikulum $\mathrm{Ca}^{2+}$-ATPase;

TEA: Triethanolamin-Hydrochlorid;

X: Xanthin;

XO: Xanthinoxidase 


\section{Literaturverzeichnis}

Adam-Vizi V. (2005). Production of reactive oxygen species in brain mitochondria: contribution by electron transport chain and non-electron transport chain sources. Antioxid Redox Signal 7, 1140-1149.

Aitken PG, Fayuk D, Somjen GG und Turner DA. (1999). Use of intrinsic optical signals to monitor physiological changes in brain tissue slices. Methods 18, 91-103.

Allen NJ, Karadottir R und Attwell D. (2005). A preferential role for glycolysis in preventing the anoxic depolarization of rat hippocampal area CA1 pyramidal cells. J Neurosci 25, 848-859.

Aracena-Parks P, Goonasekera SA, Gilman CP, Dirksen RT, Hidalgo C und Hamilton SL. (2006). Identification of cysteines involved in Snitrosylation, S-glutathionylation, and oxidation to disulfides in ryanodine receptor type 1. J Biol Chem 281, 40354-40368.

Balakrishnan S. (2006). The Mitochondrial Role in Calcium Metabolism and Differential Calcium Buffering Capacity of Amyotrophic Lateral Sclerosis (ALS) Vulnerable and Resistant Motoneurons from Mice, pp. 100. Georg-August Universität Göttingen, Göttingen.

Berg J, Tymoczko J und Stryer L. (2003). Biochemie. Spektrum Verlag.

Bidasee KR, Besch HR, Jr., Gerzon K und Humerickhouse RA. (1995). Activation and deactivation of sarcoplasmic reticulum calcium release channels: molecular dissection of mechanisms via novel semi-synthetic ryanoids. Mol Cell Biochem 149-150, 145-160.

Bindokas VP, Jordan J, Lee CC und Miller RJ. (1996). Superoxide production in rat hippocampal neurons: selective imaging with hydroethidine. J Neurosci 16, 1324-1336.

Boveris A und Chance B. (1973). The mitochondrial generation of hydrogen peroxide. General properties and effect of hyperbaric oxygen. Biochem J 134, 707-716.

Bradford MM. (1976). A rapid and sensitive method for the quantitation of microgram quantities of protein utilizing the principle of protein-dye binding. Anal Biochem 72, 248-254. 
Braford MR, Jr. (1995). Comparative aspects of forebrain organization in the ray-finned fishes: touchstones or not? Brain Behav Evol 46, 259-274.

Brocard JB, Tassetto M und Reynolds IJ. (2001). Quantitative evaluation of mitochondrial calcium content in rat cortical neurones following a glutamate stimulus. J Physiol 531, 793-805.

Cadenas E. (2004). Mitochondrial free radical production and cell signaling. Mol Aspects Med 25, 17-26.

Chakraborty S und Massey V. (2002). Reaction of reduced flavins and flavoproteins with diphenyliodonium chloride.

J Biol Chem 277, 41507-41516.

Chance B, Schoener B, Oshino R, Itshak F und Nakase Y. (1979). Oxidationreduction ratio studies of mitochondria in freeze-trapped samples. $\mathrm{NADH}$ and flavoprotein fluorescence signals.

J Biol Chem 254, 4764-4771.

Chen Q, Vazquez EJ, Moghaddas S, Hoppel CL und Lesnefsky EJ. (2003). Production of reactive oxygen species by mitochondria: central role of complex III. J Biol Chem 278, 36027-36031.

Coles CE, DE; Singer, TP. (1979). Inactivation of succinate dehydrogenase by 3-nitropropionate. J Biol Chem 254, 5161-5167.

Cotton N, Clark A und Jackson J. (1981). The effect of venturicidin on light and oxygen-dependent electron transport, proton translocation, membrane potential development and ATP synthesis in intact cells of Rhodopseudomonas capsulata. Archives of Microbiology 129, 94-99.

Coyle JT und Puttfarcken P. (1993). Oxidative stress, glutamate, and neurodegenerative disorders. Science 262, 689-695.

Croning MD und Haddad GG. (1998). Comparison of brain slice chamber designs for investigations of oxygen deprivation in vitro. J Neurosci Methods 81, 103-111.

Cross AR und Jones OT. (1986). The effect of the inhibitor diphenylene iodonium on the superoxide-generating system of neutrophils. Specific labelling of a component polypeptide of the oxidase. Biochem J 237, 111-116. 
D'Ambrosio R, Wenzel J, Schwartzkroin PA, McKhann GM, 2nd und Janigro D. (1998). Functional specialization and topographic segregation of hippocampal astrocytes. J Neurosci 18, 4425-4438.

Dooley CT, Dore TM, Hanson GT, Jackson WC, Remington SJ und Tsien RY. (2004). Imaging dynamic redox changes in mammalian cells with green fluorescent protein indicators. J Biol Chem 279, 22284-22293.

Duchen MR. (1999). Contributions of mitochondria to animal physiology: from homeostatic sensor to calcium signalling and cell death.

J Physiol 516 (Pt 1), 1-17.

Dunn KW und Young PA. (2006). Principles of multiphoton microscopy. Nephron Exp Nephrol 103, e33-40.

El-Falougy H und Benuska J. (2006). History, anatomical nomenclature, comparative anatomy and functions of the hippocampal formation.

Bratisl Lek Listy 107, 103-106.

Foster KA, Beaver CJ und Turner DA. (2005). Interaction between tissue oxygen tension and $\mathrm{NADH}$ imaging during synaptic stimulation and hypoxia in rat hippocampal slices. Neuroscience 132, 645-657.

Fowler JC. (1997). Hydrogen peroxide opposes the hypoxic depression of evoked synaptic transmission in rat hippocampal slices.

Brain Res 766, 255-258.

Gen W, Tani M, Takeshita J, Ebihara Y und Tamaki K. (2001). Mechanisms of $\mathrm{Ca}^{2+}$ overload induced by extracellular $\mathrm{H}_{2} \mathrm{O}_{2}$ in quiescent isolated rat cardiomyocytes. Basic Res Cardiol 96, 623-629.

González A, Granados MP, Pariente JA und Salido GM. (2006). $\mathrm{H}_{2} \mathrm{O}_{2}$ mobilizes $\mathrm{Ca}^{2+}$ from agonist- and thapsigargin-sensitive and insensitive intracellular stores and stimulates glutamate secretion in rat hippocampal astrocytes. Neurochem Res 31, 741-750.

Göppert-Mayer M. (1931). Über Elementarakte mit zwei Quantensprüngen.

Ann Phys (Leipzig) 9, 273-294.

Halliwell B. (1992). Reactive oxygen species and the central nervous system. J Neurochem 59, 1609-1623.

Hansen AJ. (1985). Effect of anoxia on ion distribution in the brain. Physiol Rev 65, 101-148. 
Hansen AJ und Olsen CE. (1980). Brain extracellular space during spreading depression and ischemia. Acta Physiol Scand 108, 355-365.

Hanson GT, Aggeler R, Oglesbee D, Cannon M, Capaldi RA, Tsien RY und Remington SJ. (2004). Investigating mitochondrial redox potential with redox-sensitive green fluorescent protein indicators.

J Biol Chem 279, 13044-13053.

Hawkins BJ, Madesh M, Kirkpatrick CJ und Fisher AB. (2007). Superoxide Flux in Endothelial Cells via the Chloride Channel-3 Mediates Intracellular Signaling. Mol Biol Cell 18, 2002-2012.

Hernández-Fonseca K und Massieu L. (2005). Disruption of endoplasmic reticulum calcium stores is involved in neuronal death induced by glycolysis inhibition in cultured hippocampal neurons. J Neurosci Res 82, 196-205.

Hidalgo C, Bull R, Behrens MI und Donoso P. (2004). Redox regulation of RyR-mediated $\mathrm{Ca}^{2+}$ release in muscle and neurons.

Biol Res 37, 539-552.

Hossmann KA. (2003). [Glutamate hypothesis of stroke].

Fortschr Neurol Psychiatr 71 Suppl 1, S10-15.

Ikonen S. (2001). The role of the septohippocampal cholinergic system in cognitive functions. Series of reports 54.

Kamsler A und Segal M. (2003). Hydrogen peroxide modulation of synaptic plasticity. J Neurosci 23, 269-276.

Kandel EH. (1996). Neurowissenschaften: Eine Einführung. Spektrum Akademischer Verlag $\mathrm{GmbH}$.

Karihtala P und Soini Y. (2007). Reactive oxygen species and antioxidant mechanisms in human tissues and their relation to malignancies. Apmis 115, 81-103.

Kasischke KA, Vishwasrao HD, Fisher PJ, Zipfel WR und Webb WW. (2004). Neural activity triggers neuronal oxidative metabolism followed by astrocytic glycolysis. Science 305, 99-103.

Kontos HA. (2001). Oxygen radicals in cerebral ischemia: the 2001 Willis lecture. Stroke 32, 2712-2716. 
Kostyuk P und Verkhratsky A. (1994). Calcium stores in neurons and glia.

Neuroscience 63, 381-404.

Kreisman NR, LaManna JC, Liao SC, Yeh ER und Alcala JR. (1995). Light transmittance as an index of cell volume in hippocampal slices: optical differences of interfaced and submerged positions.

Brain Res 693, 179-186.

Lamprecht W, Trautschold I und Schweitzer G. (1985). ATP: UV-Method with Hexokinase and Glucose-6-phosphate Dehydrogenase. In: Methods of Enzymatic Analysis, Third Ed, ed. Bergmeyer HU, pp. 346-357. VCH Verlagsgesellschaft, Weinheim, Germany.

Läuger PM, H; Müller, P. (1944). Über Konstitution und toxische Wirkung von natürlichen und neuen synthetischen insektentötenden Stoffen.

Helvetica Chimica Acta 27, 892-928.

Leão AAP. (1944). Spreading depression of activity in the cerebral cortex. J Neurophysiol 7, 359-390.

Lehmenkühler A, Sykova E, Svoboda J, Zilles K und Nicholson C. (1993). Extracellular space parameters in the rat neocortex and subcortical white matter during postnatal development determined by diffusion analysis. Neuroscience 55, 339-351.

Li Y und Trush MA. (1998). Diphenyleneiodonium, an NAD(P)H oxidase inhibitor, also potently inhibits mitochondrial reactive oxygen species production. Biochem Biophys Res Commun 253, 295-299.

Lipton P. (1999). Ischemic cell death in brain neurons.

Physiol Rev 79, 1431-1568.

Liu G, Abramson JJ, Zable AC und Pessah IN. (1994). Direct evidence for the existence and functional role of hyperreactive sulfhydryls on the ryanodine receptor-triadin complex selectively labeled by the coumarin maleimide 7-diethylamino-3-(4'-maleimidylphenyl)-4-methylcoumarin.

Mol Pharmacol 45, 189-200.

Lloyd DR und Phillips DH. (1999). Oxidative DNA damage mediated by copper(II), iron(II) and nickel(II) fenton reactions: evidence for sitespecific mechanisms in the formation of double-strand breaks, 8hydroxydeoxyguanosine and putative intrastrand cross-links.

Mutat Res 424, 23-36. 
Malgaroli A und Tsien RW. (1992). Glutamate-induced long-term potentiation of the frequency of miniature synaptic currents in cultured hippocampal neurons. Nature 357, 134.

Maragos WF und Korde AS. (2004). Mitochondrial uncoupling as a potential therapeutic target in acute central nervous system injury. J Neurochem 91, 257-262.

Martins-Ferreira H, Castro Gde O und Albuquerque A. (1971). [Effect of chloride ions on the variations in the intensity of light diffused by the retina during spreading depression]. C R Acad Sci Hebd Seances Acad Sci D 273, 414-417.

Masino SA, Mesches MH, Bickford PC und Dunwiddie TV. (1999). Acute peroxide treatment of rat hippocampal slices induces adenosinemediated inhibition of excitatory transmission in area CA1. Neurosci Lett 274, 91-94.

Merchenthaler I, Dellovade TL und Shughrue PJ. (2003). Neuroprotection by estrogen in animal models of global and focal ischemia.

Ann N Y Acad Sci 1007, 89-100.

Mills E und Jöbsis FF. (1972). Mitochondrial respiratory chain of carotid body and chemoreceptor response to changes in oxygen tension. J Neurophysiol 35, 405-428.

Mills SA, Jobsis FF und Seaber AV. (1977). A fluorometric study of oxidative metabolism in the in vivo canine heart during acute ischemia and hypoxia. Ann Surg 186, 193-200.

Müller M. (2005). Responses of central neurons to hypoxia and the role of mitochondri as metabolic sensors. In Recent Research Developments in Physiology Vol 3, pp. 59-90. Research Signpost, Kerala, India.

Müller M, Schmidt J, Mironov LS und Richter DW. (2003). Construction and performance of a custom-built two-photon laser scanning system. Journal of Physics D: Applied Physics 36, 1747-1757.

Müller M und Somjen GG. (1998). Inhibition of major cationic inward currents prevents spreading depression-like hypoxic depolarization in rat hippocampal tissue slices. Brain Res 812, 1-13. 
Müller M und Somjen GG. (1999). Intrinsic optical signals in rat hippocampal slices during hypoxia-induced spreading depression-like depolarization. J Neurophysiol 82, 1818-1831.

Müller M und Somjen GG. (2000). $\mathrm{Na}(+)$ and $\mathrm{K}(+)$ concentrations, extra- and intracellular voltages, and the effect of TTX in hypoxic rat hippocampal slices. J Neurophysio/ 83, 735-745.

Nakabeppu Y, Tsuchimoto D, Yamaguchi H und Sakumi K. (2007). Oxidative damage in nucleic acids and Parkinson's disease.

J Neurosci Res 85, 919-934.

Nicholls DG und Budd SL. (2000). Mitochondria and neuronal survival. Physiol Rev 80, 315-360.

Nicholls DG, Johnson-Cadwell L, Vesce S, Jekabsons M und Yadava N. (2007). Bioenergetics of mitochondria in cultured neurons and their role in glutamate excitotoxicity. J Neurosci Res.

Pellmar T. (1986). Electrophysiological correlates of peroxide damage in guinea pig hippocampus in vitro. Brain Res 364, 377-381.

Pellmar TC. (1995). Use of brain slices in the study of free-radical actions. J Neurosci Methods 59, 93-98.

Pérez-Pinzón MA, Mumford PL, Rosenthal M und Sick TJ. (1997). Antioxidants, mitochondrial hyperoxidation and electrical recovery after anoxia in hippocampal slices. Brain Res 754, 163-170.

Pou S, Keaton L, Surichamorn W und Rosen GM. (1999). Mechanism of superoxide generation by neuronal nitric-oxide synthase.

J Biol Chem 274, 9573-9580.

Prabhakar NR, Kumar GK, Nanduri J und Semenza GL. (2007). ROS Signaling in Systemic and Cellular Responses to Chronic Intermittent Hypoxia. Antioxid Redox Signal. 9, 1397-1404.

Pulsinelli WA, Brierley JB und Plum F. (1982). Temporal profile of neuronal damage in a model of transient forebrain ischemia.

Ann Neurol 11, 491-498.

Reid KH, Marrannes R und Wauquier A. (1988). Spreading depression and central nervous system pharmacology. J Pharmacol Methods 19, 1-21. 
Richardson MP, Strange BA und Dolan RJ. (2004). Encoding of emotional memories depends on amygdala and hippocampus and their interactions. Nat Neurosci 7, 278-285.

Riganti C, Gazzano E, Polimeni M, Costamagna C, Bosia A und Ghigo D. (2004). Diphenyleneiodonium inhibits the cell redox metabolism and induces oxidative stress. J Biol Chem 279, 47726-47731.

Roitbak Al und Bobrov AV. (1975). Spreading depression resulting from cortical punctures. Acta Neurobiol Exp (Wars) 35, 761-768.

Rosenthal M, Feng ZC, Raffin CN, Harrison M und Sick TJ. (1995). Mitochondrial hyperoxidation signals residual intracellular dysfunction after global ischemia in rat neocortex.

J Cereb Blood Flow Metab 15, 655-665.

Rosenthal M und Sick TJ. (1992). Glycolytic and oxidative metabolic contributions to potassium ion transport in rat cerebral cortex.

Can J Physiol Pharmacol 70 Suppl, S165-169.

Schmidt-Kastner R und Freund TF. (1991). Selective vulnerability of the hippocampus in brain ischemia. Neuroscience 40, 599.

Shuttleworth CW, Brennan AM und Connor JA. (2003). NAD(P)H fluorescence imaging of postsynaptic neuronal activation in murine hippocampal slices. J Neurosci 23, 3196-3208.

Sipos I, Tretter L und Adam-Vizi V. (2003). The production of reactive oxygen species in intact isolated nerve terminals is independent of the mitochondrial membrane potential. Neurochem Res 28, 1575-1581.

Somjen GG. (2001). Mechanisms of spreading depression and hypoxic spreading depression-like depolarization. Physiol Rev 81, 1065-1096.

Somjen GG, Aitken PG, Czeh G, Jing J und Young JN. (1993). Cellular physiology of hypoxia of the mammalian central nervous system.

Res Publ Assoc Res Nerv Ment Dis 71, 51-65.

Somjen GG, Aitken PG, Czeh GL, Herreras O, Jing J und Young JN. (1992). Mechanism of spreading depression: a review of recent findings and a hypothesis. Can J Physiol Pharmacol 70 Suppl, S248-254.

Streit DS, Ferreira Filho CR und Martins-Ferreira H. (1995). Spreading depression in isolated spinal cord. J Neurophysiol 74, 888-890. 
Sun J, Xu L, Eu JP, Stamler JS und Meissner G. (2001). Classes of thiols that influence the activity of the skeletal muscle calcium release channel. J Biol Chem 276, 15625-15630.

Suzuki S, Brown CM und Wise PM. (2006). Mechanisms of neuroprotection by estrogen. Endocrine 29, 209-215.

Suzuki YJ, Forman HJ und Sevanian A. (1997). Oxidants as stimulators of signal transduction. Free Radic Biol Med 22, 269-285.

Trushina E und McMurray CT. (2007). Oxidative stress and mitochondrial dysfunction in neurodegenerative diseases.

Neuroscience 145, 1233-1248.

Turrens JF. (2003). Mitochondrial formation of reactive oxygen species. J Physiol 552, 335-344.

Valko M, Leibfritz D, Moncol J, Cronin MT, Mazur M und Telser J. (2007). Free radicals and antioxidants in normal physiological functions and human disease Int J Biochem Cell Biol 39, 44-84.

Wang J, Green PS und Simpkins JW. (2001). Estradiol protects against ATP depletion, mitochondrial membrane potential decline and the generation of reactive oxygen species induced by 3-nitroproprionic acid in SK-N-SH human neuroblastoma cells. J Neurochem 77, 804-811.

Witter MP, Wouterlood FG, Naber PA und Van Haeften T. (2000). Anatomical organization of the parahippocampal-hippocampal network.

Ann N Y Acad Sci 911, 1-24.

Xia R, Webb JA, Gnall LL, Cutler K und Abramson JJ. (2003). Skeletal muscle sarcoplasmic reticulum contains a NADH-dependent oxidase that generates superoxide. Am J Physiol Cell Physiol 285, C215-221.

Zhang DX und Gutterman DD. (2007). Mitochondrial reactive oxygen speciesmediated signaling in endothelial cells.

Am J Physiol Heart Circ Physiol 292, H2023-2031.

Zhu X, Su B, Wang X, Smith MA und Perry G. (2007). Causes of oxidative stress in Alzheimer disease. Cell Mol Life Sci. 64, 2202-10.

Zucker RS. (1989). Short-term synaptic plasticity.

Annu Rev Neurosci 12, 13-31. 


\section{Eigene Veröffentlichungen}

Einige Teile der vorliegenden Arbeit wurden bereits in folgenden Publikationen veröffentlicht

Gerich FJ, Hepp S, Probst I und Müller M. (2006). Mitochondrial inhibition prior to oxygen-withdrawal facilitates the occurrence of hypoxiainduced spreading depression in rat hippocampal slices. J Neurophysiol 96, 492-504.

Hepp S, Gerich FJ und Müller M. (2005). Sulfhydryl oxidation reduces hippocampal susceptibility to hypoxia-induced spreading depression by activating BK channels. J Neurophysiol 94, 1091-1103.

Foster KA, Galeffi F, Gerich FJ, Turner DA und Müller M. (2006). Optical and pharmacological tools to investigate the role of mitochondria during oxidative stress and neurodegeneration. Prog Neurobiol 79, 136-171.

\section{Tagungsbeiträge}

Gerich FJ und Müller M. (2007). Dynamic probing of hippocampal reactive oxygen species (ROS) formation using redox sensitive GFPs. Poster presentation; $86^{\text {th }}$ Annual Meeting of the DPG in Hannover Acta Physiologica 189, Supp. 653.

Gerich FJ und Müller M. (2007) Modulation of rat hippocampal neurons by $\mathrm{H}_{2} \mathrm{O}_{2}$-mediated oxidative stress; Poster presentation; $7^{\text {th }}$ Göttingen Meeting of the German Neuroscience Society;

FASEB J. 2006 20: A793

Gerich FJ und Müller M. (2006). Modulation Of Rat Hippocampal Neurons By $\mathrm{H}_{2} \mathrm{O}_{2}$-Mediated Oxidative Stress. Poster presentation; $85^{\text {th }}$ Annual Meeting of the DPG 2006 in München..

Gerich FJ und Müller M. (2005), Reducing conditions favour the onset of hypoxic spreading depression while oxidative conditions postpone it, Poster presentation; $35^{\text {th }}$ Annual Meeting of the Society for Neuroscience Program No. 550.2.,

2005 Abstract Viewer/ltinerary Planner. Washington, DC: Society for Neuroscience, 2005. Online. 


\section{Danksagung}

Zuerst möchte ich mich bei Jun. Prof. Dr. Michael Müller für die Möglichkeit, diese Arbeit durchzuführen, bedanken. Die herausragende wissenschaftliche Unterstützung und ausgesprochen angenehme Atmosphäre, zu der natürlich auch die anderen Mitglieder der Arbeitsgruppe ihren Beitrag geleistet haben, haben maßgeblich zum Gelingen dieser Arbeit beigetragen. Belinda Hildebrand hat durch ihre hervorragende technische Assistenz ein großes Chaos vermieden und mir jede Menge Arbeit, vor allem Präparationen, abgenommen.

Vielen Dank auch an die Mitarbeiter und Kollegen, insbesondere Dietmar, Christina sowie Ute Renner aus dem Erdgeschoß für die Hilfe und die Beantwortung von ca. 1000 Fragen zur Zellkultur. Danke auch an Tierstall, EDV und die Werkstätten.

Bei Prof. Dr. Rüdiger Hardeland und bei Jun. Prof. Dr. Ralf Heinrich aus dem Institut für Zoologie und Anthropologie bedanke ich mich für die Übernahme des Referates bzw. des Koreferates dieser Arbeit.

Frau Prof. Dr. Irmelin Probst und Frau Kirsten Unthan-Fechner aus dem Zentrum Biochemie und Molekulare Zellbiologie danke ich für die Möglichkeit, die ATP Messungen in ihrem Labor durchzuführen, und dafür, dass sie mir über den einen oder anderen Anfängerfehler hinweggeholfen haben.

Meinen Eltern danke ich dafür, dass sie mir das Studium ermöglicht haben und mich über die Jahre hinweg immer unterstützt haben. Meiner ganzen Familie danke ich dafür, dass sie einfach da waren und so sind, wie sie sind. Hey Christian, danke für Deine Freundschaft!

$\mathrm{Zu}$ guter Letzt danke ich noch meiner Gang für die Teepausen (aber sooo viele waren es nun wirklich nicht), die innovative Definition eines Ginkos und hitzige Diskussionen, Kartrennen und Grillabende, die Tangente und den medizinisch verordneten Rettungs-Döner, für Brettspiele (danke, dass ich auch mal gewinnen durfte) und Belindas grandiose Kochkünste; kurz gesagt: Danke, mit Eurer Hilfe habe ich es geschafft: Alles ist gut! 


\section{Lebenslauf}

Name:

Florian Johannes Gerich

Geburtsdatum, -ort:

9. Juni 1972 in Köln

Eltern:

Dr. Bernhard Gerich, Arzt

Doris Gerich (geb. Gassen), Lehrerin

Geschwister:

3

Werdegang:

$1978-1982$

Grundschule Annastrasse, Köln

$1982-1991$

Kaiserin Augusta Gymnasium, Köln

Abschluss: Allgemeine Hochschulreife mit Latinum Leistungskurse: Biologie und Erdkunde

Jul. 1991 - Jun. 1992

Wehrdienst in der Fernspähkompanie 300, Fritzlar

Sep. 1992 - Jun. 1994

Ausbildung zum Biologisch-Technischen

Assistenten an der Rheinischen Akademie, Köln

ab WS 94/95

Studium Biologie, Diplom, Universität zu Köln

ab WS 98/99

Fortführung des Studiums an der Carl von Ossietzky-Universität Oldenburg

Dez. 2003

Erfolgreicher Abschluss des Studiums

Titel der Diplomarbeit: „Morphologische und physiologische Charakterisierung von Neuronen der Mausretina“, durchgeführt unter Anleitung von

Prof. Dr. Reto Weiler

Apr. 2004 -

Promotion zum Thema: „Redoxmodulation hippokampaler Neurone" in der Abteilung Neurophysiologie an der Georg-August-Universität Göttingen unter der Anleitung von Jun. Prof. Dr. Michael Müller 